Check for updates

Cite this: RSC Adv., 2018, 8, 29248

\title{
Porous sorbents for the capture of radioactive iodine compounds: a review $\dagger$
}

\author{
Joffrey Huve, ${ }^{\text {ab }}$ Andrey Ryzhikov, (D) ab Habiba Nouali, ${ }^{a b}$ Virginie Lalia, ${ }^{c}$ Grégoire Augéd
} and T. Jean Daou (D) *ab

The number of studies on the capture of radioactive iodine compounds by porous sorbents has regained major importance in the last few years. In fact, nuclear energy is facing major issues related to operational safety and the treatment and safe disposal of generated radioactive waste. In particular during nuclear accidents, such as that in 2011 at Fukushima, gaseous radionuclides have been released in the off-gas stream. Among these, radionuclides that are highly volatile and harmful to health such as long-lived ${ }^{129}$ l, short-lived ${ }^{131}$ I and organic compounds such as methyl iodide $\left(\mathrm{CH}_{3}\right)$ have been released. Immediate and effective means of capturing and storing these radionuclides are needed. In the present review, we focus on porous sorbents for the capture and storage of radioactive iodine compounds. Concerns with, and limitations of, the existing sorbents with respect to operating conditions and their capacities for iodine capture are discussed and compared.

Received 4th June 2018

Accepted 2nd August 2018

DOI: $10.1039 / \mathrm{c} 8 \mathrm{ra0} 4775 \mathrm{~h}$

rsc.li/rsc-advances

greenhouse gas emissions and economically competitive.

\section{Introduction}

Nuclear power plants are one of the main sources of electrical energy. Nuclear energy is safe, clean, without excessive

${ }^{a}$ Université de Haute-Alsace, Equipe Matériaux à Porosité Contrôlée (MPC), CNRS IS2M UMR 7361, F-68100 Mulhouse, France. E-mail: jean.daou@uha.fr; Tel: +33 3 89336739

${ }^{b}$ Université de Strasbourg, France

'ONET Technologies, 270 Chemin des Agriculteurs, 26700 Pierrelatte, France ${ }^{d}$ ONET Technologies, 13258 Marseille Cedex 9, France

$\dagger$ Electronic supplementary information (ESI) available. See DOI: $10.1039 / \mathrm{c} 8 \mathrm{ra} 04775 \mathrm{~h}$

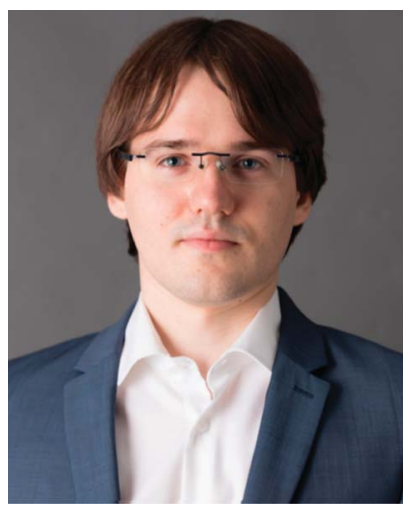

Joffrey Huve was born in 1990 in Mulhouse, France. He obtained his engineering degree in 2013 at the European School of Chemistry, Polymers and Materials (ECPM) affiliated to the University of Strasbourg. Then he obtained his PhD in 2017 from the University of Lyon 1 at the Institute of Researches on Catalysis and Environment in Lyon (IRCELYON) under the supervision of Dr David Farrusseng. After receiving his $P h D$ he was recruited as a postdoctoral fellow at the Mulhouse Materials Science Institute (IS2M) under the supervision of Dr Jean Daou.
Although it is facing major issues related to operational safety and the treatment and safe disposal of generated radioactive waste, ${ }^{\mathbf{1} 2}$ it remains an important part of today's energy mix. One of the main problems is as follows: during the aqueous reprocessing of used nuclear fuels and/or during a severe nuclear accident (Chernobyl in 1986 and Fukushima in 2011), there is a strong risk of the emission of gaseous radionuclides in the released off-gas stream. ${ }^{3,4}$ Gaseous radioactive wastes are a direct threat to the population and the environment owing to their easy dispersion through the atmosphere. The main components of such gaseous waste streams include the fission

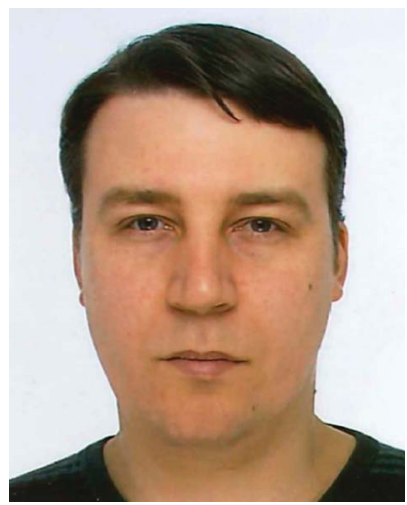

Andrey Ryzhikov was born in 1979 in Moscow, Russia. He received his $P h D$ in materials science from the Institut National Polytechnique and Moscow State University in 2005. He has performed postdoctoral research at several French laboratories in the fields of porous and nanostructured materials, adsorption, catalysis and gas sensors. Since 2012 he has been a researcher in the Institut de Science des Matériaux de Mulhouse, France. His research focuses on the synthesis and applications of microporous and mesoporous materials, in particular in the field of heterogeneous lyophobic systems. 
products technetium $\left({ }^{99} \mathrm{Tc}\right)$, cesium $\left({ }^{137} \mathrm{Cs}\right)$ and strontium $\left({ }^{90} \mathrm{Sr}\right)$, as well as actinides, lanthanides and various volatile radionuclides $\left({ }^{129} \mathrm{I},{ }^{131} \mathrm{I},{ }^{3} \mathrm{H},{ }^{14} \mathrm{C},{ }^{85} \mathrm{Kr}\right.$, etc. $) .{ }^{5-8}$ Particular attention should be paid to iodine compounds, which are particularly abundant. ${ }^{129} \mathrm{I}$ is a highly volatile long-lived isotope with a half-life $\left(t_{1 / 2}\right)$ of $\sim 1.57 \times 10^{7}$ years, which needs to be captured and reliably stored during its long decay. In contrast, ${ }^{131} \mathrm{I}$ is a volatile short-lived isotope with a $t_{1 / 2}$ of $\sim 8.02$ days, which needs to be captured immediately after being released, as it tends to accumulate and become concentrated in the thyroid gland, which seriously affects human metabolic processes. ${ }^{9-15}$ In addition, radioactive iodine is likely to form organic compounds such as methyl iodide $\left(\mathrm{CH}_{3} \mathrm{I}\right)$ with hydrocarbons and other volatile organic compounds present in the gas stream. Therefore, there is a strong interest in the nuclear energy community to develop alternative and effective means of capturing and storing these radionuclides. An efficient solution for iodine capture may consist of combining existing filtration devices such as wet scrubbing methods ${ }^{8,16}$ (Mercurex, Iodox, electrolytic and caustic scrubbing), sand bed filters and metallic filters with a supplementary capture step that potentially uses solid inorganic porous materials. Porous sorbents have been in the forefront of the removal of radioactive contaminants thanks to promising results and significant advantages such as high removal efficiency and adsorption capacities, high thermal stability, low maintenance cost, and the large range of structures and functionalizations that can be obtained. ${ }^{17}$ Numerous studies were carried out from the early 1960 s to the late $1980 \mathrm{~s}$ on the use of sorbents for the capture of radioactive iodine compounds with a specific focus on nuclear accidents ${ }^{16-64}$ (Fig. 1). These studies first focused on activated carbons and their forms impregnated with KI and/or TEDA ${ }^{18,22,23,27,36,43,51,57,58}$ and silver-exchanged zeolites for the capture of iodine. $^{17,21,29-32,34,37,38,40,47,52,56}$ These sorbents were highly praised for their good performance in iodine capture and were used in industrial applications for the trapping and treatment of iodine

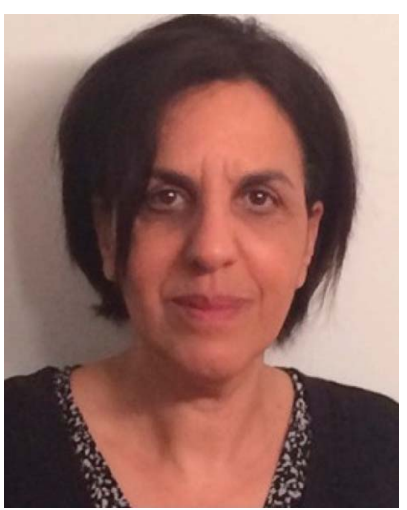

Habiba Nouali was born in 1960 in Mulhouse, France. She received her $P h D$ in organic chemistry from Strasbourg University in 1990. After her postdoctoral research at Texas A\&M University (1990-1991), she worked at the Maison de la Recherche en Environnement Industriel in Dunkerque, France until 2009. She then moved to the Institut de Science des Matériaux de Mulhouse, University of Haute-Alsace. The research in her laboratory focuses on the synthesis and study of porous and nanostructured materials for applications in the fields of adsorption, heterogeneous catalysis, ion exchange, environmental protection and energy storage.

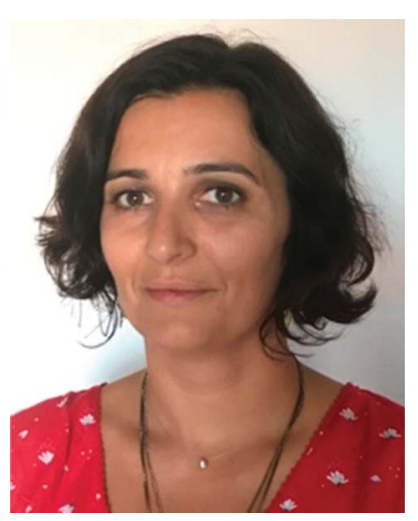

Virginie Lalia was born in Talence, France. She obtained her master's degree in chemistry in 2002 at ECPM (Ecole Européenne de Chimie, Polymères et Matériaux), Strasbourg. After her master's specializing in quality and the environment, she joined the group ONET Technologies as a process engineer and worked on the development of various chemical decontamination processes. She is in charge of the laboratory at ONET Technologies where pilots and tests on chemical processes are developed.

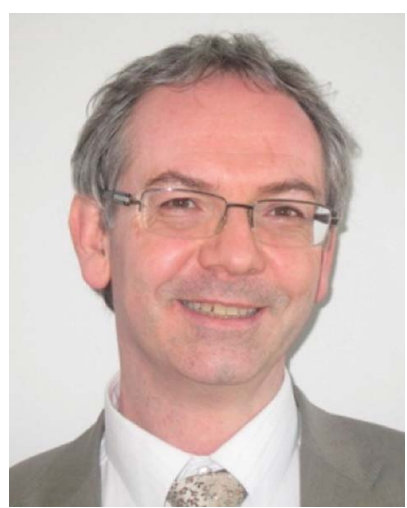

Grégoire Augé was born in 1964 in Paris, France. He obtained his PhD at INA-PG (France) in 1994. He started his career by teaching applied mathematics, statistics, and data mining. Then he focused his activity on numerical and computational methods for the treatment of nuclear fuel and waste and the development of simulation tools in an IT group. Since 2011 he has worked in the ONET Group and has extended the scope of his activity to focus on methods, chemical processes and tools for nuclear decommissioning and dismantling. He is currently Project Director-Coordinator of R\&D Programs and D\&D and Waste Expert at ONET Technologies in the Technical Department.

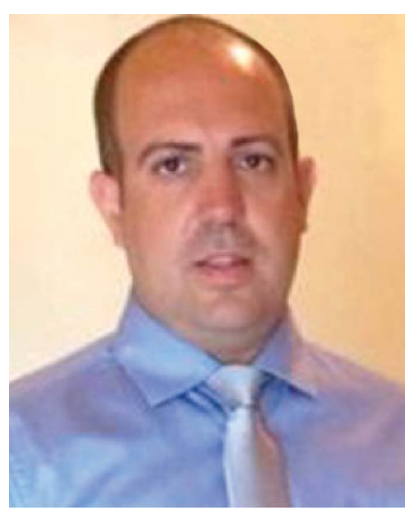

Jean Daou was born in 1979. He received his $P h D$ in materials chemistry from Louis Pasteur University (Strasbourg) in 2007. He then joined CEA-LETI, Grenoble, for a postdoctorate in the field of optical tracers. In 2008, he was hired as an assistant professor at the University of Haute-Alsace (UHA) to develop projects related to the synthesis of porous materials for applications in catalysis, molecular decontamination and energy storage. In 2016, he was promoted to professor. Currently, he is in charge of research coordination within the School of Chemistry at Mulhouse and is the president of the French Zeolite Association. 


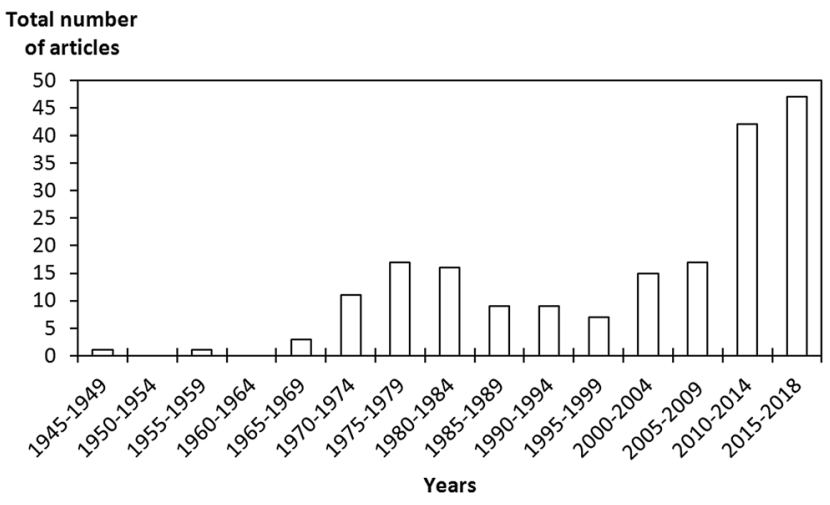

Fig. 1 Evolution of the number of publications per year on the capture of radioactive iodine contaminants by solid porous sorbent materials.

in the off-gas stream (in particular, activated carbons owing to their very low production cost). However, the high interest in these materials suddenly disappeared during the 1990s and early 2000s, when few studies were carried out on the subject. ${ }^{65-73}$ Since 2010, a resurgence in studies on iodine capture has been observed (Fig. 1). Activated carbons and zeolites were re-investigated and evaluated with greater accuracy and new methods (computational screening and studies, density functional theory (DFT), modelling, diffuse-reflectance infrared Fourier transform spectroscopy (DRIFTS),...) for a better understanding of iodine capture and its performance. ${ }^{74-81}$ In addition, new porous sorbents have been added to the list of potential sorbents for iodine trapping, including

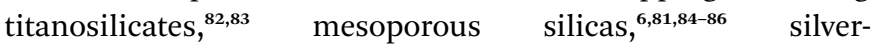
impregnated silica and alumina $\left(\mathrm{Ag} / \mathrm{SiO}_{2}\right.$ and $\mathrm{Ag} / \mathrm{Al}_{2} \mathrm{O}_{3}$, respectively), ${ }^{19,35,52,61,65,70,87-97}$ silver-functionalized aerogels, chalcogels, ${ }^{7,98-108}$ macroreticular ion exchange resins, ${ }^{16,39,41,42,44-46,50,53,55}$ metal- and covalent-organic frameworks (MOFs and COFs, respectively) $)^{6,14,109-132}$ and porous organic polymers (POPs). ${ }^{133-143}$ In the present review, we focus essentially on porous sorbents for the capture of radioactive iodine compounds and discuss concerns and limitations with respect to operating conditions.

\section{Capture of radioactive iodine contaminants by solid porous sorbent materials}

\subsection{Activated carbon}

Activated carbons (ACs) are materials that are essentially composed of carbonaceous matter with a porous structure. Thanks to their low production cost, fairly large specific surface area $\left(300-4000 \mathrm{~m}^{2} \mathrm{~g}^{-1}\right)$, easily tuned structure and porosity (pore size ranging from 4.5 to $60 \AA$ ), as well as good adsorption capacities, activated carbons are particularly attractive for the capture of radioactive iodine compounds. ${ }^{144}$ Activated carbons are generally produced in two steps: firstly by carbonization (or pyrolysis), and secondly by an activation step. ${ }^{144,145}$ The carbonization step generates porosity within the crude carbonaceous matter by removing elements other than carbon. Afterward, an activation procedure is carried out to increase the adsorption capacity of the material. Different kinds of activation procedure can be carried out, namely, physical activation (in the presence of water vapour and air under pressure) or chemical activation (usually by treatment with phosphoric acid) ${ }^{145}$ Furthermore, it is possible to increase the adsorption capacities of activated carbons by a wise choice of the crude starting materials (charcoal, bamboo, coconuts and walnuts) and by adjusting the carbonization $^{146}$ and activation steps. ${ }^{145}$ Iodine species such as iodine $\left(\mathrm{I}_{2}\right)$ and methyl iodide $\left(\mathrm{CH}_{3} \mathrm{I}\right)$ are generally physisorbed on activated carbons, but in real conditions of utilization at a high relative humidity and high temperature (in a nuclear power plant or during a nuclear incident), the efficacity of the adsorption of such materials tends to be reduced owing to competition for adsorption sites between water and iodine species. For this reason, it is necessary to increase the affinity of activated carbons for iodine species, which can be achieved by functionalizing or impregnating the material with organic and/or inorganic compounds. The commonest compounds used for the treatment and capture of iodine compounds are triethylenediamine (TEDA) $)^{6,18,43,69,73,147-155}$ and potassium iodide (KI). ${ }^{18,22,23,43,47,58,149}$ Recent studies from 2010 to 2017 on the subject have essentially focused on the utilization of activated carbon impregnated with TEDA for the capture of radioactive iodine.

2.1.1. Activated carbons impregnated with TEDA. In scientific studies, triethylenediamine (TEDA, $\mathrm{C}_{6} \mathrm{H}_{12} \mathrm{~N}_{2}$ ), also known as 1,4-diazabicyclo[2.2.2] octane (DABCO), is the commonest impregnating agent used in activated carbon filters for the capture of radioactive iodine species. TEDA has a melting point and a boiling point of $158^{\circ} \mathrm{C}$ and $174{ }^{\circ} \mathrm{C}$, respectively, and displays strongly hygroscopic properties. To increase the iodine adsorption capacities of activated carbons, these materials are impregnated with TEDA with a concentration of usually between 0 and $10 \mathrm{wt} \% .^{6,17,27,57,148,151,156,157}$ However, a decrease in the accessibility of the surface and pores was observed by Chinn et $a .^{158}$ and González-García et al. ${ }^{147,157}$ when the TEDA concentration was increased, which can be explained by the formation of TEDA clusters that blocked the entrances of pores. However, despite this phenomenon, it has been recognized that the presence of TEDA in activated carbons increases their iodine capture capacity (especially for $\mathrm{CH}_{3} \mathrm{I}$ ). ${ }^{\mathbf{1 4 7 , 1 5 7}}$ Deitz and Jonas $^{62}$ first thought that the capture of radioactive $\mathrm{CH}_{3} \mathrm{I}$ by TEDA was a first-order catalytic reaction. However, according to studies by Fessenden et al. ${ }^{159}$ and Wilhelm, ${ }^{57}$ TEDA impregnated into activated carbons is transformed by reacting with iodine compounds such as $\mathrm{CH}_{3} \mathrm{I}$ via $\mathrm{SN} 2$ nucleophilic substitution into a quaternary amine..$^{57,58,73,159}$ The general mechanism elaborated by these authors is illustrated in Fig. 2A.

On the other hand, Chun et al. ${ }^{150}$ by means of energetics diagrams showed that the impregnation of TEDA into graphene helps to lower the activation energy barriers involved in the dissociation of methyl iodide $\left(\mathrm{CH}_{3} \mathrm{I}\right)$ into $\mathrm{I}^{-}$and $\mathrm{CH}_{3}$ by the formation of a stable quaternary ammonium salt (Fig. 3). Kim ${ }^{20}$ highlighted the fact that other neutral species can form during the interaction of methyl iodide with TEDA (Fig. 2B).

Besides, the mechanism of iodine $\left(\mathrm{I}_{2}\right)$ capture by TEDA has not been the focus of studies thus far. Nonetheless, several authors, such as Fessenden et al. ${ }^{159}$ and Takahashi et al., ${ }^{160}$ 
(A)<smiles>CC1(I)CN2CCN1C2</smiles>
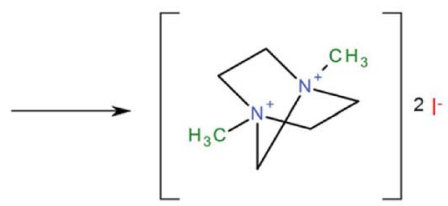

(B)

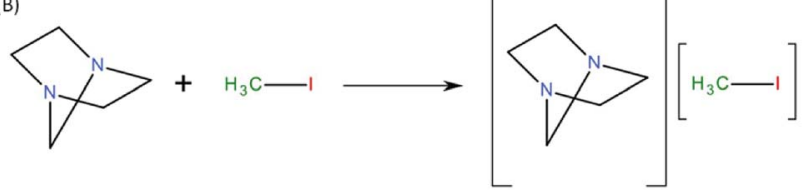

Fig. 2 (A) Formation of a non-volatile quaternary ammonium salt by an $\mathrm{SN}_{2}$ mechanism between TEDA and $\mathrm{CH}_{3} \mathrm{l}$. (B) Secondary neutral complex formed between TEDA and $\mathrm{CH}_{3}{ }^{1 .}{ }^{73}$

admitted that during a severe nuclear accident radioactive iodine $\left(\mathrm{I}_{2}\right)$ can decompose in the presence of water and/or oxygen into several iodine species $\left(\mathrm{I}^{-}, \mathrm{IO}_{3}{ }^{-}, \mathrm{HOI}\right)$ and can readily react with methane $\left(\mathrm{CH}_{4}\right)$ to form $\mathrm{CH}_{3} \mathrm{I} .{ }^{161}$ However, no information on the mechanism of the adsorption of these iodine species (except $\mathrm{CH}_{3} \mathrm{I}$ ) by activated carbon or TEDA has been reported.

Various studies have been carried out to determine the performance of activated carbon impregnated with TEDA in the capture of iodine species ${ }^{\mathbf{1 8 , 2 3 , 2 7 , 4 3 , 6 7 , 7 3 , 1 4 7}}$ (ESI, Table 1†). TEDA drastically increases the performance and adsorption capacities of activated carbons for iodine species at low temperatures. However, in these studies the test conditions and corresponding performance evaluations were not always representative of real conditions (temperature $>80{ }^{\circ} \mathrm{C}$ and relative humidity $>$ $40 \%$ ) that would be expected during a severe nuclear accident. Hence, major factors such as the temperature $\left(T,{ }^{\circ} \mathrm{C}\right)$ and relative humidity (R.H.\%) should be taken into consideration for data analysis.

Therefore, it is crucial to study the behaviour of activated carbons impregnated with TEDA in the presence of humidity. Upon an examination of all the studies carried out on this subject, humidity was revealed to be a key factor that controls the adsorption performance of activated carbons. ${ }^{\mathbf{6 6 , 6 9 , 1 4 7}}$ Nakamura et al. ${ }^{\mathbf{1 6 2}}$ demonstrated that water molecules formed clusters that were bound in a network by hydrogen bonds to the surface of activated carbons regardless of their hydrophobicity or hydrophilicity. Furthermore, it was also observed that water filled the porous network of the activated carbons, which hindered the accessibility of active sites for iodine species. Therefore, the adsorption efficiency of these sorbents declined significantly owing to adsorption competition between water vapour and iodine species. However, the problems caused by humidity can be alleviated by the presence of TEDA in the activated carbons. In fact, methyl iodide $\left(\mathrm{CH}_{3} \mathrm{I}\right)$ interacts more strongly with the support. ${ }^{150}$ Moreover, computational studies showed that TEDA attracts water molecules (to form hydroxide ions) that are localized on the surface and in the porous network of the adsorbent, which frees the active sites needed for the adsorption of iodine species. ${ }^{\mathbf{1 5 0}}$ Given that during a severe nuclear accident water is present in larger quantities than iodine species, the reaction of TEDA with water will be favoured. ${ }^{159}$

During a severe nuclear accident, in a case in which the cooling system would stop running, the process and/or system would eventually be subject to an increase in temperature. Therefore, it is essential to study the adsorption capacities of activated carbon impregnated with TEDA at high temperatures, taking into consideration the fact that TEDA has a melting point of $158{ }^{\circ} \mathrm{C}$ and an autoignition temperature of around $330{ }^{\circ} \mathrm{C}$.

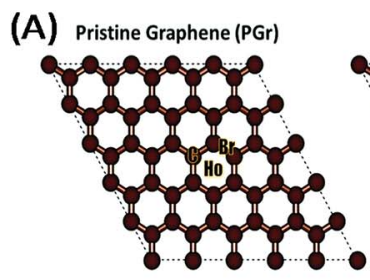

$\mathrm{C}_{6} \mathrm{H}_{12} \mathrm{~N}_{2}$ (TEDA)

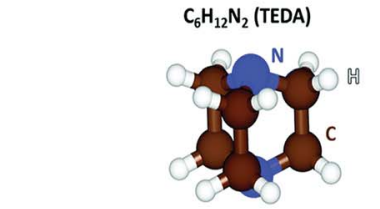

TEDA Impregnated PGr
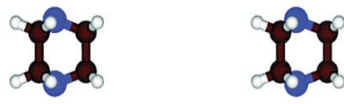

Defect Graphene (DGr)
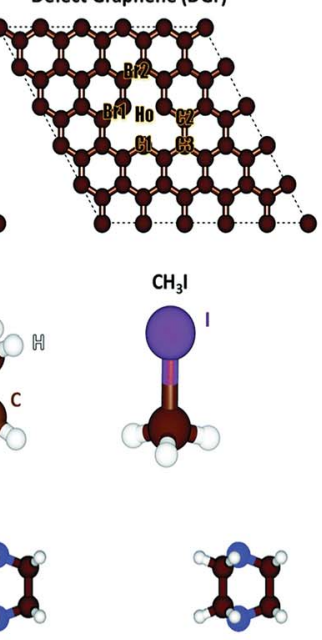

(B)

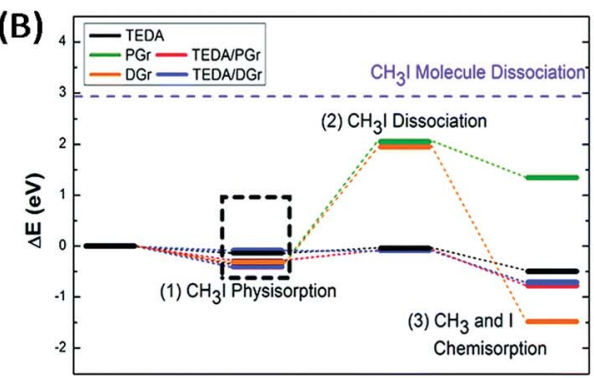

Reaction Coordinates

(1) $\mathrm{CH}_{3}$ I Physisorption
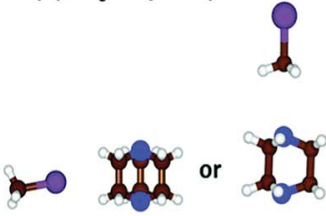

(2) $\mathrm{CH}_{3}$ I Dissociation

(3) $\mathrm{CH}_{3}$ and I Chemisorption

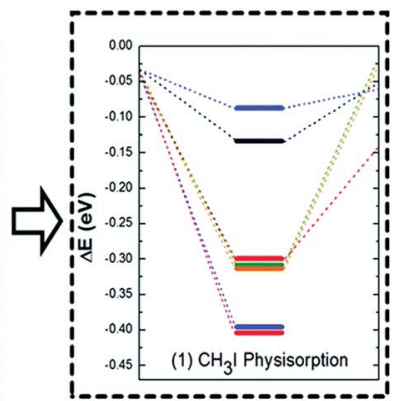

i. 0.45 (1)

\section{S}

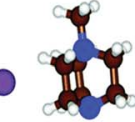

Fig. 3 (A) Model systems of the surfaces of activated carbons (pristine graphene (PGr) and defect graphene (DGr)), the impregnating agent (TEDA), $\mathrm{CH}_{3} l, \mathrm{H}_{2} \mathrm{O}$ and PGr impregnated with TEDA. (B) Free energy diagram of the adsorption of $\mathrm{CH}_{3}$ l on the surface of different systems. The dashed purple line represents the dissociation energy of a $\mathrm{CH}_{3} \mathrm{I}$ molecule. (C) Schematic figures for each reaction step on AC impregnated with TEDA. Reproduced in part from ref. 150 with the permission of the PCCP Owner Societies. 
However, it was observed several times, notably in the study by Park et al. ${ }^{73}$ on activated carbon and in the study by Ampelogova et al. ${ }^{148}$ on carbon fibres, that even at temperatures that are close to its boiling point TEDA maintains an acceptable capacity for the adsorption of methyl iodide thanks to chemisorption-type interactions (reaction of $\mathrm{CH}_{3} \mathrm{I}$ and TEDA to form a quaternary ammonium salt), in contrast to non-impregnated activated carbon, of which the adsorption capacity is controlled by physisorption-type interactions, although it was shown that the adsorption capacity of activated carbon impregnated with TEDA is reduced by a factor of 4 between 30 and $150{ }^{\circ} \mathrm{C}$. The contribution of TEDA to the adsorption (chemisorption) of $\mathrm{CH}_{3} \mathrm{I}$ was determined to be $25.4 \%$ at $70{ }^{\circ} \mathrm{C}$ by the authors, whereas this contribution increases to $73.3 \%$ at $150{ }^{\circ} \mathrm{C}$. These observations confirm that TEDA plays an important role in the capture of methyl iodide at high temperatures in an irreversible way (chemisorption interactions) and can be used up to a temperature of $150{ }^{\circ} \mathrm{C}$ (below the melting point of TEDA) in nuclear plants. It still needs to be confirmed that the autoignition temperature of TEDA and the thermal effect of its decomposition in the conditions of a real nuclear accident will not be detrimental to the capture performance of these materials. However, non-impregnated activated carbon loses adsorption efficiency when the temperature rises (weak physisorption interaction). Moreover, it can be noted that at low temperatures $\left(30^{\circ} \mathrm{C}\right)$ non-impregnated activated carbon possesses adsorption capacities that are as good as, if not even better than, those when impregnated with TEDA (Park et al. ${ }^{67,73}$ and GonzálezGarcía et $a{ }^{\mathbf{1 4 7}}$ ). TEDA was able to counterbalance the detrimental effect of humidity on the adsorption capacities of activated carbons by freeing the active sites of the support (water has a stronger affinity for TEDA than for the active sites).

2.1.2. Activated carbons impregnated with KI. On an industrial scale, potassium iodide (KI) is an impregnating compound that is widely used with activated carbon filters for the capture of radioactive iodine. It is highly thermostable with a melting point and boiling point of $686{ }^{\circ} \mathrm{C}$ and $1330{ }^{\circ} \mathrm{C}$, respectively. Potassium iodide improves the iodine capture performance of activated carbons via an increase in irreversible interactions. According to Deitz ${ }^{18}$ and Zhou et al. ${ }^{155}$ the mechanism of the capture of radioactive iodine species on activated carbons impregnated with KI involves isotopic exchange between the radioactive iodine species in the gaseous phase and the stable iodine in $\mathrm{KI}$. The following reversible reaction is believed to occur: $\mathrm{CH}_{3}{ }^{131} I_{(\mathrm{g})}+\mathrm{K}^{127} \mathrm{I}_{(\mathrm{ads})} \leftrightarrow \mathrm{CH}_{3}{ }^{127} \mathrm{I}_{(\mathrm{g})}+\mathrm{K}^{131} \mathrm{I}_{(\mathrm{ads})}$. Because this reaction is reversible, it is necessary to have an excess amount of non-radioactive iodine $\left(\mathrm{K}^{127} \mathrm{I}\right)$ to guarantee the efficient capture of radioactive iodine species. Activated carbons are generally impregnated with 0 to 10 wt $\%$ KI. 18,20,24-27,43,51,148,149,155 Various studies, especially during the 1980s and 1990s, were carried out to determine the performance of the capture of iodine species on activated carbon impregnated with KI (ESI, Table $2 \dagger$ ). Upon an examination of the work by Chien et al., ${ }^{\mathbf{1 4 9}}$ it is clearly observed that potassium iodide significantly increases the performance of activated carbon in the capture of radioactive iodine species. However, the lack of information on the test conditions used for evaluating the performance of these materials ${ }^{\mathbf{1 4 9}}$ and the fact that there are no comparisons between non-impregnated and KI-impregnated activated carbon ${ }^{155}$ in some articles are regrettable. It should be noted that at a high concentration KI drastically limits the accessibility of the pores in the support.

As indicated in Section 2.1.1, the adsorption capacities of activated carbons are particularly affected by humidity. In comparison with TEDA, KI does not possess such a high affinity for water. In 1981, Decourcière ${ }^{33}$ studied the evolution of the decontamination factor (DF) f for an activated carbon impregnated with $1 \mathrm{wt} \% \mathrm{KI}$ in the presence of humidity (in the relative humidity range of 40-96\%). A decrease in the decontamination factor from $\mathrm{DF}=10^{4}$ to $\mathrm{DF}<10^{2}$ for a relative humidity of $40 \%$ and $96 \%$, respectively, was observed. The author concluded that the filtration system should not be used if the relative humidity is higher than $40 \%$ and should be equipped with a heating apparatus to reduce the relative humidity of air. However, during a severe nuclear accident, the relative humidity will probably exceed $40 \%$. Therefore, it is essential that activated carbons impregnated with KI remain fully operational for the capture of iodine species even in conditions of high relative humidity. Qi-dong et al. ${ }^{25}$ reached the same conclusion with an activated carbon impregnated with $2 \mathrm{wt} \% \mathrm{KI}+2 \mathrm{wt} \%$ TEDA. Kitani et $a .^{43}$ and Deuber et $a .^{27}$ achieved adsorption efficiencies§ of $97 \%$ and $99 \%$, respectively, at a relative humidity of $>90 \%$. In conclusion, thus far it has been difficult to estimate whether KI is directly affected by humidity or the loss of performance is caused only by blocking of the pores and the active sites of the activated carbons. Nevertheless, humidity is detrimental for activated carbons impregnated with KI, which is why a combination of KI and TEDA is generally (or widely) used. Kitani et $a l .{ }^{43}$ studied the influence of temperature on activated carbons impregnated with 5 to $10 \mathrm{wt} \% \mathrm{KI}$ at a relative humidity of $90 \%$. A decrease in the efficiency of iodine adsorption with temperature from $97.8 \%$ at $25{ }^{\circ} \mathrm{C}(5 \mathrm{wt} \% \mathrm{KI})$ to $93.6 \%$ at $70{ }^{\circ} \mathrm{C}$ (despite an increase in concentration to $10 \mathrm{wt} \% \mathrm{KI}$ for the latter value) was observed. We could argue that this slight decrease in adsorption efficiency may be due to a decline in the accessibility of the active sites in the activated carbon caused by the increase in the KI loading rather than the increase in temperature. For activated carbons impregnated with $\mathrm{KI}+\mathrm{TEDA}^{25}$ the decontamination factor (DF) decreases by a factor of $10^{2}$ as the temperature rises from $40{ }^{\circ} \mathrm{C}$ to $70{ }^{\circ} \mathrm{C}$. Therefore, it is clear that the temperature plays a major role in the iodine capture performance of activated carbons impregnated with KI.

2.1.3. Limitations of impregnated activated carbons. There are several problematic issues with the use of activated carbons for the capture of radioactive volatile iodine species other than alterations at high temperatures and in the presence of humidity. Firstly, it is generally accepted in the scientific

$\$$ The DF is defined as the ratio of the original concentration of the contaminant to the concentration that remains after removal; a DF of 10 represents a removal of radionuclides of $90 \%$.

$\S$ The adsorption efficiency $(E \%)$ is defined as the fraction of iodine captured by the material and can be related to the decontamination factor by the equation $E$ $=(1-[1 / \mathrm{DF}]) \times 100$. 
community that the aging of activated carbons is perfectly capable of altering their adsorption performance..$^{25-27,148}$ Deuber $^{26}$ studied the performance of activated carbons impregnated with TEDA and/or KI over a time period of 0 to 12 months at $30{ }^{\circ} \mathrm{C}$ and $130{ }^{\circ} \mathrm{C}$ with a relative humidity of $95 \%$ and $2 \%$, respectively, for various bed lengths. It is clear from the penetration profiles that were obtained that the iodine adsorption performance was affected over time. In the case of adsorbents impregnated with TEDA, one can observe an increase in the penetration of iodine species through a bed with a length of $25 \mathrm{~cm}$ by a factor of $10^{2}$ at $30^{\circ} \mathrm{C}$ and a factor of $10^{2}$ to $10^{1}$ at $130^{\circ} \mathrm{C}$ after 12 months. Similar results were obtained in the case of adsorbents impregnated with KI. Therefore, the aging of activated carbons can become a major issue in the long term, especially if a severe nuclear accident occurs at the end of life of this material. According to Jubin, ${ }^{\mathbf{1 6}}$ even though activated carbons are preferentially used in the nuclear field, especially for the capture of radioactive iodine, these materials cannot be good candidates for several reasons: they are characterized by a low autoignition temperature and in contact with other compounds, such as $\mathrm{NO}_{x}$, their iodine adsorption capacities are reduced and the formation of explosive compounds is likely.

\subsection{Ag-exchanged zeolites}

Zeolites are crystalline microporous solids that belong to the group of aluminosilicates and the subgroup of tectosilicates. Their structure is composed of a three-dimensional arrangement of tetrahedral $\mathrm{TO}_{4}$ units $(\mathrm{T}=\mathrm{Si}, \mathrm{Al}$, etc. $)$. The presence of pores, channels, molecule-sized cavities and chargecompensating cations inside these materials make their properties particularly interesting for various applications, such as adsorption, catalysis and cation exchange. ${ }^{\mathbf{1 6 3 - 1 6 8}}$ In the particular case of the capture of iodine species, the adsorption properties and cation exchange capacities of zeolites make them interesting and remarkable candidates for this application. In the literature, several zeolites of different structural types have been studied for the capture of iodine species, such as mordenite (MOR structural type), ${ }^{29,34,74,76,77,79,80,169-178} \mathrm{NaX}$ and NaY zeolites (FAU type), ${ }^{5,60,75,77,78,88,132,179}$ ZSM-5 (MFI type), ${ }^{74,77}$ ferrierite (FER type) and zeolite beta (*BEA type $)^{74,77}$ (ESI, Table $3 \dagger$ ).

2.2.1. Mechanisms of iodine adsorption. Two thermodynamically viable iodine-containing precipitates are likely to be formed in silver-exchanged zeolites, namely, silver iodide (AgI) and silver iodate $\left(\mathrm{AgIO}_{3}\right) \cdot{ }^{37}$ The formation of the silver iodide species (AgI) was reported in various studies, ${ }^{21,29,34,38,40,47,52,180}$ whereas Patil et $a l .{ }^{37}$ showed the formation of a silver iodate precipitate $\left(\mathrm{AgIO}_{3}\right)$. At quite elevated temperatures $\left(>190{ }^{\circ} \mathrm{C}\right)$, the latter precipitate decomposed to form silver iodide (more stable at higher temperatures, eqn (1)). Scheele and Burger ${ }^{29}$ identified the various reactions that could potentially be triggered between iodine species $\left(\mathrm{I}_{2}, \mathrm{CH}_{3} \mathrm{I}\right)$ and active silver adsorption sites in silver-exchanged mordenite $\mathrm{Ag}^{0} \mathrm{MOR}$ (in which silver possesses different oxidation states, namely, a charged $\mathrm{Ag}^{+}$form and/or a reduced $\mathrm{Ag}^{0}$ form). They highlighted the fact that most of these reactions are thermodynamically favourable for the capture of $\mathrm{I}_{2}$ and $\mathrm{CH}_{3} \mathrm{I}$ by mordenite-type zeolites loaded with silver (AgMOR). The iodine species formed during these reactions are mainly $\mathrm{AgI}$ and $\mathrm{AgIO}_{3}$ (eqn (2) to (8)):

$$
\begin{gathered}
\mathrm{AgIO}_{3} \stackrel{\Delta}{\longrightarrow} \mathrm{AgI}+1.5 \mathrm{O}_{2} \\
\mathrm{Ag}^{0}+0.5 \mathrm{I}_{2} \leftrightarrow \mathrm{AgI} \\
2 \mathrm{Ag}^{0}+2 \mathrm{CH}_{3} \mathrm{I} \leftrightarrow 2 \mathrm{AgI}+\mathrm{C}_{2} \mathrm{H}_{6} \\
\mathrm{Ag}^{0}+\mathrm{CH}_{3} \mathrm{I}+\mathrm{H}_{2} \mathrm{O} \leftrightarrow \mathrm{AgI}+\mathrm{CH}_{3} \mathrm{OH}+0.5 \mathrm{H}_{2} \\
\mathrm{Ag}^{+}+\mathrm{CH}_{3} \mathrm{I}+\mathrm{H}_{2} \mathrm{O} \leftrightarrow \mathrm{AgI}+\mathrm{CH}_{3} \mathrm{OH}+\mathrm{H}^{+} \\
2 \mathrm{Ag}^{0}+\mathrm{I}_{2}+1.5 \mathrm{O}_{2} \leftrightarrow \mathrm{AgI}+\mathrm{AgIO}_{3} \\
\mathrm{Ag}_{2} \mathrm{O}+\mathrm{I}_{2}+\mathrm{O}_{2} \leftrightarrow \mathrm{AgIO}+\mathrm{AgI}_{3} \\
\mathrm{Ag}_{2} \mathrm{O}+\mathrm{I}_{2} \leftrightarrow 2 \mathrm{AgI}+0.5 \mathrm{O}_{2}
\end{gathered}
$$

More recently, Chapman et al. ${ }^{171}$ showed the existence of several AgI species in the same AgMOR/ $\mathrm{I}_{2}$ system. The structure adopted by silver iodide, as well as the distribution of different phases, depends on the temperature and the initial oxidation state of silver. ${ }^{181}$ At temperatures below $147{ }^{\circ} \mathrm{C} \beta$-AgI (wurtzite structure) is the more stable phase, whereas at temperatures above $147{ }^{\circ} \mathrm{C} \alpha$-AgI (cubic centred structure) becomes the more stable form. However, at high temperatures a third phase can coexist, namely, the metastable $\gamma$-AgI phase. ${ }^{181}$ The authors stated that silver is present in the form of $\mathrm{Ag}^{\mathrm{O}}$ particles with sizes of $3 \mathrm{~nm}$ on the zeolite surface. Chapman et al. ${ }^{171}$ observed two AgI phases after the adsorption of $\mathrm{I}_{2}$ : $\alpha$-AgI, which was mainly localized in the pores of the silver zeolite, and the metastable $\gamma$ AgI phase, which was characterized by larger nanoparticles that were mostly localized on the zeolite surface (Fig. 4). According to the authors, these results involve the migration of silver in the zeolite pores during the adsorption of iodine. This migration is made possible by the mobility of both the iodine species (which are initially physisorbed into the pores) and the $\mathrm{Ag}^{+}$ions, which are localized directly inside the zeolite framework. In the absence of pre-treatment with hydrogen, the non-reduced silver localized inside the mordenite gives rise to the formation of AgI confined in the zeolite pores in the form of nanoscale $\alpha$-AgI clusters.

In 2014 , in a study that combined several ex situ characterization techniques, Nenoff et al. ${ }^{173}$ proposed a mechanism for the trapping of $\mathrm{CH}_{3} \mathrm{I}$ by silver-exchanged MOR-type zeolite $\left(\mathrm{Ag}^{0} \mathrm{MOR}\right.$, in which silver is reduced to its $\mathrm{Ag}^{0}$ form). This mechanism involves the acidic sites of mordenite and the catalytic decomposition of hydrocarbons derived from $\mathrm{CH}_{3} \mathrm{I}$. In this study, the emission of various organic compounds was detected, such as dimethyl ether (DME), methanol, and methyl nitrite. These observations are consistent with a previous work by Heafner and Watson, ${ }^{182}$ in which the presence of methanol in the off-gas stream was reported. Scheele ${ }^{29}$ also suggested that methanol and DME are secondary products formed during the adsorption of $\mathrm{CH}_{3} \mathrm{I}$ onto silver. Therefore, Nenoff et al. ${ }^{173}$ explained that $\mathrm{CH}_{3} \mathrm{I}$ decomposed on the Brönsted acid sites ( $\mathrm{Si}-\mathrm{OH}-\mathrm{Al})$ of the zeolite 


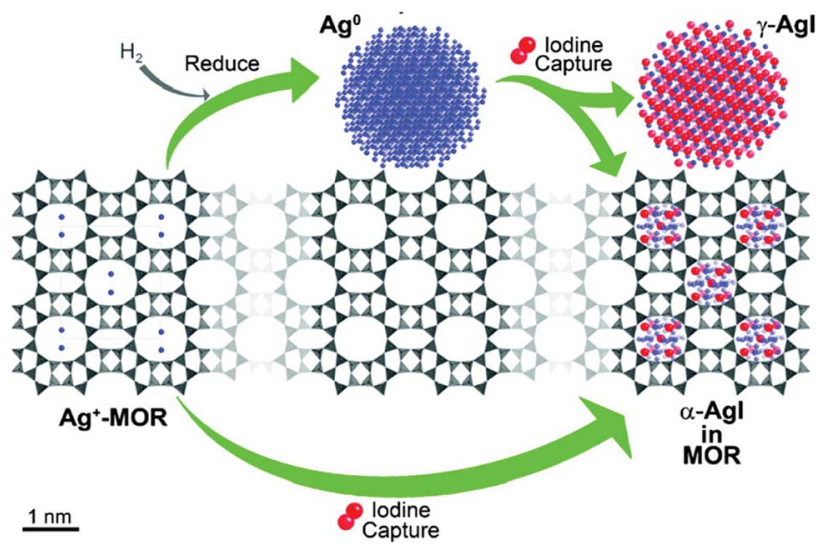

Fig. 4 Schematic of capture of iodine by a silver-containing MORtype zeolite. ${ }^{171}$ After a pre-reduction step using hydrogen, AgMOR gives rise to a mixture of $\gamma$-Agl nanoparticles and sub-nanometer $\alpha$ $\mathrm{Agl}$, whereas the direct uptake of iodine by silver-exchanged MOR exclusively produces sub-nanometer $\alpha$-Agl. Reprinted with permission from K. W. Chapman, P. J. Chupas and T. M. Nenoff, Journal of the American Chemical Society, 2010, 132, 8897-8899. Copyright 2010 American Chemical Society.

to form adsorbed methoxy species $\left(\mathrm{CH}_{3} \mathrm{O}-\right)$, which react with water to form methanol and consequently free the acidic sites of the zeolite. Dimethyl ether was observed after the reaction of methanol with the adsorbed methoxy species. Finally, the iodine formed by the decomposition of $\mathrm{CH}_{3} \mathrm{I}$ is trapped in the form of an AgI precipitate. A recent work by Chebbi $e t$ al. ${ }^{78}$ confirmed the observations by Nenoff et al. ${ }^{173}$ (Fig. 5).

In addition, it was reported in several works that the formation of AgI in silver-exchanged zeolites was accompanied by the formation of various hydrocarbon compounds. Belapurkar et al. ${ }^{31}$ reported the formation of methane $\left(\mathrm{CH}_{4}\right)$ and ethane $\left(\mathrm{C}_{2} \mathrm{H}_{6}\right)$ during the adsorption of $\mathrm{CH}_{3} \mathrm{I}$ on $\mathrm{AgX}$ zeolites in dry conditions. The formation of alkanes $\left(\mathrm{CH}_{4}\right.$ and $\left.\mathrm{C}_{3} \mathrm{H}_{8}\right)$ and alkenes $\left(\mathrm{C}_{2} \mathrm{H}_{4}\right.$ and

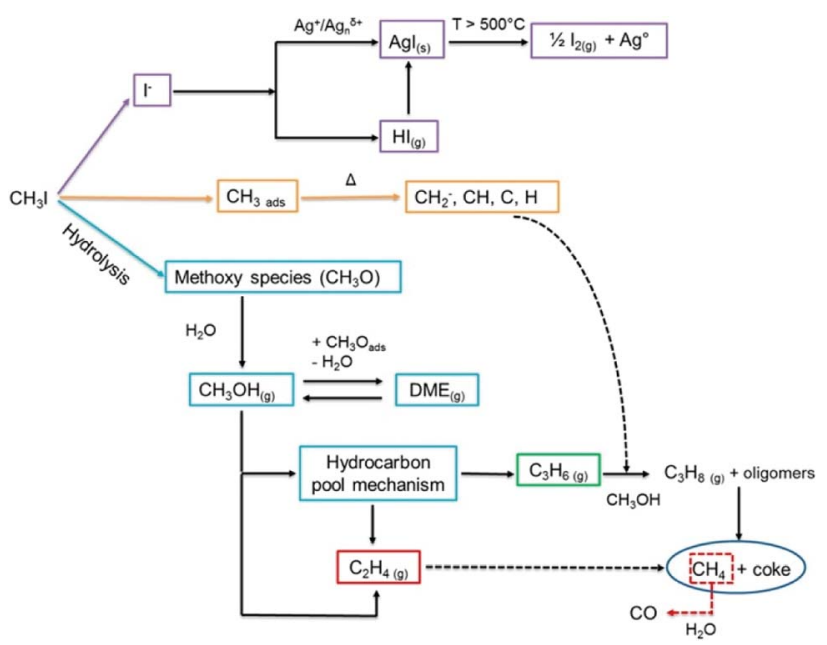

Fig. 5 Different reaction pathways and mechanisms for the adsorption and decomposition of $\mathrm{CH}_{3} \mathrm{l}$ on $\mathrm{AgY}$ zeolite. ${ }^{78}$ Reprinted with permission from M. Chebbi, B. Azambre, L. Cantrel and A. Koch, Journal of Physical Chemistry C, 2016, 120, 18694-18706. Copyright 2016 American Chemical Society.
$\mathrm{C}_{3} \mathrm{H}_{6}$ ) is linked to the decomposition of chemisorbed $\mathrm{CH}_{3} \mathrm{I}$ species. In the literature, these species were observed during the decomposition of halogenated molecules $\left(\mathrm{CH}_{3} \mathrm{I}, \mathrm{CH}_{3} \mathrm{Cl}\right)$ on supports such as AgX zeolites ${ }^{31}$ or aluminophosphates (HSAPO34). ${ }^{183}$ The formation of hydrocarbons is a result of the direct coupling of fragmented hydrocarbon species, which is catalyzed by the active sites of the zeolite (silver sites and/or Brönsted acid sites). At higher temperatures, Chebbi et al. ${ }^{78}$ also observed the formation of carbon monoxide $\left(T>420{ }^{\circ} \mathrm{C}\right)$ and iodine species such as $\mathrm{HI}$ and $\mathrm{I}_{2}\left(T>500^{\circ} \mathrm{C}\right)$. The formation of carbon monoxide could originate from the partial oxidation of methane (or oxygenated species) by water, whereas the iodine species most probably originated from the reduction-oxidation decomposition of silver iodide $\left(2 \mathrm{AgI} \rightarrow 2 \mathrm{Ag}^{0}+\mathrm{I}_{2}\right)$.

Different silver phases (with different oxidation states) can be present in the pores of AgY zeolite, as shown by Chebbi et $a l^{78}$ By using diffuse-reflectance UV-vis spectroscopy (DR-UVvis), the authors obtained information on the nature of the silver species confined in the zeolite pores. Absorption peaks around $208-328 \mathrm{~nm}$ have been attributed to silver-exchanged $\mathrm{Ag}^{+}$species, whereas absorption peaks beyond $305 \mathrm{~nm}$ are attributed to $\mathrm{Ag}^{0}$ nanoparticles. The distinction between $\mathrm{Ag}_{n}{ }^{\delta+}$ and $\mathrm{Ag}_{m}{ }^{0}$ ( $n$ and $m$ are the numbers of atoms in the clusters) is particularly difficult because the absorption spectra depend greatly on the sizes of the clusters. However, absorption peaks between 240 and $255 \mathrm{~nm}$ and at $305 \mathrm{~nm}$ are related to $\mathrm{Ag}_{n}{ }^{\delta+}(n<$ 10) charged clusters and $\mathrm{Ag}_{m}{ }^{0}$ neutral clusters, respectively. To prove their assumptions and confirm the accurate localization of the silver species inside the zeolite framework, the authors ${ }^{78}$ studied the adsorption of $\mathrm{CO}$ at $35{ }^{\circ} \mathrm{C}$ by diffuse-reflectance infrared Fourier transform spectroscopy (DRIFT). This technique revealed that the silver species are well dispersed inside the framework of zeolites of the FAU structural type and that they are localized at the level of the exchanged active sites in the form of $\mathrm{Ag}^{+}$cations. Metallic $\mathrm{Ag}_{m}{ }^{0}$ and charged $\mathrm{Ag}_{n}{ }^{\delta+}$ aggregates (clusters) were also found near the exchanged active sites, but in lower quantities. During the exposure of the silver-exchanged zeolite to a $\mathrm{CH}_{3} \mathrm{I}$ flow at $100{ }^{\circ} \mathrm{C}$, the $\mathrm{Ag}^{+}$cationic species reacted with $\mathrm{CH}_{3} \mathrm{I}$ to form AgI precipitates. The formation of AgI involved the reaction of $\mathrm{Ag}^{+}$with $\mathrm{I}^{-}$after an initial step of the dissociation of $\mathrm{CH}_{3} \mathrm{I}$. The dissociation of $\mathrm{CH}_{3} \mathrm{I}$ can occur on the silver active sites or the acidic sites of the zeolite. Then, AgI molecules tend to aggregate to form (AgI $)_{n}$ nanoclusters. The sizes of the $(\mathrm{AgI})_{n}$ aggregates increase continuously until they reach the size of the cavities and/or supercages of the zeolite. Chebbi et $a .^{78}$ also studied the effect of water vapour and temperature on $(\mathrm{AgI})_{n}$ clusters. They observed by different methods (XRD, DR-UV-vis) that some of these clusters migrated from the pores of the zeolite to its external surface. It was suggested that wet conditions promoted the formation of a microsolution inside the zeolite pores, which helped the silver to move in the pores and therefore permitted the coalescence or sintering of AgI species. To determine the reaction mechanisms, the desorption profiles of the different products and compounds formed during the decomposition of $\mathrm{CH}_{3} \mathrm{I}$ on the active sites of AgY zeolite (Brönsted acid sites, eqn (9) and (10), and/or directly on silver sites, eqn (11)) were also studied. 


$$
\begin{gathered}
\mathrm{CH}_{3} \mathrm{I}+\mathrm{H} \text {-zeolite } \rightarrow \mathrm{HI}+\mathrm{CH}_{3} \text {-zeolite } \\
\mathrm{HI}+\text { Ag-zeolite } \rightarrow \mathrm{AgI}+\mathrm{H} \text {-zeolite } \\
\mathrm{CH}_{3} \mathrm{I}+\text { Ag-zeolite }
\end{gathered}
$$

In the same context, Bucko et al. ${ }^{172}$ used computer simulations at the periodic DFT level to investigate the dissociative adsorption of iodomethane $\left(\mathrm{CH}_{3} \mathrm{I}\right)$ onto silver-exchanged mordenite (AgMOR). Using an ab initio molecular dynamics study, the authors investigated the structure, energetics and mobility of $\mathrm{Ag}\left(\mathrm{CH}_{3} \mathrm{I}\right)$ complexes in the mordenite zeolite structure. In summary, the results indicated that the mechanism of the dissociation of $\mathrm{CH}_{3} \mathrm{I}$ proceeded more in accordance with eqn (11) than (9) + (10). AgI species formed during dissociative adsorption were shown to combine spontaneously into small $(\mathrm{AgI})_{n}$ clusters, of which the dimensions were restricted by the size and geometry of the mordenite cages and pores.

To summarize, the formation of AgI precipitates is initiated by the dissociation of $\mathrm{CH}_{3} \mathrm{I}$ on the silver sites and/or Brönsted acid sites of the zeolite. AgI molecules and then (AgI $)_{n}$ aggregates/clusters are formed inside the cages of zeolites of the FAU structural type. In the presence of humidity and at elevated temperatures, AgI precipitates can readily migrate and form larger entities on the external surface of the zeolite. Furthermore, the thermal and/or catalytic decomposition of $\mathrm{CH}_{3} \mathrm{I}$ (dissociation) leads to the production of various by-products of hydrocarbons such as methanol, DME, alkanes, and alkenes.

2.2.2. Capture performance of Ag-exchanged zeolites. Numerous studies were carried out from the 1960s to the 1980s on the use of zeolites for the capture of radioactive iodine compounds in the event of nuclear accidents. In 1968 and 1970, Maeck et al. worked on more than twenty silver-impregnated zeolites in various operating conditions for the capture of iodine compounds (mainly $\mathrm{I}_{2}$ and $\mathrm{CH}_{3} \mathrm{I}$ ). ${ }^{38,40}$ The best adsorption performance was achieved with AgX zeolite (FAU type). In comparison with silver-exchanged zeolites, additional studies confirmed that zeolites in which cations were exchanged for other metals such as $\mathrm{Cu}, \mathrm{Pd}$, and $\mathrm{Cd}$ have lower adsorption capacities and poorer performance (this phenomenon will be discussed below). Later, numerous studies were carried out on this topic, especially during the $1970 \mathrm{~s}$ and $1980 \mathrm{~s}^{21,29,34,38,40,47,52,180}$ and then between 2000 and 2017.5,8,71,74-80,169-171,173-177,184-188 These studies focused on the determination of the influence of various parameters such as the temperature $\left({ }^{\circ} \mathrm{C}\right)$, silver content (wt\%), Si/Al ratio, superficial velocity, and pretreatment of the material on the adsorption capacities of silver-exchanged zeolites (ESI, Table $3 \dagger$ ). Other works focused on issues such as aging of the material under different atmospheres $\left(\mathrm{NO}_{x}\right.$, humidity). ${ }^{178,185}$ Since 2016, we have observed a resurgence in studies on silver-exchanged zeolites for iodine capture. We can in particular mention the works by Chibani, Chebbi and Azambre,${ }^{74-80}$ who performed systematic studies on the influence of zeolite parameters on their iodine adsorption capacities. These works, as well as those on the influence of the other parameters mentioned above, will be discussed in the following section.

\subsubsection{Influence of different parameters on the capture} performance of Ag-exchanged zeolites

Influence of silver content. The silver content in an exchanged zeolite has a major influence on its adsorption capacity for iodine species. In 2001, Choi et al. ${ }^{71}$ studied the influence of the silver content in a faujasite-type zeolite $(\mathrm{AgX})$ on its iodine adsorption capacity. They incorporated 10, 20 and $30 \mathrm{wt} \%$ silver by exchanging $\mathrm{Na}^{+}$in NaX zeolite for $\mathrm{Ag}^{+}$. An increase in the adsorption capacity for iodine was observed when the silver content increased. At $100{ }^{\circ} \mathrm{C}$, the adsorption capacity rose from $180 \mathrm{~g} \mathrm{~kg}_{\text {adsorbent }}{ }^{-1}$ to $250 \mathrm{~g} \mathrm{~kg}_{\text {adsorbent }}{ }^{-1}$ for a silver content of $10 \mathrm{wt} \%$ and $30 \mathrm{wt} \%$, respectively. However, a large silver content $(>20 \mathrm{wt} \%)$ entails a decrease in the pore volume, which in consequence limits the accessibility of the pores for iodine species (diffusion limitation). ${ }^{11}$ In fact, the micropore volume decreases from $2.37 \times 10^{-4} \mathrm{~m}^{3} \mathrm{~kg}^{-1}$ for a non-exchanged zeolite to $1.83 \times 10^{-4} \mathrm{~m}^{3} \mathrm{~kg}^{-1}$ in the case of the zeolite with $30 \mathrm{wt} \% \mathrm{Ag}$. The use efficiency of $\mathrm{Ag}$ was also estimated by calculating the $\mathrm{Ag} / \mathrm{I}$ ratio. This ratio was optimal $(>99 \%)$ for the zeolite with $10 \mathrm{wt} \% \mathrm{Ag}$, whereas it was only $85 \%$ and $68 \%$ for the zeolites with $20 \mathrm{wt} \%$ and $30 \mathrm{wt} \% \mathrm{Ag}$, respectively, at temperatures between 150 and $200{ }^{\circ} \mathrm{C}$. Because silver is expensive, there is interest in the incorporation of an optimal silver content with the highest efficiency. More recently, Cheng et al. ${ }^{188}$ studied the adsorption of $\mathrm{I}_{2}$ on a silver-exchanged FAU-type zeolite (AgX) at temperatures between 250 and $650{ }^{\circ} \mathrm{C}$. They observed a decontamination factor (DF) in the range of $>10^{3}$ for a silver content of greater than $15 \mathrm{wt} \%$, in contrast to $10^{1.5}$ to $10^{3}$ for a silver content of less than $15 \mathrm{wt} \%$. However, only slight differences in the decontamination factor were observed between exchanged zeolites with $15 \mathrm{wt} \% \mathrm{Ag}$ and $20 \mathrm{wt} \% \mathrm{Ag}$, which seems to be in agreement with the study by Choi et al., ${ }^{71}$ which implies that there was no real increase in the adsorption capacity at a high silver content. In studies by Chebbi et al. ${ }^{77}$ and Azambre et al. ${ }^{74}$ on several silver-exchanged zeolites (AgY, AgX, AgMOR, AgZSM5 , etc.) with different silver contents ( 0 to $35 \mathrm{wt} \%$ ) at $100{ }^{\circ} \mathrm{C}$, an increase in the adsorption capacity of silver-exchanged FAUtype zeolites (AgY and AgX) from $87 \mathrm{mg} \mathrm{g}_{\text {adsorbent }}{ }^{-1}$ to $223 \mathrm{mg}$ $\mathrm{g}_{\text {adsorbent }}{ }^{-1}$ for a silver content of $9.1 \mathrm{wt} \%$ to $22.8 \mathrm{wt} \%$ in $\mathrm{AgY}$ and from $149 \mathrm{mg} \mathrm{g}_{\text {adsorbent }}{ }^{-1}$ to $267 \mathrm{mg} \mathrm{g}_{\text {adsorbent }}{ }^{-1}$ for a silver content of $7.3 \mathrm{wt} \%$ to $35 \mathrm{wt} \%$ in AgX was observed.

Influence of the zeolite type. Studies for a long time mainly focused on zeolites of the FAU and MOR structural types. ${ }^{5,8,29,31,34,38,40,47,52,71,169-171,173,175,177,178,182,184,185,187,188}$ The interest in these two types of zeolites can be explained by their large pore openings, which allow easier diffusion of iodine $\left(\mathrm{I}_{2}\right.$, $\left.\mathrm{CH}_{3} \mathrm{I}\right)$ and non-iodine $\left(\mathrm{NO}_{x}, \mathrm{CO}_{x}, \mathrm{H}_{2} \mathrm{O}\right.$, etc. $)$ compounds inside the zeolites. Other zeolites, such as the MFI, *BEA and FER structural types, could potentially be suitable for iodine adsorption applications. After the study by Chebbi et al. ${ }^{77}$ on the influence of the silver loading, it was concluded that AgX zeolite exhibited the best performance in the capture of iodine compounds, followed closely by AgY, whereas the performance of MFI, *BEA and FER zeolites was not of as much interest. For a similar silver content ( $\sim 9 \mathrm{wt} \%$ ), AgZSM-5 and AgY have similar adsorption capacities ( $\sim 85-87 \quad \mathrm{mg}$ gadsorbent $\left.^{-1}\right)$. 
However, these results differ greatly from those observed for AgX zeolite, which exhibited a saturation capacity of $149 \mathrm{mg}$ $\mathrm{g}_{\text {adsorbent }}{ }^{-1}$ for a silver content of $7.3 \mathrm{wt} \%$. The discrepancy between these silver-exchanged zeolites indicated that the silver content is not the only parameter that has to be considered for the adsorption of iodine species. Accordingly, AgX and AgY zeolites exhibit the best performance, which is principally due to their higher silver contents, in contrast to the other zeolites with low silver contents studied by Chebbi. ${ }^{77}$ Moreover, Chebbi et al. ${ }^{77}$ highlighted the fact that AgX zeolite has a cation exchange capacity that is much higher than that of AgY zeolite (iodine adsorption capacities of $234 \mathrm{mg} \mathrm{g}_{\text {adsorbent }}{ }^{-1}$ for a silver content of $23.4 \mathrm{wt} \%$ and $267 \mathrm{mg} \mathrm{g}_{\text {adsorbent }}{ }^{-1}$ for a silver content of $35 \mathrm{wt} \%$ in AgY and AgX zeolite, respectively), thanks to its low $\mathrm{Si} / \mathrm{Al}$ ratio. In conclusion, AgX zeolite was estimated to be the best silver-exchanged zeolite in terms of performance. However, Azambre et al. ${ }^{74}$ and Chebbi et al. ${ }^{77}$ carried out further studies by examining the quantities of physisorbed and chemisorbed iodine species and those captured in the form of AgI precipitates (AgI) to determine which silver-exchanged zeolites display the best performance in the irreversible capture of iodine. By temperature-programmed desorption experiments in combination with FTIR spectrometry, they studied the adsorption and desorption profiles of $\mathrm{CH}_{3} \mathrm{I}$ on different silver-exchanged zeolites (AgX, AgY, AgZSM-5, AgMOR, AgFER and AgBEA) to determine the quantities of physisorbed and chemisorbed iodine $\left(\mathrm{CH}_{3} \mathrm{I}\right)$ at saturation (Fig. 6).

The reversibility of the capture of $\mathrm{CH}_{3} \mathrm{I}$ differs drastically depending on the structural type of the silver-exchanged zeolite considered. ${ }^{77} \mathrm{X}$ and $\mathrm{Y}$ faujasite zeolites that have large pore openings with a size of $7.4 \times 7.4 \AA$ and a silver loading of greater than $20 \mathrm{wt} \%$ exhibit the best performance in terms of iodine capture, and more than $90 \%$ of $\mathrm{CH}_{3} \mathrm{I}$ is irreversibly adsorbed (chemisorbed + AgI precipitate). In contrast to faujasite-type zeolites, the proportion of physisorbed $\mathrm{CH}_{3} \mathrm{I}$ on impregnated AgFER zeolite (4.2 wt $\% \mathrm{Ag}$ ) with pore sizes of $3.5 \times 4.8 \AA$ and 4.2 $\times 5.4 \AA$ is significantly higher $(76 \pm 16 \%)$. This behaviour cannot only be attributed to the low loading of silver, given that

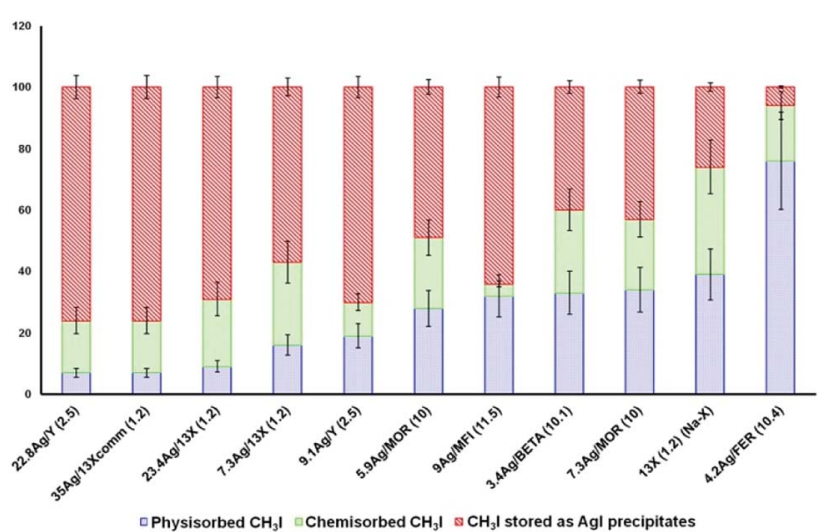

Fig. 6 Ranking of the ability of different sorbents to promote the irreversible trapping of $\mathrm{CH}_{3} \mathrm{l}$ as Agl. The best sorbents are on the left side of the diagram. Reprinted with permission from B. Azambre and M. Chebbi, ACS Applied Materials and Interfaces, 2017, 9, 2519425203. Copyright 2017 American Chemical Society. in the case of $\mathrm{Ag}^{*} \mathrm{BEA}$ zeolite $(3.4 \mathrm{wt} \% \mathrm{Ag}$ ) with pore sizes of 5.6 $\times 5.6 \AA$ and $6.6 \times 6.7 \AA$ the physisorbed component comprises only $33 \pm 7 \%$. The kinetic diameter of $\mathrm{CH}_{3} \mathrm{I}$ (between 5 and $6 \AA$ ) is far greater than the pore sizes of AgFER zeolite $(3.5 \times 4.8 \AA$ and $4.2 \times 5.4 \AA$ ), which could partly explain why physisorption is favoured at the expense of the formation of an AgI precipitate. The structure of the zeolite seems to have a non-negligible influence on the adsorption capacity and retention of iodine species, as zeolites with small pores favour physisorption, whereas zeolites with larger pores favour retention by chemisorption and the formation of an AgI precipitate. ${ }^{77}$

Influence of the Si/Al ratio in the zeolite framework. The amounts of silver that can be exchanged in a zeolite greatly depend on the $\mathrm{Si} / \mathrm{Al}$ ratio in the zeolite framework. In fact, Chebbi et $a{ }^{.77}$ and Azambre et $a l^{74}$ obtained silver loadings of greater than $20 \mathrm{wt} \%$ after several cation exchange steps in NaXand NaY-type zeolites. However, in the case of MFI-, MOR-, FERand *BEA-type zeolites the silver loading never exceeded $10 \mathrm{wt} \%$. The discrepancies between these structures can be linked to the fact that FAU-type zeolites have a low $\mathrm{Si} / \mathrm{Al}$ molar ratio in the framework $(1<\mathrm{Si} / \mathrm{Al}<3)$, which leads to a higher cation exchange capacities. Moreover, a study performed using density functional theory (DFT) ${ }^{79}$ has shown that the interaction energies of iodine compounds increase considerably when the $\mathrm{Si} / \mathrm{Al}$ ratio decreases (Fig. 7). The interaction energy increases from $145 \mathrm{~kJ} \mathrm{~mol}^{-1}$ to $190 \mathrm{~kJ} \mathrm{~mol}^{-1}$ and from $135 \mathrm{~kJ} \mathrm{~mol}^{-1}$ to $300 \mathrm{~kJ} \mathrm{~mol}^{-1}$ for $\mathrm{CH}_{3} \mathrm{I}$ and $\mathrm{I}_{2}$, respectively, as the $\mathrm{Si} / \mathrm{Al}$ ratio decreases from 47 to 5 . Chibani et al. proved via this study that (1) for a zeolite framework with a low $\mathrm{Si} / \mathrm{Al}$ ratio contaminants such as $\mathrm{H}_{2} \mathrm{O}$ and $\mathrm{CO}$ have little or no effect on the adsorption capacities of silver for iodine compounds and (2) at the same $\mathrm{Si}$ / Al ratios iodine compounds interact more strongly with silver, which enables the dissociation of $\mathrm{I}_{2}$ and formation of $\mathrm{AgI}$ for the immobilization of iodine. Therefore, the $\mathrm{Si} / \mathrm{Al}$ ratio has a strong influence on the iodine adsorption capacity. Hence, a low Si/Al ratio has two advantages: it provides greater silver exchange capacities and favours interactions between silver and iodine compounds.
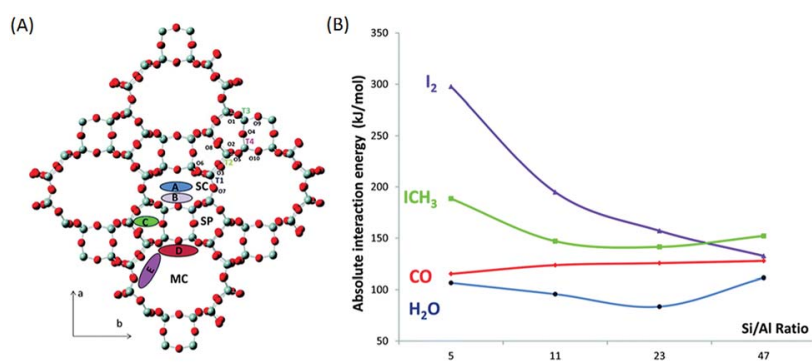

Fig. 7 (A) Schematic of the different channels present in the mordenite structure: main channel (MC), side pocket (SP) and side channel (SC). The potential locations of aluminium atoms at the four nonequivalent tetrahedral sites T1 to T4 are indicated. The capital letters A-E correspond to different Mortier sites, which can be occupied by extra-framework $\mathrm{Ag}^{+}$cations. Colour code: $\mathrm{O}$ atoms are in red and $\mathrm{Si}$ atoms are in pale blue. (B) Average interaction energies of $\mathrm{CH}_{3} \mathrm{I}_{2} \mathrm{I}_{2} \mathrm{CO}$ and $\mathrm{H}_{2} \mathrm{O}$ at T1-E sites as a function of the Si/Al ratio. Reproduced from ref. 79 with the permission of the PCCP Owner Societies. 
Influence of pretreatment with hydrogen. Several studies have established that the pretreatment of silver-exchanged zeolites with hydrogen significantly improves their performance in the capture of $\mathrm{CH}_{3} \mathrm{I}$ and $\mathrm{I}_{2}$. In 1978, Thomas et al. ${ }^{60}$ reported an increase in the adsorption capacity for $\mathrm{I}_{2}$ by a factor of two after pretreatment with hydrogen $\left(5 \mathrm{~L} \mathrm{~min}^{-1} \mathrm{H}_{2}, 500{ }^{\circ} \mathrm{C}, 24 \mathrm{~h}\right)$ for silver-exchanged mordenite ( $\mathrm{Ag}^{.0} \mathrm{MOR}, Q=138 \mathrm{mg}_{\mathrm{I}_{2}} \mathrm{~g}_{\mathrm{Ag}}{ }^{-1}$, bed length $2.5 \mathrm{~cm}$ ) in comparison with a non-pretreated silverexchanged mordenite (AgMOR, $Q=71 \mathrm{mg}_{\mathrm{I}_{2}} \mathrm{~g}_{\mathrm{Ag}}{ }^{-1}$, bed length $2.5 \mathrm{~cm}$ ). Subsequently, these results were confirmed by Jubin ${ }^{28,64}$ and Scheele et al. ${ }^{29}$ for the same type of zeolite. In 1980, studies led by Jubin ${ }^{28}$ showed that pretreatment with $\mathrm{H}_{2}\left(100 \% \mathrm{H}_{2}\right)$ at high temperatures $\left(200,400\right.$ and $\left.500{ }^{\circ} \mathrm{C}\right)$ for a long duration $(24 \mathrm{~h}$ and $48 \mathrm{~h})$ led to a decrease in the adsorption capacity for iodine compounds $\left(\mathrm{CH}_{3} \mathrm{I}\right)$. At $200{ }^{\circ} \mathrm{C}$, the adsorption capacity decreased from $35.6 \mathrm{mg}_{\mathrm{CH}_{3} \mathrm{I}} \mathrm{g}^{-1}$ to $12.3 \mathrm{mg}_{\mathrm{CH}_{3} \mathrm{I}} \mathrm{g}^{-1}$ for a pretreatment duration of 24 and 48 hours, respectively. The same results were obtained at higher temperatures $\left(400^{\circ} \mathrm{C}\right.$ and $500{ }^{\circ} \mathrm{C}$ ). This sudden decrease in performance is explained by the formation of silver nanoclusters and large aggregates, which limits the accessibility of silver. Therefore, it is necessary to define accurately the two parameters of pretreatment (temperature and duration) to maximize the adsorption capacities of silver-exchanged zeolites. With this in mind, Nan et al. ${ }^{174}$ recently determined the optimal temperature for the pretreatment with $\mathrm{H}_{2}$ of silver-supported mordenite (AgMOR, $12 \mathrm{wt} \%$ ) for the adsorption of iodine $\left(\mathrm{I}_{2}\right)$. They showed that after reduction by hydrogen $\left(4 \% \mathrm{H}_{2}\right.$ in argon, $\left.500 \mathrm{~mL} \mathrm{~min}^{-1}\right)$ for 24 hours the iodine adsorption capacity of $\mathrm{Ag}^{0} \mathrm{MOR}$ increased when the pretreatment temperature was increased from $170{ }^{\circ} \mathrm{C}$ to $400{ }^{\circ} \mathrm{C}$. However, after the temperature reached $400{ }^{\circ} \mathrm{C}$ the adsorption capacity did not increase further. Studies by Zhao et al. ${ }^{177}$ and Aspromonte et al. ${ }^{169}$ confirmed these results.

Influence of the operating temperature. Temperature is a crucial parameter that can significantly influence the adsorption capacities for iodine compounds of a silverexchanged zeolite. In 1982, Vance et al. ${ }^{34}$ studied the thermal stability in iodine capture of the silver-exchanged zeolites AgY (28 wt\%), AgX (37 wt\%) and AgMOR (20 wt\%). These three zeolites were first saturated with iodine under dry conditions at $130{ }^{\circ} \mathrm{C}$. Then, the temperature was increased from $130{ }^{\circ} \mathrm{C}$ to $1300{ }^{\circ} \mathrm{C}$ to observe the effect of temperature on the iodine content in these zeolites. A significant decrease in the iodine content captured in the zeolites was observed upon an increase in the temperature. The iodine content in AgY zeolite ( $28 \mathrm{wt} \%)$ decreased monotonically from $210 \mathrm{mg}_{\mathrm{I}_{2}} \mathrm{~g}_{\text {adsorbent }}{ }^{-1}$ to $50 \mathrm{mg}_{\mathrm{I}_{2}}$ $\mathrm{g}_{\text {adsorbent }}{ }^{-1}$ at temperatures of $130^{\circ} \mathrm{C}$ and $1300{ }^{\circ} \mathrm{C}$, respectively. However, it can be observed that at temperatures above $700{ }^{\circ} \mathrm{C}$ the zeolite framework generally tends to collapse and consequently loses crystallinity and becomes amorphous. This could explain the significant decrease in the iodine content observed by these authors. ${ }^{34}$ In 2001, the influence of temperature on AgX zeolite loaded with 10, 20 and $30 \mathrm{wt} \%$ silver was studied by Choi et $a .^{71} \mathrm{An}$ increase in temperature led to a decrease in the adsorption capacities of the zeolite for iodine compounds. For AgX zeolite (10 wt\%), the adsorption capacity decreased from
$180 \mathrm{mg}_{\text {adsorbent }}{ }^{-1}$ to $130 \mathrm{mg} \mathrm{g}_{\text {adsorbent }}{ }^{-1}$ at temperatures of $100{ }^{\circ} \mathrm{C}$ and $400{ }^{\circ} \mathrm{C}$, respectively. Similar conclusions were reached by Belapurkar et al. ${ }^{31}$ regarding the adsorption capacities for $\mathrm{CH}_{3} \mathrm{I}$ of dehydrated $\mathrm{AgX}$ zeolites at temperatures between 25 and $150{ }^{\circ} \mathrm{C}$. Furthermore, Cheng et al. observed a relatively significant decrease in the decontamination factor (DF) for silver-exchanged AgX zeolite between $250{ }^{\circ} \mathrm{C}$ and $650^{\circ} \mathrm{C}$. In the case of a $15 \mathrm{wt} \% \mathrm{AgX}$ zeolite, the decontamination factor decreased from $10^{3.4}$ to $10^{3.0}$ as the temperature was increased from $250{ }^{\circ} \mathrm{C}$ to $650{ }^{\circ} \mathrm{C}$.

From all these studies, it should be expected that the iodine adsorption capacity of a silver-exchanged zeolite decreases with temperature. However, Nan et al. ${ }^{174}$ observed an increase in the adsorption capacity of silver-reduced $\mathrm{Ag}^{0} \mathrm{MOR}(12 \mathrm{wt} \%)$ upon an increase in the temperature from $100^{\circ} \mathrm{C}$ to $150{ }^{\circ} \mathrm{C}$. Nevertheless, the adsorption capacity still decreased at temperatures above $150{ }^{\circ} \mathrm{C}$. Nan et al. linked this behaviour to the influence of water on the adsorption capacity and properties of mordenite. In fact, various studies have reported that water has a negative effect on the adsorption capacity for iodine. It was reported that the influence of water is less pronounced at higher temperatures than at lower temperatures. The probability that silver will react with water to form silver oxide $\left(\mathrm{Ag}_{2} \mathrm{O}\right)$ or its hydroxide decreases. Furthermore, iodine compounds have easier access to the pores and adsorption sites of the zeolite.

Influence of superficial velocity. Another factor that affects iodine adsorption performance is the flow rate of the carrier gas through the zeolite bed. According to Scheele et al. ${ }^{29}$ the flow rate is governed by four parameters, namely, the superficial velocity, bed diameter, bed length and residence time. Few studies have examined the effects of these parameters on the iodine capture performance of silver-exchanged zeolites. The bed diameter and length and the superficial face velocity and contact time are interrelated. In a study by Scheele et al.,$^{29}$ the authors decided to ignore potential effects of the bed size and contact time by arbitrarily selecting a bed diameter and bed length to exceed the expected zone of mass transfer and thus regrouped these factors into one variable, namely, superficial face velocity. In their work, the authors ${ }^{29}$ confirmed that an increase in the superficial velocity from $3.75 \mathrm{~m} \mathrm{~min}^{-1}$ to $15 \mathrm{~m} \mathrm{~min}^{-1}$ decreased the adsorption capacities of AgMOR zeolites for $\mathrm{CH}_{3} \mathrm{I}$ from $71 \mathrm{mg}$ $\mathrm{g}_{\text {adsorbent }}{ }^{-1}$ to $7 \mathrm{mg} \mathrm{g}_{\text {adsorbent }}{ }^{-1}$, respectively. This trend was also observed by Pence et $a l^{40}$ for AgX-type zeolites. A thorough knowledge of the related operating conditions in reactors and the associated kinetics is crucial for maximising the adsorption capacities of silver-exchanged zeolites.

Influence of inhibitors. During a severe nuclear accident, several compounds such as $\mathrm{H}_{2} \mathrm{O}, \mathrm{CO}, \mathrm{CO}_{2}$, nitrogen oxides $\left(\mathrm{NO}_{x}\right)$, hydrocarbons and halogenated organic compounds are released. These compounds can act as inhibitors and poisons and thus limit the iodine adsorption capacities of silverexchanged zeolites.

Influence of water. First of all, the influence of water and humidity on a silver-exchanged zeolite was studied. In 1976, Thomas et al. ${ }^{52,60}$ showed that very little variation in the iodine $\left(\mathrm{I}_{2}\right)$ adsorption capacity of $\mathrm{Ag}^{0} \mathrm{MOR}$ was observed in the 
presence of water (dew point $35{ }^{\circ} \mathrm{C}$ ) in the carrier gas flow $(4 \pm$ $\left.12 \mathrm{mg}_{\mathrm{I}_{2}} \mathrm{~g}_{\mathrm{AgMOR}}{ }^{-1}\right)$. They concluded that the presence of water did not affect or only slightly affected the $\mathrm{I}_{2}$ trapping performance, which was contradicted by more recent studies. The effect of water on the adsorption capacity for $\mathrm{CH}_{3} \mathrm{I}$ was also studied by Scheele and Burger. ${ }^{29,32}$ The authors demonstrated that a water concentration of around $5 \times 10^{-4} \mathrm{~mol} \mathrm{~L}^{-1}$ in the carrier gas was beneficial for the adsorption capacity for $\mathrm{CH}_{3} \mathrm{I}(Q$ $=139 \mathrm{~g} \mathrm{~kg}_{\text {adsorbent }}{ }^{-1}$ ) rather than a lower concentration of $4.3 \times$ $10^{-6} \mathrm{~mol} \mathrm{~L}^{-1}\left(Q=30 \mathrm{~g} \mathrm{~kg}_{\text {adsorbent }}{ }^{-1}\right)$. These observations were confirmed by Jubin, ${ }^{28,64}$ who asserted that the presence of a moderate amount of water increased the adsorption capacities for $\mathrm{CH}_{3} \mathrm{I}$ of $\mathrm{Ag}^{0} \mathrm{MOR}$ zeolites, whereas a dry atmosphere or high relative humidity led to a decrease in the adsorption capacities. Water in the carrier gas seems to be beneficial for increasing the adsorption capacities of silver-exchanged zeolites. However, no advanced studies have determined the exact conditions of humidity for the optimal utilization of silver-exchanged zeolites.

The adsorption capacities for $\mathrm{CH}_{3} \mathrm{I}$ were also studied by Belapurkar et al. ${ }^{31}$ for temperatures between 25 and $150{ }^{\circ} \mathrm{C}$ and degrees of hydration between 0 and $18 \mathrm{wt} \%$. They determined that humidity has a negative effect on performance. This was particularly significant at low temperatures, as a decrease in capacity of $56 \%$ was observed at $25{ }^{\circ} \mathrm{C}$ in contrast to $17 \%$ at $150{ }^{\circ} \mathrm{C}$. Further studies by Belapurkar et al. ${ }^{31}$ showed that in the absence of silver (NaX) the effect of hydration on adsorption capacities is far more pronounced than in the case of a silverexchanged zeolite (AgX). This discrepancy between the two zeolites can be explained by the fact that in zeolites in which no cations are exchanged for silver ( $\mathrm{NaX}$ ) adsorption phenomena are dominated by physisorption. In fact, notably at low temperatures, competition between water molecules and $\mathrm{CH}_{3} \mathrm{I}$ species occurs for adsorption sites. Consequently, the adsorption capacities for $\mathrm{CH}_{3} \mathrm{I}$ are reduced. In the case of silver-exchanged zeolites, chemisorption phenomena are prevalent. Therefore, the effect of water is reduced, especially at high temperatures.

In a similar way, Choi et al. ${ }^{\mathbf{1 8 5}}$ demonstrated that water (relative humidity of $50 \%$ ) had a negative effect on the decontamination factor of an AgX zeolite $\left(\mathrm{DF}=3 \times 10^{4}\right.$ to $\mathrm{DF}=2 \times$ $10^{3}$ at $200{ }^{\circ} \mathrm{C}$ ). Finally, Jubin et al. ${ }^{189}$ studied the effect of longterm aging (up to 6 months) of a commercial $\mathrm{Ag}^{0} \mathrm{MOR}$ zeolite under dry and humid conditions before the adsorption of $I_{2}$. After exposure to a dry atmosphere for 6 months, a decrease of $40 \%$ in the iodine adsorption capacity was observed. On the other hand, in the case of exposure to a humid atmosphere a decrease of $45 \%$ in the iodine adsorption capacity was observed in only 1 month. The authors explained that aging in dry conditions for 6 months is equivalent to aging for 1 month in humid conditions, which underlined the strong effect of water on the adsorption capacities of silver-exchanged zeolites. In conclusion, despite a certain amount of contradiction in the literature, the general effect of water and/or humidity on the adsorption capacities of silver-exchanged zeolites seems to be negative. However, a low concentration of water is believed to favour the mechanism of the trapping of $\mathrm{CH}_{3} \mathrm{I}$ on silver.
Influence of $\mathrm{NO}_{x}$. Nitrogen oxides, which are more commonly known as $\mathrm{NO}_{x}$, are acknowledged by the scientific community to influence the retention and capture performance of silverexchanged zeolites. ${ }^{\mathbf{2 8 , 6 3 , 6 4}} \mathrm{NO}_{x}$ have a more or less adverse effect depending on the iodine species in consideration, their concentrations, the type of zeolite used and the operating conditions (superficial velocity, temperature, presence of other contaminants). Even though several studies reported ambiguous or conflicting results, the majority agreed on the fact that $\mathrm{NO}_{x}$ impair to a certain extent the adsorption performance of silverexchanged zeolites. In 1979, Holladay ${ }^{63}$ studied the effect of NO and $\mathrm{NO}_{2}$ on the iodine retention capacity of silver-exchanged mordenite $\left(\mathrm{Ag}^{0} \mathrm{MOR}\right)$. In the absence of $\mathrm{NO}_{x}$ contaminants, the capacity for iodine that was measured was $113 \pm 12 \mathrm{mg}$ $\mathrm{g}_{\mathrm{Ag}^{0} \mathrm{MOR}}{ }^{-1}$. Surprisingly, when $2 \%$ NO was added to the carrier gas the adsorption capacity of silver-exchanged mordenite increased to $129 \pm 10 \mathrm{mg} \mathrm{g}_{\mathrm{Ag}^{0} \mathrm{MOR}}{ }^{-1}$. However, when $2 \% \mathrm{NO}_{2}$ was added to the feed gas, this time a decrease in the adsorption capacity could be observed ( $68 \pm 12 \mathrm{mg} \mathrm{g}_{\mathrm{Ag}^{0} \mathrm{MOR}}{ }^{-1}$ ). The author ${ }^{63}$ assumed that $\mathrm{NO}$ acts as a reducing agent in the presence of oxygen to maintain silver in its highly reactive reduced metallic form $\left(\mathrm{Ag}^{0}\right)$. However, the presence of $\mathrm{NO}_{2}$ allows the slow oxidation of silver to silver oxide $\left(\mathrm{Ag}_{2} \mathrm{O}\right)$, which is less reactive and would consequently decrease the adsorption capacity. The presence of both compounds $\left(\mathrm{NO}+\mathrm{NO}_{2}\right)$ in the carrier gas slightly modified the adsorption capacity $\left(119 \pm 12 \mathrm{mg}_{\mathrm{I}_{2}} \mathrm{~g}_{\mathrm{Ag}^{\mathrm{O} M O R}}{ }^{-1}\right)$. Jubin ${ }^{28,64}$ also carried out experiments on the adsorption of $\mathrm{CH}_{3} \mathrm{I}$ onto an $\mathrm{Ag}^{0} \mathrm{MOR}$ zeolite in the presence of $\mathrm{NO}_{x}(0-3 \%$ NO and $0-3 \%$ $\mathrm{NO}_{2}$ ). The results indicated that the presence of $\mathrm{NO}_{x}$ slightly modified the adsorption performance. Recent studies led by Bruffey et $a{ }^{178}$ finally helped to conclude that the presence of nitrogen oxides such as $\mathrm{NO}_{x}\left(\left[\mathrm{NO}_{x}\right]=10000 \mathrm{ppm}\right.$ in air $)$ has a negative effect on the adsorption capacities of silver-exchanged zeolites for $\mathrm{CH}_{3} \mathrm{I}$, with a decrease from $125 \mathrm{mg}_{\mathrm{CH}_{3} \mathrm{I}} \mathrm{g}_{\mathrm{Ag}^{0} \mathrm{MOR}}{ }^{-1}$ to 56 $\mathrm{mg}_{\mathrm{CH}_{3} \mathrm{I}} \mathrm{g}_{\mathrm{Ag}^{0} \mathrm{MOR}}{ }^{-1}$. In the presence of $\mathrm{NO}$ and $\mathrm{NO}_{2}$ in the carrier gas, the adsorption capacity for $\mathrm{CH}_{3} \mathrm{I}$ decreases by $40 \%$ in comparison with the adsorption capacity determined in dry air alone. Furthermore, the presence of $\mathrm{NO}_{x}$ allows the oxidation of $\mathrm{CH}_{3} \mathrm{I}$ to $\mathrm{I}_{2}$ (ref. 178) according to the following thermodynamically favoured reactions ${ }^{29}$ (eqn (12), $\Delta G=-1079 \mathrm{~kJ} \mathrm{~mol}^{-1}, T=$ $400 \mathrm{~K}$ and eqn (13), $\left.\Delta G=-853 \mathrm{~kJ} \mathrm{~mol}^{-1}, T=400 \mathrm{~K}\right)$ :

$$
\begin{gathered}
7 \mathrm{NO}+2 \mathrm{CH}_{3} \mathrm{I} \leftrightarrow \mathrm{I}_{2}+3 \mathrm{H}_{2} \mathrm{O}+2 \mathrm{CO}_{2}+7 / 2 \mathrm{~N}_{2} \\
7 \mathrm{NO}_{2}+4 \mathrm{CH}_{3} \mathrm{I} \leftrightarrow 2 \mathrm{I}_{2}+6 \mathrm{H}_{2} \mathrm{O}+4 \mathrm{CO}_{2}+7 / 2 \mathrm{~N}_{2}
\end{gathered}
$$

However, no experimental studies have proved the occurrence of such reactions during tests on the adsorption of $\mathrm{CH}_{3} \mathrm{I}$ and $\mathrm{I}_{2}$ in the presence of $\mathrm{NO}_{x}$. Studies of the long-term influence of $\mathrm{NO}_{2}(200 \mathrm{ppm})$ on the adsorption capacity of a silverexchanged $\mathrm{X}$ zeolite (10 wt\% Ag) were carried out by Choi et $a{ }^{185}$ These studies demonstrated that no significant effect could be observed on the adsorption performance of the zeolite in the presence of $\mathrm{NO}_{x}$ in the short term (several weeks). However, in the long term, i.e., after poisoning by $\mathrm{NO}_{x}$ for 16 months, the adsorption efficiency declined from 99.9\% (DF = $10^{4}$ ) to $99.0 \%\left(\mathrm{DF}=10^{2}\right)$ (Fig. 8$)$. 


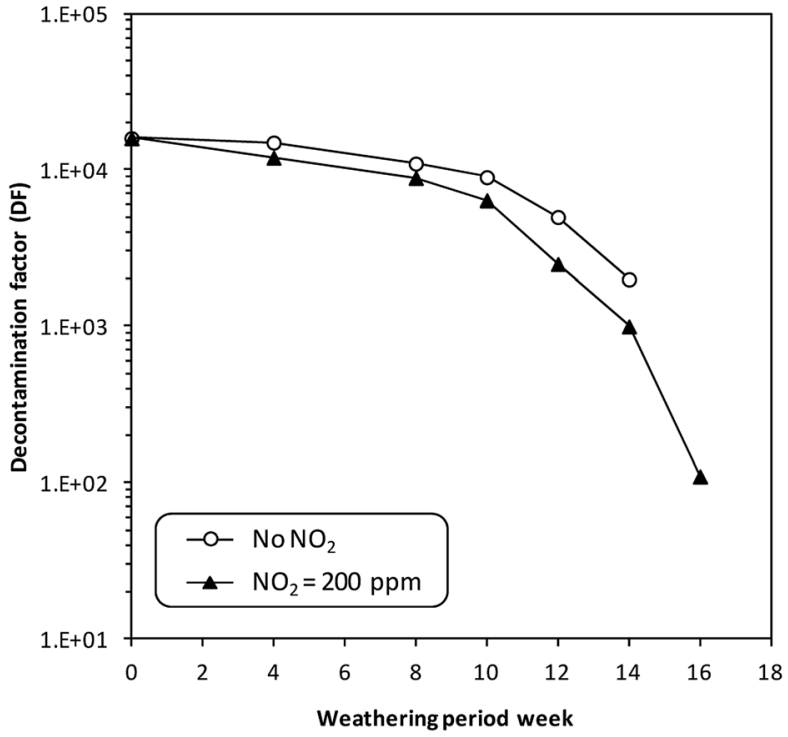

Fig. 8 Effect of long-term weathering on the decontamination factor for the retention of radioactive methyl iodide using a $10 \mathrm{wt} \% \mathrm{AgX}$ adsorbent with $\mathrm{NO}_{2}$ gas poisoning. Adapted by permission from Springer Nature from B. S. Choi, G. Il Park, J. W. Lee, H. Y. Yang and S. K. Ryu, Journal of Radioanalytical and Nuclear Chemistry, 2003, 256, 1926, Copyright 2003.

Bruffey et al. ${ }^{175}$ studied the iodine trapping stability of an $\mathrm{Ag}^{0} \mathrm{MOR}$ zeolite in the presence of $2 \% \mathrm{NO}_{2}$ for a duration of 1 to 4 months. The authors initially saturated the zeolite with iodine to give an average adsorption capacity of $72 \mathrm{mg}_{\mathrm{I}_{2}} \mathrm{~g}_{\mathrm{Ag}^{0} \mathrm{MOR}}{ }^{-1}$. Then, aging and stability tests were carried out at $150{ }^{\circ} \mathrm{C}$ with $2 \% \mathrm{NO}_{2}$ in the carrier gas for 1, 2, 3 and 4 months. The different tests showed an absence of released iodine after exposure to $\mathrm{NO}_{x}$ for 4 months. In conclusion, the presence of nitrogen oxide $\left(\mathrm{NO}_{x}\right)$ in the carrier gas or the surrounding atmosphere is believed to affect negatively the adsorption performance of silver-exchanged zeolites, but the effect is not drastic. According to the literature, this could be attributed to a modification of the oxidation state of silver $\left(\mathrm{Ag}^{0}\right.$ to $\left.\mathrm{Ag}_{2} \mathrm{O}\right)$. However, in the case of a few studies the presence of $\mathrm{NO}_{x}$ did not have any important effect on the iodine adsorption capacities of zeolites. Furthermore, aging studies show a more pronounced adverse effect in the long term rather than in the short term.

Influence of organics and halogen compounds. Organics and halogen compounds are also acknowledged to have an influence on the adsorption capacities of silver-exchanged zeolites. Jolley et $a l^{30}$ studied the effect of various volatile organic compounds (alkanes, alkenes, aromatics, ketones, alcohols, and chlorine- and bromine-containing compounds) on the efficiency of the adsorption of $\mathrm{CH}_{3} \mathrm{I}$ by silver-exchanged $\mathrm{X}$ zeolite (AgX). The adsorption capacity for $\mathrm{CH}_{3} \mathrm{I}$ was unaffected or only slightly affected by small molecules (such as hexane or ethanol), whereas in the case of molecules with larger sizes the performance of the silver-containing material was greatly affected in a negative way. Different families of organic compounds had the following inhibitory effects on the adsorption capacity of AgX zeolite: alkynes > alcohols > ketones and aromatics > alkanes; alkynes had the most detrimental influence on the adsorption capacity. The size of the molecule appears to play an important role, as it sterically hinders access to the zeolite pores. Therefore, the capture of iodine by silver inside the zeolite pores is limited (diffusion limitation). However, this steric hindrance effect is not the only factor in the decrease in the adsorption capacity of the silver-exchanged zeolite. In fact, heteroatoms such as chlorine, bromine and oxygen and/or unsaturated compounds can be adsorbed onto silver sites thanks to the strong interactions that exist between them and silver. Halogenated compounds, especially chlorinecontaining compounds, tend to dissociate and release chlorine, which will poison the silver active sites. Surface analysis techniques (XPS, EDX) have shown that the adsorption of halogenated compounds (such as chloromethane or bromomethane) gives rise to the formation of metallic silver halide precipitates ( $\mathrm{AgCl}$ and $\mathrm{AgBr})$. From a thermodynamic point of view, chlorine is the main inhibitor of the adsorption of iodine onto silver-exchanged zeolites. Undeniably, because an $\mathrm{AgCl}$ precipitate $\left(\Delta_{\mathrm{f}} G^{\circ}=-109.9 \mathrm{~kJ} \mathrm{~mol}^{-1}\right)$ is more stable than an AgI precipitate $\left(\Delta_{\mathrm{f}} G^{\circ}=-66.3 \mathrm{~kJ} \mathrm{~mol}^{-1}\right)$, the presence of a large excess of $\mathrm{Cl}_{2}, \mathrm{HCl}$ or $\mathrm{CH}_{3} \mathrm{Cl}$ in the environment near a silverexchanged zeolite significantly affects and impairs its performance. Burchsted et al. ${ }^{56}$ reported in 1976 that a silverexchanged zeolite bed became totally ineffective for the capture of iodine nearly instantly after $\mathrm{HCl}$ was introduced into it. Similar studies by Ackley et al. ${ }^{49}$ showed that the presence of chlorine $\left(\mathrm{Cl}_{2}\right)$ significantly impaired the iodine adsorption performance of an $\mathrm{AgX}$ zeolite in terms of the decontamination factor (DF). They reported for a silver-exchanged zeolite that was exposed to $\mathrm{Cl}_{2}$ concentrations between 0.4 and $0.8 \mathrm{mmol} \mathrm{mL}$ that the decontamination factor for a bed length of $10 \mathrm{~cm}$ decreased to $\mathrm{DF}=14-20$ in contrast to $\mathrm{DF}=10^{2}$ in the absence of chlorine. In conclusion, organic compounds, especially halogenated compounds, have a strong influence on the iodine adsorption capacities of silver-exchanged zeolites. It can be observed that chlorine is the most strongly inhibiting compound for this type of material, which is principally due to its high affinity for silver as shown by the formation of a stable AgCl precipitate.

Influence of other compounds. Other compounds can also be present during a severe nuclear accident, such as $\mathrm{CO}_{x}\left(\mathrm{CO}_{2}\right.$ and $\mathrm{CO}), \mathrm{SO}_{x}\left(\mathrm{SO}_{2}\right.$ and $\left.\mathrm{SO}_{3}\right)$ and, to a lesser extent, $\mathrm{P}_{4} \mathrm{O}_{10} \cdot{ }^{186}$ These compounds, which have not been studied in depth, seem to not significantly affect the iodine adsorption performance of silverexchanged zeolites. However, in their presence, the diffusion of iodine species inside zeolite pores might become limited for steric reasons.

Despite a few contradictions in the literature, most studies acknowledged that the inhibitors mentioned previously $\left(\mathrm{H}_{2} \mathrm{O}\right.$, $\mathrm{NO}_{x}$, organics, halogenated compounds, $\mathrm{CO}_{x}, \mathrm{SO}_{x}$, etc.) generally have a negative effect on the iodine adsorption capacities of silver-exchanged zeolites. A recent study performed by Chebbi et al. ${ }^{81}$ confirmed all the observations cited above.

Influence of $\gamma$-radiation. Little information can be found in the literature on the influence of $\gamma$-radiation on the iodine 
adsorption performance of silver-exchanged zeolites. ${ }^{59}$ Evans $^{59}$ studied an AgX zeolite, which had been saturated with iodine beforehand, in the presence of $\gamma$-radiation for exposure durations of up to 104 hours. These tests demonstrated that at temperatures of $>45{ }^{\circ} \mathrm{C}$ and in a water-rich atmosphere the destabilisation of trapped $\mathrm{I}_{2}$ is favoured. The desorption rate was $0.1 \%$ per hour at a temperature of $80{ }^{\circ} \mathrm{C}$ and a relative humidity of $90 \%$. After desorption for 105 hours (in various operating conditions: $35{ }^{\circ} \mathrm{C} \leq T \leq 80{ }^{\circ} \mathrm{C}$ and $20 \% \leq$ R.H. $\leq$ $95 \%$ ), the total quantity of iodine released remained fairly low (approximately $0.74 \%$ of the initial quantity of iodine trapped beforehand). These results show that the stability of iodine trapped in silver-exchanged zeolites $(\mathrm{AgX})$ is not significantly affected by the presence of $\gamma$-radiation. Recent studies by Chebbi et al. confirmed the absence of an influence of $\gamma$-radiation on the iodine adsorption capacities of AgY and AgX zeolites. $^{\mathbf{8 1}}$

All these studies that were performed on silver-exchanged zeolites used for iodine capture and carried out under different operating conditions (inlet iodine concentration, bed length, etc.) are difficult to compare. Furthermore, in some studies the zeolites used were not completely crystalline. In addition, sometimes commercial and home-made zeolites with different loadings of silver were compared, which is not appropriate.

2.2.4. Zeolites loaded with other metals for the capture of radioactive iodine. One of the main drawbacks of silverexchanged zeolites is the inherent cost of the silver metal used. For this reason, other elements have been studied to obtain low-cost metal-exchanged zeolites for the adsorption of iodine. Between 1968 and 1970 Maeck and Pence ${ }^{38-40}$ studied the iodine capture performance of approximately twenty zeolites impregnated with metals (Ag, Na, Cu, Pd, Tl, etc.). Their studies on $\mathrm{NaX}$ zeolite proved the great superiority of silver in terms of iodine adsorption over the other elements. The silverexchanged zeolite (AgX) exhibited an iodine adsorption efficiency of $99.9 \%$, whereas those of the other exchanged zeolites were less than $30 \%$. No elements other than silver proved to have acceptable performance for the adsorption of iodine. After these works, Staples et al. ${ }^{52}$ studied the effect of the exchanged cations $\left(\mathrm{Na}^{+}, \mathrm{Ag}^{+}, \mathrm{Pb}^{2+}, \mathrm{Cd}^{2+}\right)$ on the irreversibility of the capture of iodine $\left(\mathrm{I}_{2}\right)$ by the faujasite-type $\mathrm{X}$ zeolite at $150{ }^{\circ} \mathrm{C}$. Even though the iodine adsorption capacity of every cation was acceptable, only silver was capable of trapping iodine in an irreversible way. Recent studies, ${ }^{75,76,79,80}$ especially those using density functional theory (DFT) simulations, enabled the determination of the influence of the valence of cations on the selective adsorption of iodine species by zeolites. In an initial study, Chebbi et al. ${ }^{75}$ showed that copper $\left(\mathrm{Cu}^{+}\right)$- and silver $\left(\mathrm{Ag}^{+}\right)$exchanged faujasite zeolites (CuX and AgX, respectively) preferentially adsorbed iodine compounds rather than species such as water, chloromethane and chlorine. Furthermore, the adsorption of iodine species is much more pronounced on the $\mathrm{CuX}$ and AgX zeolites rather than on the protonated or sodium forms of faujasite zeolites. However, the presence of inhibitors such as carbon monoxide (CO) or nitrogen oxide (NO) limits the selectivity of $\mathrm{Cu}^{+}$zeolites for the adsorption of iodine. Despite its good performance in the adsorption of iodine, CuX zeolite cannot be used in the presence of elevated quantities of $\mathrm{CO}$ or NO, which would be present during a severe nuclear accident. In contrast to $\mathrm{CuX}$ zeolite, AgX zeolite displayed good adsorption of iodine species in the presence of NO. It can be observed that these modelling results do not agree totally with the experimental results described in the section on the influence of inhibitors. In a second study, the influence of the presence of $\mathrm{Cu}^{2+}, \mathrm{Pb}^{2+}$, and $\mathrm{Hg}^{2+}$ in mordenite zeolite on its iodine adsorption performance, with a comparison of the adsorption energies of $\mathrm{CH}_{3} \mathrm{I}$ and $\mathrm{I}_{2}$, was investigated. In the presence of large quantities of contaminants $\left(\mathrm{H}_{2} \mathrm{O}, \mathrm{CO}, \mathrm{CH}_{3} \mathrm{Cl}, \mathrm{Cl}_{2}\right)$, HgMOR was found to be the best adapted metal-exchanged mordenite for the adsorption of iodine. From a thermodynamic point of view, the tendency of a metal to form the corresponding halide (MI) can be estimated from the Gibbs free energy of formation $\left(\Delta_{\mathrm{f}} G^{\circ}, \mathrm{kJ} \mathrm{mol}^{-1}\right)$. By comparing the energies of formation of halides and the corresponding oxides, it is possible to identify the most thermodynamically stable compounds. Table 1 lists the Gibbs free energies of formation of several halides and oxides. ${ }^{\mathbf{1 9 0 , 1 9 1}}$

In the majority of cases, the oxide will be preferentially formed rather than the halide form, except for silver (Ag) and mercury ( $\mathrm{Hg})$. It is therefore not surprising that in most studies the authors observed that other metals had low adsorption capacities in comparison with that of silver. In conclusion, studies on zeolites in which cations were exchanged for various metals ( $\mathrm{Na}, \mathrm{Cu}, \mathrm{Pd}, \mathrm{Cd}, \mathrm{Tl}$, etc.) proved that their efficiency in the capture of iodine species is low and showed that silverexchanged zeolites have the highest iodine adsorption capacities. Despite its inherent high cost, silver proved once again its ability to trap iodine compounds efficiently in an irreversible way. Furthermore, silver has the ability to form thermodynamically and chemically stable compounds with iodine.

\subsection{Titanosilicates}

Titanosilicates are a family that is analogous to aluminosilicate zeolites in which aluminium is replaced by titanium. Recently, Wu et al. ${ }^{83}$ studied silver-exchanged titanosilicates (named as

Table 1 Comparison of Gibbs free energies of formation of iodides and oxides $\left(\Delta_{\mathrm{f}} \mathrm{G}^{\circ}, \mathrm{kJ} \mathrm{mol}^{-1}\right)^{190,191}$

\begin{tabular}{lllll}
\hline Metal & Iodide & $\begin{array}{l}\Delta_{\mathrm{f}} G^{\circ} \\
\left(\mathrm{kJ} \mathrm{mol}^{-1}, 25{ }^{\circ} \mathrm{C}\right)\end{array}$ & Oxide & $\begin{array}{l}\Delta_{\mathrm{f}} G^{\circ} \\
\left(\mathrm{kJ} \mathrm{mol}^{-1}, 25{ }^{\circ} \mathrm{C}\right)\end{array}$ \\
\hline $\mathrm{Ag}$ & $\mathrm{AgI}$ & -66.3 & $\mathrm{Ag}_{2} \mathrm{O}$ & -11.2 \\
$\mathrm{Cu}$ & $\mathrm{CuI}$ & -69.4 & $\mathrm{CuO}$ & -129.8 \\
$\mathrm{Hg}$ & $\mathrm{HgI}_{2}$ & -102.3 & $\mathrm{HgO}$ & -58.6 \\
& $\mathrm{Hg}_{2} \mathrm{I}_{2}$ & -111.2 & $\mathrm{HgO}$ & -58.6 \\
$\mathrm{Fe}$ & $\mathrm{FeI}_{2}$ & -109.1 & $\mathrm{FeO}$ & -246.5 \\
$\mathrm{Tl}$ & $\mathrm{TlI}_{\mathrm{II}}$ & -125.5 & $\mathrm{Tl} \mathrm{O}$ & -147.3 \\
$\mathrm{Sn}$ & $\mathrm{SnI}_{2}$ & -144.3 & $\mathrm{SnO}$ & -257.0 \\
& $\mathrm{SnI}_{4}$ & -215.2 & $\mathrm{SnO}_{2}$ & -519.9 \\
$\mathrm{Cd}$ & $\mathrm{CdI}_{2}$ & -201.4 & $\mathrm{CdO}^{2}$ & -228.6 \\
$\mathrm{~Pb}$ & $\mathrm{PbI}_{2}$ & -173.6 & $\mathrm{PbO}^{2}$ & -188.0 \\
$\mathrm{Ti}$ & $\mathrm{TiI}_{2}$ & -258.7 & $\mathrm{TiO}_{2}$ & -884.9 \\
& $\mathrm{TiI}_{4}$ & -370.9 & $\mathrm{TiO}_{2}$ & -884.9
\end{tabular}


ETS-10 and ETS-2) for trapping iodine $\left(\mathrm{I}_{2}\right)$. The ETS-10 adsorbent is characterized by a stable chemical structure (isolated octahedral titanium chains in the silica network) with pores exclusively based on silicon. The composition of ETS-10 endows this adsorbent with hydrophobic properties and high chemical stability in acidic conditions. In contrast, ETS-2 is composed of sodium and titanium and possesses a reasonable specific surface area $\left(260 \mathrm{~m}^{2} \mathrm{~g}^{-1}\right)$, which corresponds to its external surface, without structural microporosity. Unlike ETS-10, ETS-2 has a high capacity for cation exchange (with sodium), like that of zeolites. It was shown that the iodine adsorption capacities of silver-doped and silver-exchanged titanosilicates were elevated, at around $220 \mathrm{~g}_{\mathrm{I}_{2}} \mathrm{~kg}_{\text {adsorbent }}{ }^{-1}$ and $243 \mathrm{~g}_{\mathrm{I}_{2}} \mathrm{~kg}_{\text {adsorbent }}{ }^{-1}$ in dry conditions for ETS-10 (35 wt\% Ag) and ETS-2 (40 wt\% Ag), respectively. The effect of humidity on the adsorption performance of these materials was also studied. A non-negligible decline of $30 \%$ in the adsorption capacity was measured for the Ag-ETS-10 adsorbent. According to the authors, the porous structure of the ETS-10 adsorbent favours the condensation of water inside the pores, which limits the accessibility of the silver adsorption sites for iodine. In the case of the non-porous ETS-2 adsorbent, the performance was much less affected by the presence of water. ETS-10 titanosilicate-type adsorbents supported on a hollow carbon nanostructured polyhedral adsorbent (C@ETS-10) were also studied. ${ }^{94}$ An adsorption capacity of $40 \mathrm{~g}_{\mathrm{I}_{2}} \mathrm{~kg}_{\text {adsorbent }}{ }^{-1}$ at $20{ }^{\circ} \mathrm{C}$ was recorded.

\subsection{Porous oxide materials}

2.4.1. Silver-doped silica and alumina $\left(\mathrm{Ag} / \mathrm{SiO} \mathrm{O}_{2}, \mathrm{Ag} / \mathrm{Al}_{2} \mathrm{O}_{3}\right)$. Silver-exchanged zeolites are not the only inorganic materials that are suitable for the capture of iodine compounds. Oxidetype materials such as alumina $\left(\mathrm{Al}_{2} \mathrm{O}_{3}\right)$ and silica $\left(\mathrm{SiO}_{2}\right)$ that are impregnated with silver, which are designated as $\mathrm{Ag} / \mathrm{Al}_{2} \mathrm{O}_{3}$ and $\mathrm{Ag} / \mathrm{SiO}_{2}$, respectively, are another class of adsorbents that can be found in the literature. These materials have been the focus of various studies $\mathbf{1 9 , 3 5 , 5 2 , 6 1 , 6 5 , 7 0 , 8 7 - 9 7}$ and have been used for the capture of iodine $\left(I_{2}\right)$ on an industrial scale. ${ }^{65,88-90,96}$ These adsorbents, which contain silver nitrate $\left(\mathrm{AgNO}_{3}\right)$, proved their efficiency for the elimination of iodine $\left(\mathrm{I}_{2}\right)$ and iodomethane $\left(\mathrm{CH}_{3} \mathrm{I}\right)$ in a spent fuel reprocessing plant. The mechanism of the capture of iodine by these silver-impregnated materials has been detailed by Wilhelm et al. ${ }^{\mathbf{4 8 , 5 4}}$ Silver nitrate $\left(\mathrm{AgNO}_{3}\right)$ reacts with elemental iodine to form stable silver iodide (AgI) or silver iodate $\left(\mathrm{AgIO}_{3}\right)$ by the following reactions:

$$
\begin{gathered}
\mathrm{AgNO}_{3}+\mathrm{I}_{2} \rightarrow \mathrm{AgI}+\mathrm{INO}_{3} \\
2 \mathrm{INO}_{3}+\mathrm{AgNO}_{3} \rightarrow \mathrm{AgIO}_{3}+3 \mathrm{NO}_{2}+0.5 \mathrm{I}_{2} \\
\mathrm{INO}_{3} \rightarrow \mathrm{NO}_{2}+0.5 \mathrm{O}_{2}+0.5 \mathrm{I}_{2} \\
\mathrm{AgNO}_{3}+\mathrm{CH}_{3} \mathrm{I} \rightarrow \mathrm{CH}_{3} \mathrm{NO}_{3}+\mathrm{AgI}
\end{gathered}
$$

An amorphous silver-doped silica, which was commercialized under the name of AC-6120, was used in the Karlsruhe spent fuel reprocessing plant (WAK) in Germany for the capture of iodine $\left(\mathrm{I}_{2}\right) .{ }^{88}$ This adsorbent has a nominal BET surface area of $65-110 \mathrm{~m}^{2} \mathrm{~g}^{-1}$, a pore size distribution of $20-40 \mathrm{~nm}$, a pore volume of $0.6 \mathrm{~cm}^{3} \mathrm{~g}^{-1}$ and a silver loading of $8-12 \mathrm{wt} \%$. Decontamination factors (DFs) for iodine of between 100 (>99.0\% efficiency) and 50 (98.0\% efficiency) were achieved during its utilization on an industrial scale. ${ }^{\mathbf{4 8 , 5 4 , 8 8}}$ On the laboratory scale, this silver-doped silica displayed decontamination factors for $\mathrm{I}_{2}$ that were higher than $10^{4}$ ( $>99.99 \%$ efficiency) at a temperature of $150{ }^{\circ} \mathrm{C}$ (bed length of $10 \mathrm{~cm}$, superficial velocity of $25 \mathrm{~cm} \mathrm{~s}^{-1}$, in the presence of $\left.1-5 \% \mathrm{NO}_{2}\right){ }^{48,54}$ The efficiency declined from $99.9944 \%$ to $27 \%$ at a relative humidity of $70 \%$ and $100 \%$, respectively. In addition, Wilhelm and Schuttelkopf ${ }^{48}$ stated that an increase in temperature up to $200{ }^{\circ} \mathrm{C}$ slightly improved the performance. Nevertheless, an increase in temperature becomes less attractive in terms of balancing cost against efficiency.

On the other hand, Herrmann et $a .^{89}$ studied alumina materials that were impregnated with silver (10 wt\% $\mathrm{Ag}$ and $24 \mathrm{wt} \% \mathrm{Ag}$ ), which were developed in Japan at the Tokai spent fuel reprocessing plant ${ }^{87,192}$ for the retention of iodine species $\left(\mathrm{I}_{2}\right.$ and $\mathrm{CH}_{3} \mathrm{I}$ ). The silver-doped alumina was tested at $150{ }^{\circ} \mathrm{C}$ with a superficial velocity of $20 \mathrm{~cm} \mathrm{~s}^{-1}$ and an inlet concentration of $\mathrm{CH}_{3} \mathrm{I}$ of $30 \mathrm{ppm}$. A decontamination factor (DF) of higher than 500 (which corresponds to an adsorption capacity of $120 \mathrm{mg}_{\mathrm{CH}_{3} \mathrm{I}}$ $\mathrm{cm}_{\mathrm{Ag} / \mathrm{Al}_{2} \mathrm{O}_{3}}{ }^{-3}$ ) was achieved using alumina with $10 \mathrm{wt} \% \mathrm{Ag}$. For the alumina with the higher loading (24 wt\% Ag), $\mathrm{NO}_{x}(1.5 \%)$ were introduced into the feed. In this case the decontamination factor exceeded 500 and corresponded to an adsorption capacity of $350 \mathrm{mg}_{\mathrm{CH}_{3} \mathrm{I}} \mathrm{cm}_{\mathrm{Ag} / \mathrm{Al}_{2} \mathrm{O}_{3}}{ }^{-3}$. Therefore, this study demonstrated that the silver-doped adsorbents exhibited rather good resistance in the presence of $\mathrm{NO}_{x}$. In addition, it was reported ${ }^{\mathbf{1 6}}$ that an elevated concentration of $\mathrm{NO}_{2}$ (between 1 and 10\%) improved the iodine adsorption performance by preventing the reduction of silver (in the form of $\mathrm{AgNO}_{3}$ ) to metallic silver $\mathrm{Ag}^{0}$. The adsorption efficiency was about $99.9961 \%$ and $99.9973 \%$ in the presence of $1 \%$ and $10 \% \mathrm{NO}_{2}$, respectively, in contrast to $99.9944 \%$ in the absence of $\mathrm{NO}_{x}$. It was also shown that a large quantity of organic contaminants, as well as a high relative humidity $(>70 \%)$, could impair the performance of the material in the absence of a sufficient quantity of $\mathrm{NO}_{x}$.

Finally, the authors highlighted the fact that these types of adsorbents $\left(\mathrm{Ag} / \mathrm{Al}_{2} \mathrm{O}_{3}\right.$ and $\left.\mathrm{Ag} / \mathrm{SiO}_{2}\right)$ were generally less expensive by a factor of 3 to 10 than silver-exchanged zeolites. Furthermore, an atmosphere of $\mathrm{NO}_{2}$ is needed to prevent the reduction of silver to its metallic form.

2.4.2. Silver-doped mesoporous silica. Another class of materials, namely, mesoporous structured silica, has aroused the interest of scientists for iodine capture applications. These materials have been the focus of many studies, especially in the fields of catalysis and adsorption. Mesoporous silica materials are characterized by amorphous silica walls that delimit wellordered mesocavities, a regular arrangement of mesopores and a particularly large specific surface area (it can reach values of higher than $1000 \mathrm{~m}^{2} \mathrm{~g}^{-1}$ ). These materials also possess the advantage of having pore sizes $(3-10 \mathrm{~nm})$ that are larger than those in zeolites $(<1 \mathrm{~nm})$, which ultimately improve the accessibility of the pores and active sites in mesoporous silica. Furthermore, silanol functions, which are localized on the silica 
surface, can be replaced via functionalization with organic and/ or organometallic functional groups to improve their properties and performance depending on the intended applications. Few studies have focused on these materials for iodine capture applications. ${ }^{\mathbf{8 1 , 8 4 , 8 6}}$ Mainly, the works by Mnasri et al. on silverdoped MCM-41 mesoporous silica, ${ }^{84}$ Yang et al. on bismuthdoped SBA- $15^{86}$ and Chebbi on silver-doped SBA- $15^{81}$ can be found in the literature.

The study by Mnasri et al. ${ }^{84}$ focused on the adsorption of iodine compounds by three types of silver-impregnated MCM41 mesoporous silica with the following pore diameters: 2.4, 3.3 and $3.8 \mathrm{~nm}$. Silver that was introduced into the mesoporous silica was reduced by $\mathrm{NaBH}_{4}$ to obtain metallic silver (between 1.65 and $2.16 \mathrm{wt} \% \mathrm{Ag}$ ). These materials were tested for the adsorption of iodine $\left(\mathrm{I}_{2}\right)$ at $35{ }^{\circ} \mathrm{C}$ in the gas phase. The iodine adsorption capacities of the non-impregnated materials were on average between 90 and $130 \mathrm{~g}_{\mathrm{I}_{2}} \mathrm{~kg}_{\text {adsorbent }}{ }^{-1}$. The difference in performance between the non-impregnated materials was associated with the discrepancy in their pore sizes and specific surface areas. ${ }^{84}$ In the presence of silver, the performance was significantly improved as the adsorption capacity reached 760$770 \mathrm{~g}_{\mathrm{I}_{2}} \mathrm{~kg}_{\text {adsorbent }}{ }^{-1}$. The irreversibility of the capture of iodine at $120{ }^{\circ} \mathrm{C}$ and $527{ }^{\circ} \mathrm{C}$ was also studied by TGA, and no weight losses were indicated. In summary, these forms of mesoporous silica possess interesting and important iodine adsorption capacities, with the addition of a high degree of irreversibility when silver is added.

More recently, Chebbi $^{81}$ studied, in parallel to his academic works on silver-exchanged zeolites, silver-doped mesoporous silica (SBA-15) for use in the field of iodine adsorption. Tests on the retention of $\mathrm{CH}_{3} \mathrm{I}\left(\left[\mathrm{CH}_{3} \mathrm{I}\right]=450 \mathrm{ppm}, T=10^{\circ} \mathrm{C}\right)$ in the liquid phase were carried out on SBA-15 mesoporous silica doped with $0,10,20$, and $40 \mathrm{wt} \%$ silver. Silver is assumed to be in the form of $\mathrm{Ag}^{\mathrm{O}}$ nanoparticles in the mesopores and on the external surfaces with an average crystallite size of $20 \mathrm{~nm}$. In the case of the non-impregnated parent compound SBA-15, an adsorption capacity of $49 \mathrm{~g}_{\mathrm{CH}_{3} \mathrm{I}} \mathrm{kg}_{\text {adsorbent }}{ }^{-1}$ was achieved. For the latter material, the capture of $\mathrm{CH}_{3} \mathrm{I}$ is controlled by physisorption-type interactions and is consequently reversible. The presence of $\mathrm{Ag}^{0}$ nanoparticles at different loadings inside the SBA-15 material significantly improves its iodine adsorption performance. Chebbi also highlights the quasi-linear relationship between the silver loading and the maximum amount of $\mathrm{CH}_{3} \mathrm{I}$ that can be adsorbed in the SBA-15. However, only a fraction of the silver is used to trap iodine. In fact, if the contribution of the physisorbed fraction of $\mathrm{CH}_{3} \mathrm{I}$ in the parent SBA-15 is considered (49 $\mathrm{g}_{\mathrm{CH}_{3} \mathrm{I}} \mathrm{kg}_{\text {adsorbent }}{ }^{-1}$ for $0 \mathrm{wt} \%$ silver), the $\mathrm{I} / \mathrm{Ag}$ ratio in the silverimpregnated SBA-15 is particularly low (0.21 and 0.13 for a silver loading of 10 and $40 \mathrm{wt} \%$, respectively). These results were compared with those for a silver-exchanged AgY zeolite in another work (silver loading of $23 \mathrm{wt} \%, \mathrm{Si} / \mathrm{Al}$ ratio of 40 ), in which the I/Ag ratio was 0.30 for a crystallite size of $9.1 \mathrm{~nm}$. According to the authors, these discrepancies between the performance of silver-doped mesoporous silica and silverexchanged zeolites mainly arise from the high dispersion of silver inside the structure. In addition, the absence of exchange sites in mesoporous silica and the large pore diameters facilitate the migration of silver to the surface, which leads to the aggregation of silver in the form of metallic nanoparticles, which ultimately block access to the pores. In the case of nanoparticles, only a small part of the silver can be used for the capture of iodine, which is probably due to the unfavourable core/shell ratio. In a similar way, the adsorption of $\mathrm{I}_{2}$ by the same silver-loaded SBA-15 $\left(\left[\mathrm{I}_{2}\right]=400 \mathrm{ppm}, T=25^{\circ} \mathrm{C}\right)$ was studied. ${ }^{81}$ In another study by Chebbi, ${ }^{81}$ in the case of the parent compound SBA-15 no adsorption of iodine was observed. Once more, the presence of silver significantly improved the iodine adsorption performance. It should be noted that the efficiency of the capture of $I_{2}$ per silver atom is higher than in the case of $\mathrm{CH}_{3} \mathrm{I}$. A decrease in the efficiency of silver from $\mathrm{I} / \mathrm{Ag}=0.90$ to I/ $\mathrm{Ag}=0.59$ was also observed when the silver loading was increased from 10 to $40 \mathrm{wt} \%$. In a similar way to zeolites with a high loading of silver, the less efficient utilization of silver can essentially be attributed to accessibility problems that prevented iodine from reaching silver inside pores.

2.4.3. Other porous oxide materials. SBA-15 that was functionalized with aminopropyltrimethoxysilane (APTMS) was also used for the retention of iodine $\left(\mathrm{I}_{2}\right)$ in the same standard conditions $\left(\left[\mathrm{I}_{2}\right]=400 \mathrm{ppm}, T=25^{\circ} \mathrm{C}\right)$ as in previous studies by Chebbi. ${ }^{81}$ An iodine adsorption capacity of $179 \mathrm{~g}_{\mathrm{I}_{2}} \mathrm{~kg}_{\text {adsorbent }}{ }^{-1}$ was achieved with this material. The affinity between $\mathrm{I}_{2}$ and the APTMS-functionalized silica was explained by the formation of a charge transfer complex. Then, this material was studied in conditions $\left(\left[\mathrm{I}_{2}\right]>600 \mathrm{ppm}, T=25{ }^{\circ} \mathrm{C}\right)$ such that the saturation capacity for iodine $\left(600 \mathrm{~g}_{\mathrm{I}_{2}} \mathrm{~kg}_{\text {adsorbent }}{ }^{-1}\right)$ of the functionalized SBA-15 was reached. However, it should be noted that the functionalization with APTMS can deteriorate upon an increase in the temperature, and therefore it would not be efficient to use it for the adsorption of iodine in a nuclear power plant in the event of a severe nuclear accident.

In a study by Yang et al., ${ }^{86}$ the remarkable efficiency for iodine capture of bismuth-doped mesoporous silica (SBA-15) was proved. Bismuth was incorporated into the SBA-15 material by previously modifying the silica surface with thiol groups and subsequent thermal treatment that led to the formation of a $\mathrm{BI}_{2} \mathrm{~S}_{3}$ phase. The bismuth-doped mesoporous silica displayed a maximum iodine adsorption capacity of around $540 \mathrm{~g}_{\mathrm{I}_{2}}$ $\mathrm{kg}_{\text {adsorbent }}{ }^{-1}\left(T=200{ }^{\circ} \mathrm{C}, 6 \mathrm{~h}\right.$ under static air $)$. The good adsorption performance of the material was attributed by the authors to the strong interactions between bismuth sulphide and iodine, the elevated specific surface area and the porosity of SBA-15. Bismuth, when combined with iodine, can form particularly thermodynamically stable compounds such as BiOI and $\operatorname{BiI}_{3}\left(\Delta_{\mathrm{f}} G^{\circ}=-219.5\right.$ and $-139.7 \mathrm{~kJ} \mathrm{~mol}^{-1}$, respectively). The large pores in SBA-15 (ranging from 50 to $300 \AA$, with a uniform distribution), as well as the strong affinity of bismuth for iodine, minimized the physical adsorption of iodine, which allowed chemisorption-type interactions to be the main capture process. Finally, the authors highlighted the low cost of bismuth and the easy preparation of SBA-15 as definite advantages for industrial applications. Another study led by Yang et al. ${ }^{193}$ on bismuthbased adsorbents (bismuth oxide) demonstrated an iodine trapping capacity that was approximately 1.9 times higher $\left(0.468 \mathrm{~g}_{\mathrm{I}_{2}} \mathrm{~kg}_{\text {adsorbent }}{ }^{-1}\right)$ than that of commercial AgX zeolite. 
Other porous oxide materials, such as metallic oxides ( $\mathrm{MgO}$, $\mathrm{ZnO}, \mathrm{La}_{2} \mathrm{O}_{3}, \mathrm{ZrO}_{2}$, etc.) have been studied for trapping iodine in the gas phase. ${ }^{194-197}$ Among these, Glinski et al. ${ }^{194}$ reported that $\mathrm{La}_{2} \mathrm{O}_{3}$ and $\mathrm{MgO}$ had high iodine adsorption capacities of 31 and $48 \mathrm{~g}_{\mathrm{I}_{2}} \mathrm{~kg}_{\text {adsorbent }}{ }^{-1}$, respectively, in comparison with other metal oxides at $T=100{ }^{\circ} \mathrm{C}$ under an anhydrous stream of $\mathrm{N}_{2}$ saturated with $\mathrm{I}_{2}$. More recently, Nandanwar et al. ${ }^{\mathbf{1 9 5}}$ achieved a maximum iodine adsorption capacity of $196 \mathrm{~g}_{\mathrm{I}_{2}} \mathrm{~kg}_{\text {adsorbent }}{ }^{-1}$ at room temperature with porous microspheres of magnesium oxide (the size of the microspheres was 5-7 $\mu \mathrm{m}$ ).

Besides, no studies have focused on the utilization of all these mesoporous materials in conditions closer to those of real utilization (temperature, presence of inhibitors such as $\mathrm{NO}_{x}$ and $\mathrm{H}_{2} \mathrm{O}$ ).

\subsection{Silver-functionalized silica aerogels}

Several authors have studied aerogels as potential adsorbents for iodine trapping. Aerogels are porous materials that possess an elevated specific surface area $\left(>1000 \mathrm{~m}^{2} \mathrm{~g}^{-1}\right)$. Matyás et al. ${ }^{\mathbf{1 0 0 - 1 0 2}}$ developed silver-functionalized aerogels for trapping iodine compounds. These materials exhibited promising results, with an iodine adsorption capacity of $310 \quad \mathrm{~g}_{\mathrm{I}_{2}}$ $\mathrm{kg}_{\text {adsorbent }}{ }^{-1}$ and a decontamination factor (DF) of higher than $10^{5}$. More recently, Riley et al. ${ }^{105}$ studied silver-functionalized aluminosilicate aerogels (Na-Al-Si-O) for the capture of iodine. An iodine adsorption capacity of greater than $500 \mathrm{mg}_{\mathrm{I}_{2}}$ $\mathrm{g}_{\text {adsorbent }}{ }^{-1}$ was observed. For comparison, the adsorption capacity of silver-exchanged mordenite ( $\left.\mathrm{Ag}^{0} \mathrm{MOR}\right)$ tested in the same conditions only reached $190 \mathrm{mg}_{\mathrm{I}_{2}} \mathrm{~g}_{\text {adsorbent }}{ }^{-1}$ (Fig. 9). These studies proved that silver-functionalized aerogels can be potential candidates for iodine capture. However, few articles on the subject can be found in the literature and no test was performed in conditions similar to those of real utilization.

\subsection{Chalcogen-based aerogels (chalcogels)}

Aerogels based on chalcogens ( $\mathrm{S}, \mathrm{Se}, \mathrm{Te})$, which are called "chalcogels", have been the focal point of a few studies on iodine trapping. ${ }^{\mathbf{8} 85,90,91,93-95}$ Chalcogels are synthesized from

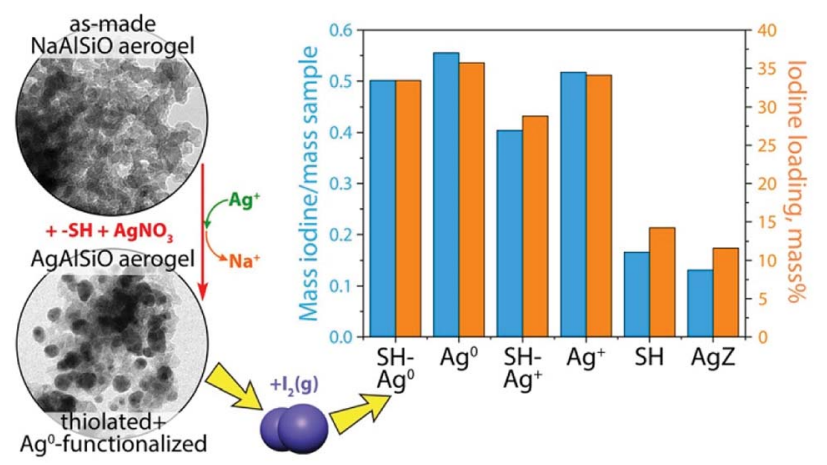

Fig. 9 Comparison of the iodine adsorption capacities of different silver-functionalized aerogels $\left(\mathrm{SH}-\mathrm{Ag}^{0}, \mathrm{Ag}^{0}, \mathrm{SH}_{-} \mathrm{Ag}^{+}, \mathrm{Ag}^{+}\right.$, and $\left.\mathrm{SH}\right)$ with that of a silver-loaded mordenite (AgZ) ${ }^{105}$ Reprinted with permission from B. J. Riley, J. O. Kroll, J. A. Peterson, J. Matyáš, M. J. Olszta, X. Li and J. D. Vienna, ACS Applied Materials \& Interfaces, 2017, 9, 3290732919. Copyright 2017 American Chemical Society. chalcogen clusters $\left(\mathrm{Ge}_{4} \mathrm{~S}_{10}{ }^{4-}, \mathrm{Sn}_{2} \mathrm{~S}_{6}{ }^{4-}, \mathrm{Sn}_{4} \mathrm{~S}_{4}{ }^{4-}, \mathrm{MoS}_{4}{ }^{4-}\right)$ interconnected by a secondary metallic species (such as $\mathrm{Pt}^{2+}, \mathrm{Co}^{2+}$, $\mathrm{Sn}^{2+}, \mathrm{Sb}^{3+}, \mathrm{Bi}^{3+}, \mathrm{Ni}^{2+}$, and $\mathrm{Zn}^{2+}$ ). Chalcogens enclosed in chalcogels are classified as weak Lewis bases according to the HSAB concept (hard and soft acids and bases). Consequently, they have a high affinity for iodine $\left(\mathrm{I}_{2}\right)$, which is known to be a weak Lewis acid. This strong affinity for iodine was demonstrated for a large range of chalcogels, including $\mathrm{PtGe}_{2} \mathrm{~S}_{5}, \mathrm{Sn}_{2} \mathrm{~S}_{3}, \mathrm{CoMoS}_{4}$, $\mathrm{NiMoS}_{4}, \mathrm{CoS}_{5}, \mathrm{Sb}_{4}\left(\mathrm{SnS}_{4}\right)_{3}$ and $\mathrm{ZnSn}_{2} \mathrm{~S}_{6} \cdot{ }^{7,104,107,108}$ Riley et al. ${ }^{107}$ developed $\mathrm{SnS}\left(\mathrm{Sn}_{2} \mathrm{~S}_{3}\right)$ structured chalcogels for trapping iodine $\left(\mathrm{I}_{2}\right)$ with an iodine uptake of up to 32.7 and $68.3 \mathrm{wt} \%$ for the best chalcogel formulations. Furthermore, the adsorption mechanism was studied. During adsorption, iodine interacts with SnStype chalcogels by chemical reactions (chemisorption) to form crystalline $\mathrm{SnI}_{4}$ and $\mathrm{SnI}_{4}\left(\mathrm{~S}_{8}\right)_{2}$ species, which was observed by Xray diffraction analysis. This reaction is particularly favourable, with a Gibbs formation enthalpy of $\Delta_{\mathrm{f}} G^{\circ}=-215.1 \mathrm{~kJ} \mathrm{~mol}^{-1}$ at $298.15 \mathrm{~K}\left(25{ }^{\circ} \mathrm{C}\right)$. Subrahmanyam et al. ${ }^{7}$ carried out studies of the adsorption of iodine onto $\mathrm{NiMoS}_{4}, \mathrm{CoMoS}_{4}, \mathrm{Sb}_{4} \mathrm{Sn}_{3} \mathrm{~S}_{12}$, $\mathrm{Zn}_{2} \mathrm{Sn}_{2} \mathrm{~S}_{6}$ and $\mathrm{K}_{0.16} \operatorname{CoS}_{x}(x=4-5)$ chalcogel-type adsorbents. A mass uptake of up to $225 \mathrm{wt} \%$ was achieved for the $\mathrm{Zn}_{2} \mathrm{Sn}_{2} \mathrm{~S}_{6}$ and $\mathrm{NiMoS}_{4}$ chalcogels. As already mentioned, this high iodine adsorption capacity is due to the chemical reaction between iodine and the adsorbent (by chemisorption) and also the large specific surface areas that range from 200 to $490 \mathrm{~m}^{2} \mathrm{~g}^{-1}$. Iodine reacts chemically with $\mathrm{Zn}_{2} \mathrm{Sn}_{2} \mathrm{~S}_{6}, \mathrm{Sb}_{4} \mathrm{Sn}_{3} \mathrm{~S}_{12}$ and $\mathrm{K}_{0.16} \mathrm{CoS}_{x}(x=$ 4-5) chalcogels to form metallic halides such as $\mathrm{SnI}_{4}, \mathrm{SbI}_{3}$ and $\mathrm{KI}$, whereas only physisorption interactions are observed for $\mathrm{NiMoS}_{4}$ and $\mathrm{CoMoS}_{4}$ chalcogels. TGA analysis ${ }^{7}$ showed that $\mathrm{Zn}_{2} \mathrm{Sn}_{2} \mathrm{~S}_{6}$ and $\mathrm{Sb}_{4} \mathrm{Sn}_{3} \mathrm{~S}_{12}$ chalcogels with stored iodine were stable up to $150{ }^{\circ} \mathrm{C}$, but beyond that temperature iodine was released progressively ( $40 \mathrm{wt} \%$ in 30 days). Moreover, the other chalcogels release iodine above $75{ }^{\circ} \mathrm{C}$. The weight loss is attributed to the sublimation of iodine molecules and $\mathrm{SnI}_{4}$, as well as the release of physisorbed iodine from the surface. In conclusion, this type of material possesses excellent iodine adsorption capacities. However, the thermal stability of iodine capture (or the formed iodides) is quite low.

\subsection{Macroreticular resins}

Synthetic macroreticular resins are macromolecular structures formed by polymerisation reactions (from vinylbenzene monomers, for example). Functionalized chemical groups, such as acrylic esters and polystyrene, can be grafted onto the structural framework of the resins. A resin can be defined by the following properties: its crosslinking rate (percentage of crosslinking monomer in the resin), the porosity of the framework (presence of variable pore and/or channel sizes), its granulometric composition (mean size of resin beads), its selectivity and its ion exchange capacity (quantity of ions that can be fixed for a given mass or volume of the resin). In general, macroreticular resins possess elevated specific surface areas (up to $900 \mathrm{~m}^{2} \mathrm{~g}^{-1}$ ) and can exhibit cation or anion exchange properties. Resins are known to have high chemical stability and can be restored to their initial state by washing with the appropriate solutions. Furthermore, their crosslinked structure does not limit the 
diffusion of molecules or substances and therefore helps to increase their storage and/or trapping capacities. The possibility of employing these kinds of adsorbents for trapping iodine has been the focus of several studies. ${ }^{16,39,41,42,44-46,50,53,55}$ However, very few studies have focused on the mechanism of the trapping of iodine $\left(\mathrm{I}_{2}\right)$ and organic iodine compounds by these adsorbents. In general, macroreticular resins have a strong affinity for any kind of substance thanks to their tunable hydrophobic and hydrophilic properties. Because most of these adsorbents also have non-ionic functions, they can have a strong affinity for uncharged molecules such as iodine $\left(\mathrm{I}_{2}\right)$ or organic iodine compounds such as $\mathrm{CH}_{3} \mathrm{I}$. Most studies focused on the trapping of iodine in aqueous solutions. Few studies have focused on the behaviour of these adsorbents in the gaseous phase for iodine adsorption applications because of their limited stability under air. The objective was to develop an iodine filtration medium that was both cheaper than silverdoped adsorbents (e.g., silver-exchanged zeolites) and more stable than activated carbons. ${ }^{16}$ In 1968, Hirling ${ }^{39}$ studied a cation exchange resin (Varion KS) for iodine trapping applications. Tests showed a strong affinity for iodine with adsorption capacities of between 872 and $1437 \mathrm{~g}_{\mathrm{I}_{2}} \mathrm{~kg}_{\text {adsorbent }}{ }^{-1}$. However, because of the saturation of the adsorbent bed, an efficiency of only $40 \%$ was achieved. This resin was also impregnated with silver to capture HI, which endowed the resin with a trapping capacity of $93.1 \%$ and an $\mathrm{HI}$ adsorption capacity of $1437 \mathrm{~g}_{\mathrm{HI}} \mathrm{kg}_{\text {adsorbent }}{ }^{-1}$. Resins of another type, namely, Amberlite XAD, were also tested for trapping iodine compounds. These resins are macroporous and can have rigid and three-dimensional structures, depending on the monomer used. These adsorbents can incorporate a large quantity of extractant thanks to their elevated specific surface areas, high mechanical resistance, superior crosslinking and low swelling during impregnation. Amberlite XAD resins have specific surface areas of between 150 and $900 \mathrm{~m}^{2} \mathrm{~g}^{-1}$ with a mean pore diameter of between 4 and $9 \mathrm{~nm}$ and a pore volume of 0.6 to 1.1 $\mathrm{cm}^{3} \mathrm{~g}^{-1}$. The first studies were carried out by Moore et al. ${ }^{\mathbf{4 1 , 4 2 , 4 4 , 4 6}}$ At $21{ }^{\circ} \mathrm{C}$ in dry conditions, decontamination factors (DFs) of higher than $10^{4}$ were achieved for an iodine $\left(\mathrm{I}_{2}\right)$ adsorption capacity of $213 \mathrm{mg}_{\mathrm{I}_{2}} \mathrm{~g}_{\text {adsorbent }}{ }^{-1}$. With Amberlite XAD-12 resin, a maximum iodine adsorption capacity of $1.39 \mathrm{~g}_{\mathrm{I}_{2}} \mathrm{~g}_{\text {adsorbent }}{ }^{-1}$ at $25{ }^{\circ} \mathrm{C}$ was achieved, but only $84 \mathrm{mg}_{\mathrm{I}_{2}} \mathrm{~g}_{\text {adsorbent }}{ }^{-1}$ could be adsorbed at $50{ }^{\circ} \mathrm{C}$. In the same way, maximum iodine adsorption capacities of $278 \mathrm{mg}_{\mathrm{I}_{2}} \mathrm{~g}_{\text {adsorbent }}{ }^{-1}$ and $15 \mathrm{mg}_{\mathrm{I}_{2}} \mathrm{~g}_{\text {adsorbent }}{ }^{-1}$ at $21{ }^{\circ} \mathrm{C}$ and $25{ }^{\circ} \mathrm{C}$, respectively, were achieved with Amberlite $\mathrm{XAD}-4$ resin. However, it is quite surprising to observe such a great discrepancy for a temperature difference of $4{ }^{\circ} \mathrm{C}$. At higher temperatures and in the presence of humidity a decrease in the decontamination factor was observed. In conclusion, macroreticular resins possess elevated iodine adsorption capacities (between 200 and $1437 \mathrm{mg}$ gadsorbent $^{-1}$ ). ${ }^{\mathbf{4 1 , 4 2 , 4 4 , 4 6}}$ Furthermore, these materials are fairly stable in the presence of irradiation. ${ }^{16,50,55}$ On the other hand, significant decreases in their adsorption capacities were observed at high temperatures $\left(>50{ }^{\circ} \mathrm{C}\right)$ or in the presence of humidity. These drawbacks would drastically limit their utility in the real conditions of a severe nuclear accident.

\subsection{Metal-organic frameworks (MOFs)}

In the past fifteen years, the number of studies on metalorganic frameworks (MOFs) has grown sharply thanks to their very large specific surface areas (up to $\sim 10^{4} \mathrm{~m}^{2} \mathrm{~g}^{-1}$ ) and welldefined pore sizes. ${ }^{8}$ MOFs are organic-inorganic hybrid materials that consist of inorganic parts comprising metal ions, which are referred to as secondary building units, linked by organic entities, which are most commonly referred to as ligands. The secondary building units can be composed of single metallic cations, dimers, trimers, chains, planes and/or a three-dimensional structure. The organic ligands need to possess a charge and/or unbound electron pairs, which ensure strong bonds with the inorganic components of the framework. The most commonly used ligands are organic compounds that contain carboxylic acid or imidazole $\left(\mathrm{C}_{3} \mathrm{H}_{4} \mathrm{~N}_{2}\right)$ groups. The best advantages of these types of materials are their large assortment of organic and inorganic entities that can generate a wide range of MOFs with various structures, topologies and pore sizes. In 2003, Abrahams et al. ${ }^{\mathbf{1 2 1}}$ demonstrated the feasibility of introducing iodine into a hydrated zinc saccharate $\left(\left[\mathrm{Zn}\left(\mathrm{C}_{6} \mathrm{H}_{8} \mathrm{O}_{8}\right)\right]\right.$. $2 \mathrm{H}_{2} \mathrm{O}$ ). Since then, MOFs have been particularly popular for the retention of iodine. , $14,109,110,115,116,118-127,129-132$ Most of the studies were carried out on materials based on divalent metals such as $\mathrm{Zn}^{2+}$ and $\mathrm{Cu}^{2+}$, as well as aluminium-based structures. In fact, the most commonly studied MOFs for the capture of iodine were the zeolitic imidazolate framework $\mathrm{Zn}(2$ methylimidazolate $)_{2}$ (ZIF-8) and HKUST-1 ( $\mathrm{Cu}_{3}$ (benzene-1,3,5tricarboxylate $)_{2}\left(\mathrm{H}_{2} \mathrm{O}\right)_{3}$, Cu-BTC). ${ }^{\mathbf{1 4 , 1 1 5 , 1 2 4 , 1 2 5 , 1 2 9 , 1 3 2}}$ These two MOFs have elevated specific surface areas of 1875 and $1798 \mathrm{~m}^{2} \mathrm{~g}^{-1}$, respectively, with pore diameters of 11.6 and $9 \AA$, respectively. ${ }^{127}$ The most prominent studies on this subject were carried out by Sava et al. ${ }^{\mathbf{1 4 , 1 2 4 , 1 2 5 , 1 2 9 , 1 3 0}}$ In fact, Sava et al. ${ }^{\mathbf{1 4}}$ performed experiments on the iodine capture capacity of ZIF-8 at atmospheric pressure with a vapour pressure of iodine $\left(\mathrm{I}_{2}\right)$ of 0.014 atm at 350 K. Once equilibrium had been reached (5-12 hours), the iodine adsorption capacity of ZIF-8 was $1.25 \mathrm{~g}_{\mathrm{I}_{2}} \mathrm{~g}_{\text {adsorbent }}{ }^{-1}\left(1250 \mathrm{~g}_{\mathrm{I}_{2}}\right.$ $\mathrm{kg}_{\text {adsorbent }}{ }^{-1}$ ) for an $\mathrm{I} / \mathrm{Zn}$ ratio of 2.2 . According to the results from Sava et al., the capture of iodine is due to the favourable interactions between iodine and the ligand (2-methylimidazolate, MeIM). Only $25 \%$ of the iodine is localized at the surface of the MOF, whereas $75 \%$ of the iodine is confined in the sodalite cages of ZIF-8. Studies by Hughes et al. ${ }^{129}$ give complementary information on the thermal stability of, and chemisorption of iodine by, ZIF-8. They showed that iodine interacts strongly with hydrogen atoms in the methyl group on the one hand and the carbon atom in the ligand methine (= $\mathrm{CH}-$ ) group on the other hand. Furthermore, they observed that the complex formed inside the sodalite cages is thermally stable at temperatures of up to $300{ }^{\circ} \mathrm{C}$, which is the limit of the thermal stability of the ZIF-8 material. ${ }^{129}$ However, iodine molecules that are adsorbed on the external surface interact weakly with the material $\left(\Delta H_{\mathrm{ads}}=-18.06 \pm 2.03 \mathrm{~kJ} \mathrm{~mol}^{-1}\right)$, which ultimately permits the release of iodine at temperatures below $125{ }^{\circ} \mathrm{C}$. On the other hand, iodine that is confined in the cages is thermally stable with an adsorption energy of $\Delta H_{\text {ads }}=$ $-41.47 \pm 0.62 \mathrm{~kJ} \mathrm{~mol}^{-1}$. 
Another study by Sava et $a l .{ }^{\mathbf{1 3 0}}$ focused on the iodine adsorption capacity of Cu-BTC (HKUST-1). The study of this material was carried out at atmospheric pressure with a relative humidity of $3.5 \%$ and at $77^{\circ} \mathrm{C}$. Iodine was introduced in the vapour phase with a ratio to water of $1: 1$ (vapour pressures of $\mathrm{I}_{2}$ and water of 10.47 and $10.11 \mathrm{mmHg}$, respectively). An adsorption capacity of $1.75 \mathrm{~g}_{\mathrm{I}_{2}} \mathrm{~g}_{\text {adsorbent }}{ }^{-1}\left(1750 \mathrm{~g}_{\mathrm{I}_{2}} \mathrm{~kg}_{\text {adsorbent }}{ }^{-1}\right)$ for an $\mathrm{I} / \mathrm{Cu}$ ratio of 3 was found. Via this study, the authors demonstrated that the adsorption of iodine occurs in two steps. In the first step, iodine is adsorbed in the small triangular cages of the MOF ( $5 \AA$ ), and then interactions take place in the larger cages (11 and $13.55 \AA$ ) thanks to the strong interactions between iodine and the benzene rings of the tricarboxylate ligand (van der Waals interactions). Finally, in the larger cages, $\mathrm{I}_{2}-\mathrm{I}_{2}$ intermolecular interactions could also be observed. Furthermore, the favourable adsorption of iodine in preference to water $(0.15$ $\mathrm{g}_{\mathrm{H}_{2} \mathrm{O}} \mathrm{g}_{\text {adsorbent }}{ }^{-1}$ ) was explained by the formation of a hydrophobic barrier due to the presence of iodine (iodine limits the access of water to the adsorption sites), which makes this material very interesting for real applications, including severe nuclear accidents. However, high temperatures would still be harmful to this kind of material.

Aluminium-based MOFs have also been studied for iodine trapping applications. ${ }^{\mathbf{1 1 5 , 1 1 6 , 1 2 0}}$ Studies were carried out on the MIL-53 family of MOFs. These materials are particularly attractive owing to their high chemical and thermal stability. Furthermore, these materials are commercially available. Falaise et al. ${ }^{116}$ studied seven aluminium-based MOFs of the MIL family (MIL-96, MIL-100, MIL-101-NH $\mathrm{NH}_{2}$ MIL-118, MIL-120, CAU-1, and MIL-53-X, where $\mathrm{X}$ is $\mathrm{H}, \mathrm{Cl}, \mathrm{Br}, \mathrm{CH}_{3}, \mathrm{NH}_{2}, \mathrm{NO}_{2}$, $(\mathrm{OH})_{2}, \mathrm{COOH}$, or $(\mathrm{COOH})_{2}$ ) with different structural properties (functionalization, pore diameter, specific surface area, etc.). They first studied the MIL-53-X family to examine the effect of functionalization on the iodine adsorption capacity in the liquid phase. Among the above functional groups $(\mathrm{H}, \mathrm{Cl}, \mathrm{Br}$, $\mathrm{CH}_{3}, \mathrm{NH}_{2}, \mathrm{NO}_{2},(\mathrm{OH})_{2}, \mathrm{COOH}$, and $\left.(\mathrm{COOH})_{2}\right)$, only MOFs that contained electron-donating groups $\left(\mathrm{NH}_{2}\right.$ and $\left.\mathrm{OH}\right)$ exhibited interesting iodine capture properties. In the case of nonfunctionalized MIL-53, only 5\% of iodine was adsorbed from a solution in cyclohexane after 48 hours. In contrast, the best performance was achieved with MIL-53- $\mathrm{NH}_{2}$, which exhibited a maximum iodine adsorption of $60 \%$ after 48 hours. For the other MOFs that were studied, only MIL-101- $\mathrm{NH}_{2}$ displayed excellent iodine adsorption capacities, with an efficiency of $90 \%$ after only 30 hours. Other MOFs such as CAU-1 and MIL-120 also exhibited fairly good performance ( $\sim 80 \%$ after 30 hours). In the same context, Assaad et al. ${ }^{\mathbf{1 2 0}}$ confirmed that MIL-101 could exhibit an iodine adsorption efficiency of higher than $90 \%(96.61 \%)$.

Some computer simulation studies on the adsorption of iodine on MOFs have been performed. Assfour et al. ${ }^{\mathbf{1 1 9}}$ studied the performance of twelve MOFs for the retention of iodine by molecular modeling. Their simulations obtained definite information and an understanding of the influence of the pore volumes and specific surface areas on the iodine storage capacity. They showed that MOFs with elevated pore volumes and specific surface areas were most suitable for the capture of iodine in conditions of normal temperature and pressure. However, at lower pressures MOFs with the smallest pore volumes were more suitable for the capture of iodine. Nevertheless, several materials exhibited important iodine adsorption capacities in conditions of normal temperature and pressure (up to $\sim 13 \mathrm{~g}_{\mathrm{I}_{2}} \mathrm{~g}_{\text {adsorbent }}{ }^{-1}$ for NU-110). The modelling studies by Yuan et al. ${ }^{\mathbf{1 2 5}}$ helped to identify ZIF-10 as the MOF with the most important iodine adsorption capacity $\left(2.39 \mathrm{~g}_{\mathrm{I}_{2}}\right.$ $\mathrm{g}_{\text {adsorbent }}{ }^{-1}$ at $25{ }^{\circ} \mathrm{C}$ and in conditions of moderate pressure).

In conclusion, the studies in the literature mainly focused on the adsorption capacities of MOFs for iodine $\left(\mathrm{I}_{2}\right)$, whereas no studies have focused on organic iodine compounds such as $\mathrm{CH}_{3}$ I. MOFs with high iodine capacities are a promising alternative for the capture of iodine, principally thanks to their high adsorption capacities. Furthermore, in the case of Cu-BTC, iodine is preferentially adsorbed rather than water, which is a major advantage in the real conditions of a severe nuclear incident. However, these materials have limited thermal stability and are not produced on a large scale, which makes them particularly expensive.

\subsection{Covalently linked porous organic polymers (POPs)}

In parallel to the increasing development of MOFs, porous organic polymers (POPs) have recently attracted attention owing to their highly tunable molecular design, large surface areas, low skeleton densities (lightweight elements), strong covalent linkages, high physicochemical stabilities and tunable porosities. ${ }^{133-143}$ Although POPs are usually amorphous solids, unlike crystalline MOFs, their excellent physicochemical stability makes them more suited for real applications. In addition, the synthetic diversity of POPs makes it possible to attain control over their functionality by the rational design and choice of molecular building blocks. On the basis of their physicochemical robustness and pore features, POPs have huge potential to be efficient adsorbents for the capture of volatile radioactive iodine. It is widely accepted that the introduction of active sites such as metallic species, $\mathrm{N}, \mathrm{S}$, and $\mathrm{C}=\mathrm{C}$ into the porous network of POPs can greatly improve their affinity for iodine molecules, which ultimately significantly increases the uptake of iodine. In general, the uptake of iodine depends on both the pore features (pore size and/or pore volume) and the affinity of the adsorbent for iodine molecules. To date, a certain number of POPs have been employed for this purpose, such as nanoporous organic polymers (NOPs), ${ }^{\mathbf{1 3 4}}$ conjugated microporous polymers (CMPs) ${ }^{139,141,142}$ such as metalloporphyrin-based CMPs $^{138}$ and hexaphenylbenzene-based CMPs, ${ }^{135}$ azo-bridged porous triptycene networks ${ }^{\mathbf{1 4 0 , 1 4 3}}$ and crystalline covalent organic frameworks (COFs). ${ }^{111-114,117,128}$

Chen et al. ${ }^{134}$ studied the iodine adsorption performance of a series of hierarchically porous organic polymers based on tetraphenyladamantane (named as NOP-53, NOP-54 and NOP55). Their pore properties were controlled by adjusting the lengths and rigidities of the linkers; for example, rigid tetrahedral building blocks of 1,3,5,7-tetraphenyladamantane were linked with flexible alkyl chains to obtain different hierarchical NOPs. NOP-53 and NOP-54 feature hierarchically porous 
structures, whereas NOP-55 was found to be only microporous with a broad micropore size distribution. NOP-54 exhibits the largest BET specific surface area and pore volume $\left(1178 \mathrm{~m}^{2} \mathrm{~g}^{-1}\right.$ and $1.32 \mathrm{~cm}^{3} \mathrm{~g}^{-1}$, respectively), followed by NOP-53 $\left(744 \mathrm{~m}^{2} \mathrm{~g}^{-1}\right.$ and $0.73 \mathrm{~cm}^{3} \mathrm{~g}^{-1}$, respectively) and NOP-55 $\left(526 \mathrm{~m}^{2} \mathrm{~g}^{-1}\right.$ and 0.42 $\mathrm{cm}^{3} \mathrm{~g}^{-1}$, respectively). Chen et al. ${ }^{134}$ determined their uptakes of iodine $\left(\mathrm{I}_{2}\right)$ by gravimetric measurements. Samples were loaded into a sealed container in the presence of iodine pellets. The container was degassed and kept at $75{ }^{\circ} \mathrm{C}$. According to Chen et al. ${ }^{\mathbf{1 3 4}}$ the iodine uptake increased gradually over a period of 4 hours until the system reached saturation. NOP-54 displayed the highest uptake of iodine of up to $2.02 \mathrm{~g}_{\mathrm{I}_{2}} \mathrm{~g}_{\text {adsorbent }}{ }^{-1}$, followed by NOP-53 (1.77 $\left.\mathrm{g}_{\mathrm{I}_{2}} \mathrm{~g}_{\text {adsorbent }}{ }^{-1}\right)$ and NOP-55 $\left(1.39 \mathrm{~g}_{\mathrm{I}_{2}}\right.$ $\left.\mathrm{g}_{\text {adsorbent }}{ }^{-1}\right)$. According to the authors, NOP-53 and NOP-54 adsorb iodine at a faster rate than NOP-55. They attributed these observations to the existence of the hierarchical porous structures, which facilitated the transport of iodine in the networks.

Li et al. ${ }^{143}$ developed in 2016 a novel porous azo-bridged porphyrin-phthalocyanine network, which was synthesized by combining an azo skeleton with $\pi$-conjugated building blocks. AzoPPN was synthesized by a catalyst-free coupling reaction between the free base form of 5,10,15,20-tetrakis(4-nitrophenyl) porphyrin $\left(\mathrm{H}_{2} \mathrm{TPP}\left(\mathrm{NO}_{2}\right)_{4}\right)$ and nickel tetraaminophthalocyanine $\left(\mathrm{NiPc}\left(\mathrm{NH}_{2}\right)_{4}\right)$ under alkaline conditions. This adsorbent has a BET specific surface area of $400 \mathrm{~m}^{2} \mathrm{~g}^{-1}$. According to the authors, the porous structure, together with the porphyrin and phthalocyanine units, provides effective sorption sites that can greatly increase the affinity for iodine both physically and chemically. As a result, AzoPPN exhibits an iodine adsorption capacity of up to $2.9 \mathrm{~g}_{\mathrm{I}_{2}} \mathrm{~g}_{\text {adsorbent }}{ }^{-1}$. Similarly, Dang et al. ${ }^{\mathbf{1 4 0}}$ studied an azo-linked porous organic network (Azo-Trip), in which triptycene was incorporated as a building block via a facile $\mathrm{Zn}$-induced reductive homocoupling reaction. This adsorbent also has a large BET surface area $\left(510 \mathrm{~m}^{2} \mathrm{~g}^{-1}\right)$ and an iodine uptake of up to $2.38 \mathrm{~g}_{\mathrm{I}_{2}} \mathrm{~g}_{\text {adsorbent }}{ }^{-1}$.

Conjugated microporous polymers (CMPs) are a class of amorphous materials that permit the linking of building blocks in a $\pi$-conjugated fashion and possess three-dimensional (3D) networks. They are usually synthesized using metal-catalyzed cross-coupling chemistry to form 3D networks with extended $\pi$-conjugation. Their finely tuned porosity, very large specific surface area, and relatively high thermal and chemical stability, which originates from their rigid $\pi$-conjugated structure, and the high affinity of $I_{2}$ for $\pi$-conjugated CMP networks make them attractive candidates for the adsorption and capture of radioactive iodine molecules.

Sigen et al. ${ }^{138}$ developed a new conjugated microporous polymer based on a metalloporphyrin (NiP-CMP), which was synthesized via a homocoupling polymerization reaction. NiP-CMP possesses a large BET surface area of greater than $2600 \mathrm{~m}^{2} \mathrm{~g}^{-1}$ and a large pore volume of $2.3 \mathrm{~cm}^{3} \mathrm{~g}^{-1}$. To determine its iodine adsorption performance, the NiP-CMP material was placed in a sealed vessel in the presence of solid iodine. The iodine sublimed into the porous adsorbent over time at $77^{\circ} \mathrm{C}$ and ambient pressure, which are typical conditions in fuel reprocessing. An uptake of iodine $\left(\mathrm{I}_{2}\right)$ of
$2.02 \mathrm{~g}_{\mathrm{I}_{2}} \mathrm{~g}_{\text {adsorbent }}{ }^{-1}$ from iodine vapour was determined by gravimetric measurements. Similarly, Chen et al. ${ }^{139}$ studied conjugated microporous polymer nanotubes (CMPNs) for the capture of iodine. The material exhibited a maximum uptake of $2.08 \mathrm{~g}_{\mathrm{I}_{2}} \mathrm{~g}_{\text {adsorbent }}{ }^{-1}$ in the adsorption of $\mathrm{I}_{2}$. Sigen et al. ${ }^{138}$ also studied the reversibility of adsorption and regeneration of the sorbent. In fact, the authors easily removed iodine from the framework by immersing the $\mathrm{I}_{2} @ N i P-C M P$ material in an organic solvent (96\% of iodine was desorbed after 8 hours in ethanol). The authors highlighted the fact that the absorbed iodine can be recovered and that the NiP-CMP sorbent can be easily recycled and reused. The reversibility of the material was also confirmed for the CMPN material studied by Chen et al. ${ }^{\mathbf{1 3 9}}$

Ren et al. ${ }^{141}$ studied the iodine adsorption performance of conjugated microporous polymers (SCMPs). Two SCMP networks (SCMP-I and SCMP-II), which are based on the monomer 3,3',5,5'-tetrabromo-2,2'-bithiophene and were obtained by a palladium-catalyzed Sonogashira-Hagihara crosscoupling reaction, have interesting honeycomb-like porous $3 \mathrm{D}$ network structures. SCMP-I is composed of agglomerated spheres with different sizes, whereas SCMP-II has an intertwining porous structure. Furthermore, the specific surface areas were found to be $2.72 \mathrm{~m}^{2} \mathrm{~g}^{-1}$ for SCMP-I and $119.76 \mathrm{~m}^{2}$ $\mathrm{g}^{-1}$ for SCMP-II. The uptakes of iodine $\left(\mathrm{I}_{2}\right)$ were determined by gravimetric measurements, and the capture of iodine vapour was conducted at $80{ }^{\circ} \mathrm{C}$ and ambient pressure. The authors suggest that the high uptake of iodine by SCMP-II of up to 3.45 $\mathrm{g}_{\mathrm{I}_{2}} \mathrm{~g}_{\text {adsorbent }}{ }^{-1}$ may be attributed to its unique macroscopically honeycomb-like porous features, as well as the $\pi$-conjugated network structure, which has been confirmed to have a relatively strong affinity for iodine molecules.

Liao et al. ${ }^{135}$ studied a series of conjugated microporous polymers based on hexaphenylbenzene (HCMPs) with secondary amine functional groups. The HCMPs had a moderate microporous BET surface area of up to $430 \mathrm{~m}^{2} \mathrm{~g}^{-1}$ and a narrow pore size distribution with a uniform ultramicropore size of less than $1 \mathrm{~nm}$. These materials exhibit excellent iodine adsorption capacities with an uptake of iodine of up to $3.16 \mathrm{~g}_{\mathrm{I}_{2}} \mathrm{~g}_{\text {adsorbent }}{ }^{-1}$, with the possibility of a further increase in the uptake to $3.36 \mathrm{~g}_{\mathrm{I}_{2}} \mathrm{~g}_{\text {adsorbent }}{ }^{-1}$ when the polymers are reduced with anhydrous hydrazine. The authors studied the desorption rate of the iodine-loaded HCMPs by placing the materials in organic solvents such as ethanol at room temperature. Furthermore, Liao et al. showed that the release of iodine can be induced by heating the iodine-loaded material at 120 $200{ }^{\circ} \mathrm{C}$. An iodine-loaded HCMP was heated at $125^{\circ} \mathrm{C}$ in air for 30 minutes. They achieved an iodine release efficiency of $98.8 \%$. In addition, recycling of the HCMP material was studied, and the iodine uptake capacity was found to be $2.95 \mathrm{~g}_{\mathrm{I}_{2}} \mathrm{~g}_{\text {adsorbent }}{ }^{-1}$ and $2.88 \mathrm{~g}_{\mathrm{I}_{2}} \mathrm{~g}_{\text {adsorbent }}{ }^{-1}$ upon completion of the first and second cycles, respectively, which represented a retention of $93.3 \%$ and $91.3 \%$, respectively, of the initial capacity. The authors emphasized the fact that these materials are attractive as robust, recyclable and reversible adsorbents for iodine uptake.

Zhu et al. ${ }^{142}$ developed two novel conjugated porous materials based on BODIPY for studies of the adsorption of iodine 
$\left(\mathrm{I}_{2}\right)$. BDP-CPP-1 and BDP-CPP-2 were synthesized via a Sonogashira cross-coupling reaction between 1,3,5-triethynylbenzene (TEB) and dibromo-substituted derivatives. Both materials exhibit high iodine adsorption capacities of $2.83 \mathrm{~g}_{\mathrm{I}_{2}} \mathrm{~g}_{\text {adsorbent }}{ }^{-1}$ and $2.23 \mathrm{~g}_{\mathrm{I}_{2}} \mathrm{~g}_{\text {adsorbent }}{ }^{-1}$, respectively. Owing to the highly $\pi$ conjugated porous structure (coexistence of triple bonds, phenyl rings and aromatic pyrrole moieties) of BODIPY, BDPCPP-1 displays a high capacity $\left(2.83 \mathrm{~g}_{\mathrm{I}_{2}} \mathrm{~g}_{\text {adsorbent }}{ }^{-1}\right)$ for volatile iodine at $75{ }^{\circ} \mathrm{C}$ and a high iodine adsorption rate in an organic solution at $25{ }^{\circ} \mathrm{C}(90 \%$ of iodine in a solution in hexane was captured after 7 hours). According to the authors, these high capacities can be attributed to the large BET surface area ( 635 $\left.\mathrm{m}^{2} \mathrm{~g}^{-1}\right)$ and pore volume $\left(0.78 \mathrm{~cm}^{3} \mathrm{~g}^{-1}\right)$ and the chemical substitution reaction at the 2- and 6-positions of the BODIPY core (i.e., adsorption of volatile iodine via a chemical mechanism involving the hydrogen atoms at the 2- and 6-positions). Furthermore, the BDP-CPPs display high thermal stability, with a decomposition temperature of about $300{ }^{\circ} \mathrm{C}$. In addition, these CMPs exhibit excellent recyclability after 4 cycles, which, according to the authors, may result from the $\pi$-conjugated porous structure.

Finally, covalent-organic frameworks (COFs) are a class of material in which organic ligands are linked together to form a periodic structure via strong covalent bonds. COFs have a well-ordered architecture with particularly interesting structural properties, such as a low structural density, easily tuned porosity, elevated specific surface areas, and quite high thermal (up to $600{ }^{\circ} \mathrm{C}$ in the best case) and chemical stability, as well as a wide range of functionalization. ${ }^{117,128,198}$ Lan et al. ${ }^{128}$ used computational studies to determine the theoretical adsorption capacities of COFs for iodine $\left(\mathrm{I}_{2}\right)$ and iodomethane $\left(\mathrm{CH}_{3} \mathrm{I}\right)$ in the conditions of real applications. The results show that $3 \mathrm{D}-\mathrm{COFs}$ have the best adsorption performance for $\mathrm{I}_{2}$ and $\mathrm{CH}_{3} \mathrm{I}$ in contrast to 2D-COFs. A pyrene-based 3D-COF (3D-Py$\mathrm{COF}$ ) has been found to possess a high adsorption capacity for iodine compounds of $16.7 \mathrm{~g}_{\mathrm{I}_{2}} \mathrm{~g}_{\text {adsorbent }}{ }^{-1}$, which is an extremely high value in comparison with those for the other adsorbents described in this review. The morphologies of the pores play a crucial role in the adsorption of $\mathrm{CH}_{3} \mathrm{I}$. Consequently, 3D-COFs with a ctn topology and a pore size of $9 \AA$ display the highest adsorption capacities in comparison with other COFs. COF-103 was identified as the best adsorbent for $\mathrm{CH}_{3} \mathrm{I}$, with an adsorption capacity that reached $2.8 \mathrm{~g}_{\mathrm{I}_{2}}$ $\mathrm{g}_{\text {adsorbent }}{ }^{-1}$. COFs have not yet been the focus of many studies. ${ }^{111-114,117,128}$ Furthermore, they are still new laboratory materials and are therefore produced in very small quantities at high prices.

\section{Summary and conclusion}

Taking into account the severe operating conditions in the case of a nuclear incident, sorbents for the capture of radioactive iodine $\left(\mathrm{CH}_{3} \mathrm{I}\right.$ and $\left.\mathrm{I}_{2}\right)$ should fulfil the following requirements: a high adsorption capacity over a wide temperature range, irreversibility of capture, selectivity, high thermal stability of the adsorbed species, high stability against irradiation and strong resistance in the presence of molecules of various gases such as water and $\mathrm{NO}_{x}$ (Table 2). Various kinds of porous sorbents have been studied for the capture of iodine. Activated carbons doped with KI and TEDA and porous solids doped with silver (zeolites, porous silica and alumina, aerogels and porous titanosilicates) have been the most widely studied sorbents. Activated carbons proved to exhibit good performance in the adsorption of iodine, especially when loaded with KI and TEDA, with strong capture of radioactive iodine. However, their performance declined significantly in the presence of humidity $(>40 \%)$ and at high temperatures $(T>80$ ${ }^{\circ} \mathrm{C}$ ), whereas such operating conditions are probable in the case of a severe nuclear accident. Furthermore, they are particularly affected by $\mathrm{NO}_{x}$ and aging. Silver-doped materials, in particular, silver-exchanged zeolites, were meant to overcome the issues with activated carbons by being more resistant to harsh conditions such as high humidity, the presence of $\mathrm{NO}_{x}$ and high temperatures. Most studies revealed that silverexchanged zeolites exhibit high performance and capacities for the capture of iodine with strong irreversible adsorption of iodine. The best results were obtained for zeolites with large pores (AgX and $\mathrm{AgY}$ ) and a high silver content. On the other hand, silver-based sorbents proved to be particularly expensive in comparison with activated carbons and other sorbents. The doping of zeolites with less expensive metals was found to be much less effective in comparison with silver. However, bismuth-doped mesoporous silica displays high capacities for the adsorption of iodine and thermal stability of the captured iodine.

Interesting results have also been obtained for chalcogenbased aerogels, in particular, those based on tin sulphide, but the thermal stability of the captured iodine is relatively low and the influence of humidity on the capture of iodine has not yet been studied. Other porous sorbents such as metal-organic frameworks (MOFs) and porous organic polymers (POPs) demonstrated great potential for the trapping of iodine. All these sorbents possess good iodine adsorption capacities, which reach $1750 \mathrm{~g}_{\mathrm{I}_{2}} \mathrm{~kg}_{\text {adsorbent }}{ }^{-1}$ in the case of MOFs. However, although they have promising iodine adsorption properties, most of these sorbents were not fully characterized, and more precise studies on the influence of various operating parameters (such as temperature, humidity, and the presence of $\mathrm{NO}_{x}$ ) are still needed before an accurate judgement regarding the best sorbent for iodine removal applications. Furthermore, some sorbents, such as MOFs and POPs, are laboratory objects and thus not suitable for industrial applications at the moment. It can be concluded that these new sorbents should be studied more thoroughly from the point of view of real applications, which implies cost-effective solutions and tests in a wide range of operating conditions.

Thus, the development of new sorbents that combine a high iodine adsorption capacity over a wide temperature range, high stability and selectivity in the capture of iodine at high temperatures and humidities and in the presence of other molecules, and low cost still remains a challenge. The use of several kinds of iodine sorbents to combine their advantages could be a promising way to fulfil the requirements of real applications. 
Table 2 Summary of the advantages and drawbacks of the various porous sorbents described in this review

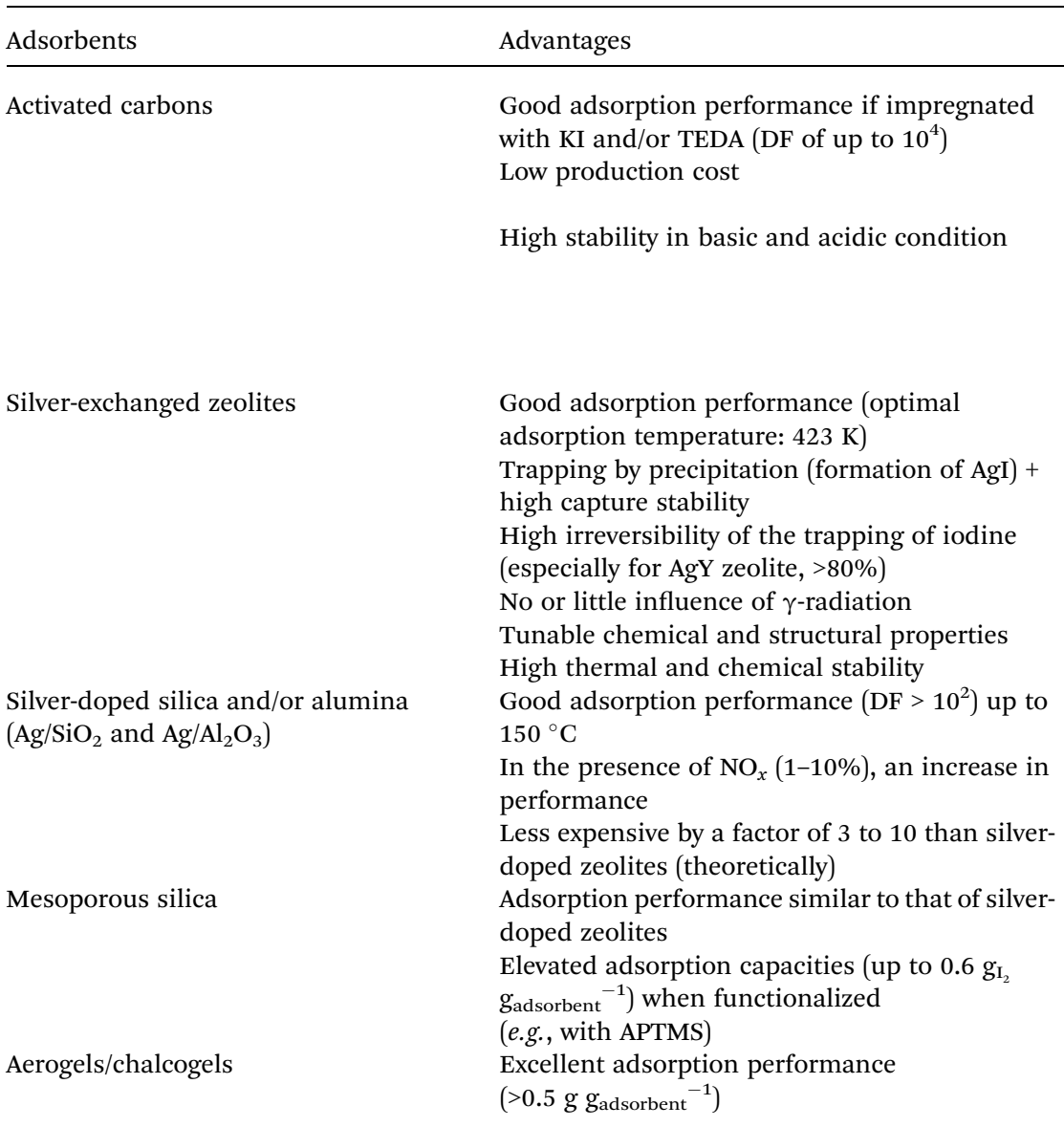

Titanosilicates

Macroreticular resins

Metal-organic frameworks (MOFs)

Porous organic polymers
Adsorption performance similar to that of silverdoped zeolites when doped with silver

Excellent adsorption performance (up to $1 \mathrm{~g}$ $\mathrm{g}_{\text {adsorbent }}{ }^{-1}$ )

Stable in presence of $\gamma$-radiation

Resistant in acidic conditions $\left(\mathrm{NO}_{x}\right)$

Excellent adsorption performance (up to $1.75 \mathrm{~g}_{\mathrm{I}_{2}}$ $\mathrm{g}_{\text {adsorbent }}{ }^{-1}$ ) theoretically and in ideal conditions High selectivity toward $I_{2}$ rather than water

Trapping via chemisorption/physisorption Large range of existing MOFs (pores, specific surface areas, variable structures) + possibility of adjusting properties

Excellent adsorption performance (up to $3.45 \mathrm{~g}_{\mathrm{I}_{2}}$ $\mathrm{g}_{\text {adsorbent }}{ }^{-1}$ )

Highly tunable molecular design

Low skeleton densities (lightweight elements) High physicochemical stabilities and tunable porosities reversible adsorption of iodine
Drawbacks

Decline in adsorption performance in the presence of humidity $(>40 \%)$

Decline in adsorption performance at high temperatures $\left(T>80^{\circ} \mathrm{C}\right)$

Alteration of the adsorption performance due to aging

Low autoignition temperature

Strong influence of $\mathrm{NO}_{x}$

(formation of explosive compounds)

Expensive

Alteration of the adsorption performance due to organic compounds (especially chlorides) Negative effects of $\mathrm{NO}_{x}$ and humidity on performance

Loss of efficiency at temperatures of $<200{ }^{\circ} \mathrm{C}+$ higher operating cost

Loss of performance in the presence of a large excess of organic contaminants

Alteration of the adsorption performance with humidity $(>70 \%)$

Few studies on the influence of humidity and/or inhibitors ( $\mathrm{NO}_{x}$, organics, etc.)

Limited thermal stability when functionalized

Few studies on the influence of humidity and/or inhibitors $\left(\mathrm{NO}_{x}\right.$, organics, etc.) Little literature on these materials Expensive Low adsorption capacities

Few studies on the influence of humidity and/or inhibitors ( $\mathrm{NO}_{x}$, organics, etc.) Significant decline in adsorption performance at temperatures of higher than $50{ }^{\circ} \mathrm{C}$ or in the presence of humidity

No studies on the influence of humidity and/or inhibitors $\left(\mathrm{NO}_{x}\right.$, organics, etc.) No information on the adsorption and capture of $\mathrm{CH}_{3} \mathrm{I}$

Low thermal stability at high temperatures Expensive

Laboratory objects

No information on the adsorption and capture of $\mathrm{CH}_{3} \mathrm{I}$

No studies on the influence of humidity and/or inhibitors $\left(\mathrm{NO}_{x}\right.$, organics, etc.)

Expensive

Laboratory objects 
Table 2 (Contd.)

\begin{tabular}{|c|c|c|}
\hline Adsorbents & Advantages & Drawbacks \\
\hline \multirow[t]{3}{*}{$\begin{array}{l}\text { Covalent-organic frameworks } \\
\text { (COFs) }\end{array}$} & $\begin{array}{l}\text { Excellent adsorption performance (up to } 16.7 \mathrm{~g}_{\mathrm{I}_{2}} \\
\mathrm{~g}_{\text {adsorbent }}{ }^{-1} \text { ) theoretically and in ideal conditions }\end{array}$ & Theoretical studies only \\
\hline & $\begin{array}{l}\text { Studies on the adsorption and capture of } \mathrm{I}_{2} \text { and } \\
\mathrm{CH}_{3} \mathrm{I} \\
\text { Large range of existing COFs } \\
\text { (pores, specific surface areas, variable } \\
\text { structures) }\end{array}$ & $\begin{array}{l}\text { No studies on the influence of humidity and/or } \\
\text { inhibitors }\left(\mathrm{NO}_{x} \text {, organics, } \text { etc.) }\right. \\
\text { Little literature on these materials for the } \\
\text { capture of iodine compounds }\end{array}$ \\
\hline & & $\begin{array}{l}\text { Expensive } \\
\text { Laboratory objects }\end{array}$ \\
\hline
\end{tabular}

\section{Conflicts of interest}

There are no conflicts to declare.

\section{Acknowledgements}

We would like to thank ONET Technologies for funding this work.

\section{Notes and references}

1 OECD (Organisation for Economic Co-operation and Development), Nuclear Energy in a Sustainable Development Perspective, 2000.

2 International Atomic Energy Agency, Nuclear Safety Review, IAEA/NSR, 2017.

3 T. H. Woo, Ann. Nucl. Energy, 2013, 53, 197-201.

4 K. Kosaka, M. Asami, N. Kobashigawa, K. Ohkubo, H. Terada, N. Kishida and M. Akiba, Water Res., 2012, 46, 4397-4404.

5 N. R. Soelberg, T. G. Garn, M. R. Greenhalgh, J. D. Law, R. Jubin, D. M. Strachan and P. K. Thallapally, Sci. Technol. Nucl. Install., 2013, 2013, 12.

6 S. U. Nandanwar, K. Coldsnow, V. Utgikar, P. Sabharwall and D. Eric Aston, Chem. Eng. J., 2016, 306, 369-381.

7 K. S. Subrahmanyam, D. Sarma, C. D. Malliakas, K. Polychronopoulou, B. J. Riley, D. A. Pierce, J. Chun and M. G. Kanatzidis, Chem. Mater., 2015, 27, 2619-2626.

8 B. J. Riley, J. D. Vienna, D. M. Strachan, J. S. McCloy and J. L. Jerden, J. Nucl. Mater., 2016, 470, 307-326.

9 C. M. Grossman, W. E. Morton and R. H. Nussbaum, Arch. Environ. Health, 1996, 51, 175-176.

10 C. M. Grossman, R. H. Nussbaum and F. D. Nussbaum, Arch. Environ. Health, 2002, 57, 9-15.

11 C. M. Grossman, R. H. Nussbaum and F. D. Nussbaum, Arch. Environ. Health, 2003, 58, 267-274.

12 J. R. Goldsmith, C. M. Grossman, W. E. Morton, R. H. Nussbaum, E. A. Kordysh, M. R. Quastel, R. B. Sobel and F. D. Nussbaum, Environ. Health Perspect., 1999, 107, 303-308.

13 G. D. Thomas, S. M. Smith and J. A. Turcotte, Health Promotion Practice, 2009, 10, 92-101.
14 D. F. Sava, M. A. Rodriguez, K. W. Chapman, P. J. Chupas, J. A. Greathouse, P. S. Crozier and T. M. Nenoff, J. Am. Chem. Soc., 2011, 133, 12398-12401.

15 W. E. Lee, M. I. Ojovan, M. C. Stennett and N. C. Hyatt, $A d v$. Appl. Ceram., 2006, 105, 3-12.

16 R. T. Jubin, ORNL/TM-6607, Oak Ridge National Laboratory, Oak Ridge, TN, 1979.

17 J. Romans and V. Deitz, Proceedings of the 15th DOE Nuclear Air Cleaning Conference, Conf. 780819, The Harvard Air Cleaning Laboratory, Cambridge, Massachusetts, 1978, vol. 1.

18 V. R. Deitz, Carbon, 1987, 25, 31-38.

19 R. D. Scheele, L. L. Burger and B. T. Halko, PNL-6607, Pacific Northwest Laboratory, Richland, WA, 1988.

20 Y. S. Kim, Proceedings of the 20th DOE/NRC Nuclear Air Cleaning Conference, Conf. 880815, TU.S. Department of Energy, U.S. Nuclear Regulatory Commission, The Harvard Air Cleaning Laboratory, Boston, Massachusetts, 1988, vol. 1, pp. 602-618.

21 L. Puppe and J. Wilhelm, European Patent, EP0332964A2, 1989.

22 V. R. Deitz, US Pat., US4518562A, 1985.

23 H. Deuber, Nucl. Technol., 1986, 72, 44-48.

24 H. Deuber, K. Gerlach, V. Giraud and R. Kaempffer, Proceedings of the 19th DOE/NRC Nuclear Air Cleaning Conference, Conf. 860820, U.S. Department of Energy, U.S. Nuclear Regulatory Commission, The Harvard Air Cleaning Laboratory, Seattle, Washington, 1986, pp. 30-50.

25 I. Qi-Dong and H. Sui-yuang, Proceedings of the 18th DOE Nuclear Airborne Waste Management and Air Cleaning Conference, Conf. 840806, U.S. Department of Energy, The Harvard Air Cleaning Laboratory, Baltimore, Maryland, 1984, pp. 78-92.

26 H. Deuber, Proceedings of the 18th DOE Nuclear Airborne Waste Management and Air Cleaning Conference, Conf. 840806, U.S. Department of Energy, The Harvard Air Cleaning Laboratory, Baltimore, Maryland, 1984, pp. 44-64.

$27 \mathrm{H}$. Deuber and J. G. Wilhelm, Proceedings of the 17th DOE Nuclear Air Cleaning Conference, Conf. 820833, U.S. Department of Energy, The Harvard Air Cleaning Laboratory, Denver, Colorado, 1982, pp. 248-277.

28 R. T. Jubin, Proceedings of the 17th DOE Nuclear Air Cleaning Conference, 1982, pp. 519-530. 
29 R. D. Scheele, L. L. Burger and C. L. Matsuzaki, PNL-4489, Pacific Northwest Laboratory, Richland, Washington, 1983.

30 J. G. Jolley and H. G. Tompkins, J. Mater. Sci., 1984, 19, 2870-2874.

31 A. D. Belapurkar, K. A. Rao, N. M. Gupta and R. M. Iyer, Surf. Technol., 1984, 21, 263-272.

32 L. L. Burger, R. D. Scheele and K. D. Wiemers, PNL-4045, Pacific Northwest Laboratory, Richland, Washington, 1981.

33 P. Decourcière, Iodine removal from gaseous effluents in the nuclear industry, 1981.

34 E. R. Vance and D. K. Agrawal, J. Mater. Sci., 1982, 17, 18891894.

35 R. McNabney and A. M. Lyon, ARSC-28, U.S. Atomic Energy Commission, Richland, WA, 1949.

36 T. D. Ackley, Ind. Eng. Chem., 1959, 51, 1467-1470.

37 K. C. Patil, C. N. R. Rao, J. W. Lacksonen and C. E. Dryden, J. Inorg. Nucl. Chem., 1967, 29, 407-412.

38 W. J. Maeck, D. T. Pence and J. H. Keller, Proceedings of the 10th AEC Nuclear Air Cleaning Conference, Conf. 680821, The Harvard Air Cleaning Laboratory, New York, 1968, pp. 354361.

39 J. Hirling, Treatment of Airborne Radioactive Wastes, IAEA, Vienna, 1968, p. 465.

40 D. T. Pence, F. A. Duce and W. J. Maeck, Proceedings of the 11th AEC Nuclear Air Cleaning Conference, Conf. 700816, The Harvard Air Cleaning Laboratory, Richland, WA, 1970, pp. 581-599.

41 J. G. Moore and W. B. Howerton, LMFBR Fuel Cycle Studies Progress Report for July 1970, No. 17, Sect. 10.1, ORNL-TM3095, 1970.

42 J. G. Moore and W. B. Howerton, LMFBR Fuel Cycle Studies Progress Report for September 1970, No. 19, Sect. 10.1, ORNL-3180, 1970.

43 S. Kitani, T. Noro, T. Kohara, S. Kitani, T. Noro and T. Kohara, J. Nucl. Sci. Technol., 1971, 9(4), 197-202.

44 J. G. Moore and W. B. Howerton, LMFBR Fuel Cycle Studies Progress Report for January, 1971, No. 23, ORNL-TM-3312, 1971, p. 26.

45 D. E. Ferguson, Chemical Technology Division Annual Progress Report for Period Ending, March 31, 1971, ORNL4682, 1971.

46 J. G. Moore and W. B. Howerton, LMFBR Fuel Cycle Studies Progress Report for April 1971, No. 26, ORNL-TM-3412, 1971, p. 31.

47 D. T. Pence, F. A. Duce and W. J. Maeck, Proceedings of the 12th AEC Air Cleaning Conference, Conf. 720823, The Harvard Air Cleaning Laboratory, Oak Ridge, TN, 1972, pp. 417-433.

48 J. G. Wilhelm, H. Schuttelkopf and M. W. First, Proceedings of the 12th AEC Air Cleaning Conference, Conf. 720823, The Harvard Air Cleaning Laboratory, Oak Ridge, TN, 1972, pp. 434-444.

49 T. D. Ackley and Z. Combs, ORNL/TM-4227, Oak Ridge National Laboratory, Oak Ridge, TN, 1973.

50 Y. Huh, G. W. Donalson and F. J. Johnston, Radiat. Res., 1974, 60, 40.

51 A. J. Juhola, Carbon, 1975, 13, 437-442.
52 B. A. Staples, L. P. Murphy and T. R. Thomas, Proceedings of the 14th ERDA Air Cleaning Conference, Conf. 760822, Sun Valley, Idaho, 1976, pp. 363-380.

53 S. Bhagwandas, S. B. Hingorani, K. Sri and K. S. Venkateswarlv, Kerntechnik, 1976, 18, 207-209.

54 J. G. Wilhelm, J. Furrer and E. Schultes, Proceedings of the 14th ERDA Air Cleaning Conference, Conf. 760822, Sun Valley, Idaho, 1976, pp. 447-477.

55 S. B. Hingorani and K. S. Venkateswarlv, Health Phys., 1976, 30, 493.

56 C. A. Burchsted, J. E. Khan and A. B. Fuller, Nuclear Air Cleaning Handbook, ERDA, 1977.

57 J. G. Wilhelm, Iodine Filters in Nuclear Power Stations, 1977. 58 V. R. Deitz and C. H. Blachly, US Pat., US4016242A, 1977.

59 A. G. Evans, Proceedings of the 15th DOE Nuclear Air Cleaning Conference, Conf. 780819, The Harvard Air Cleaning Laboratory, Cambridge, Massachusetts, 1978, vol. 1, pp. 416-427.

60 T. R. Thomas, B. A. Staples and L. P. Murphy, Proceedings of the 15th DOE Nuclear Air Cleaning Conference, Conf. 780819, The Harvard Air Cleaning Laboratory, Cambridge, Massachusetts, 1978, vol. 1, pp. 394-415.

61 M. Kikuchi, M. Kitamura and H. Yusa, Nucl. Eng. Des., 1978, 47, 283-287.

62 V. R. Deitz and L. A. Jonas, Nucl. Technol., 1978, 37, 59-64. 63 D. W. Holladay, ORNL/TM-6350, Oak Ridge National Laboratory, Oak Ridge, TN, 1979.

64 R. T. Jubin, Proceedings of the 16th DOE Nuclear Air Cleaning Conference, Conf. 801038, The Harvard Air Cleaning Laboratory, San Diego, California, 1980, pp. 519-530.

65 F. J. Hermann, V. Motoi, B. Hermann, A. van Schoor, D. Fang and H. Fies, Proceedings of the 21th DOE/NRC Nuclear Air Cleaning Conference, Conf. 900809, U.S. Department of Energy, U.S. Nuclear Regulatory Commission, International Society of Nuclear Air, The Harvard Air Cleaning Laboratory, San Diego, California, 1991, pp. 222-233.

66 C. M. Ecob, A. J. Clements, P. Flaherty, J. G. Griffiths, D. Nacapricha and C. G. Taylor, Sci. Total Environ., 1993, 131, 419-427.

67 S. W. Park, W. K. Lee and H. Moon, Sep. Technol., 1993, 3, 133-142.

68 R. T. Jubin, ORNL/TM-6853, Oak Ridge National Laboratory, Oak Ridge, TN, 1994.

69 S. W. Park, H. S. Park, W. K. Lee and H. Moon, Sep. Technol., 1995, 5, 35-44.

70 K. Funabashi, T. Fukasawa and M. Kikuchi, Nucl. Technol., 1995, 109, 366-372.

71 B. S. Choi, G. Il Park, J. H. Kim, J. W. Lee and S. K. Ryu, Adsorption, 2001, 7, 91-103.

72 J. Gan, N. E. Megonnell and S. R. Yates, Atmos. Environ., 2001, 35, 941-947.

73 G. Park, I. Kim, J. K. Lee, S. K. Ryu and J. H. Kim, Science, 2001, 2, 9-14.

74 B. Azambre and M. Chebbi, ACS Appl. Mater. Interfaces, 2017, 9, 25194-25203. 
75 M. Chebbi, S. Chibani, J. F. Paul, L. Cantrel and M. Badawi, Microporous Mesoporous Mater., 2017, 239, 111-122.

76 S. Chibani, I. Medlej, S. Lebègue, J. G. Ángyán, L. Cantrel and M. Badawi, ChemPhysChem, 2017, 18, 1642-1652.

77 M. Chebbi, B. Azambre, L. Cantrel, M. Huvé and T. Albiol, Microporous Mesoporous Mater., 2017, 244, 137-150.

78 M. Chebbi, B. Azambre, L. Cantrel and A. Koch, J. Phys. Chem. C, 2016, 120, 18694-18706.

79 S. Chibani, M. Chebbi, S. Lebègue, L. Cantrel and M. Badawi, Phys. Chem. Chem. Phys., 2016, 18, 25574-25581.

80 S. Chibani, M. Chebbi, S. Lebègue, T. Bučko and M. Badawi, J. Chem. Phys., 2016, 144, 244705.

81 M. Chebbi, PhD thesis, Université de Lorraine, 2016.

82 S. U. Nandanwar, K. Coldsnow, M. Green, V. Utgikar, P. Sabharwall and D. E. Aston, Chem. Eng. J., 2016, 287, 593-601.

83 L. Wu, J. a. Sawada, D. B. Kuznicki, T. Kuznicki and S. M. Kuznicki, J. Radioanal. Nucl. Chem., 2014, 302, 527532.

84 N. Mnasri, C. Charnay, L. C. De Ménorval, Y. Moussaoui, E. Elaloui and J. Zajac, Microporous Mesoporous Mater., 2014, 196, 305-313.

85 J. Wang, H. Ge and W. Bao, Mater. Lett., 2015, 145, 312-315. 86 J. H. Yang, Y. J. Cho, J. M. Shin and M. S. Yim, J. Nucl. Mater., 2015, 465, 556-564.

87 T. Fukasawe, K. Funabashi and Y. Kondo, Proceedings of the 24th DOE/NRC Nuclear Air Cleaning and Treatment Conference, Conf. 960715, U.S. Department of Energy U.S. Nuclear Regulatory, International Society of Nuclear Air Treatment, Commission International, The Harvard Air Cleaning, 1996, pp. 563-574.

88 D. R. Haefner and T. J. Tranter, INL/EXT-07-12299, Idaho National Laboratory, Idaho Falls, ID, 2007.

89 F. J. Herrmann, B. Hermann, K. D. Kuhn, A. van Schoor, M. Weishaupt, J. Furrer and W. Knoch, Proceedings of the 24th DOE/NRC Nuclear Air Cleaning and Treatment Conference, Conf. 960715, U.S. Department of Energy U.S. Nuclear Regulatory, International Society of Nuclear Air Treatment, Commission International, The Harvard Air Cleaning Laboratory, 1996, pp. 618-627.

90 O. Kindel, V. Hoeflich, F. J. Herrmann and P. Patzelt, J. Radioanal. Nucl. Chem. Lett., 1993, 176, 251-259.

91 S. A. Kulyukhin, L. V. Mizina, E. V. Zanina, I. A. Rumer, N. A. Konovalova and D. S. Levushkin, Radiochemistry, 2012, 54, 368-378.

92 H. Mineo, M. Gotoh, M. Iizuka, S. Fujisaki and G. Uchiyama, J. Nucl. Sci. Technol., 2002, 39, 241-247.

93 T. Sakurai and A. Takahashi, J. Nucl. Sci. Technol., 1994, 31, 86-87.

94 K. Takeshita and Y. Azegami, J. Nucl. Sci. Technol., 2004, 41, 91-94.

95 H. Tanabe, T. Sakuragi, K. Yamaguchi, T. Sato and H. Owada, Adv. Sci. Technol., 2010, 73, 158-170.

96 H. Mineo, M. Gotoh, M. Iizuka, S. Fujisaki, H. Hagiya and G. Uchiyama, Sep. Sci. Technol., 2003, 38, 1981-2001.

97 G. Modolo and R. Odoj, Nucl. Technol., 1997, 117, 80-86.
98 S. Bag and M. G. Kanatzidis, J. Am. Chem. Soc., 2010, 1495114959.

99 S. Bag, P. N. Trikalitis, P. J. Chupas, G. S. Armatas and M. G. Kanatzidis, Science, 2007, 317, 490-493.

100 J. Matyáš, Research and Development FY 2012 Accomplishments Report, Idaho National Laboratory, Idaho Falls, ID, 2013, FCRD-SWF-12-000073.

101 J. Matyáš, G. E. Fryxell and M. J. Robinson, Characterization of Dry-Air Aged Granules of Silver-Functionalized Silica Aerogel, Pacific Northwest National Laboratory, September 2012, FCRD-SWF-2012-000214.

$102 \mathrm{~J}$. Matyáš and R. K. Engler, Assessment of Methods to Consolidate Iodine-Loaded Silver-Functionalized Silica Aerogel, Pacific Northwest National Laboratory, September 2013, FCRD-SWF-2013-000589 PNNL-22874.

103 Y. Oh, S. Bag, C. D. Malliakas and M. G. Kanatzidis, Chem. Mater., 2011, 23, 2447-2456.

104 B. J. Riley, J. Chun, W. Um, W. C. Lepry, J. Matyas, M. J. Olszta, X. Li, K. Polychronopoulou and M. G. Kanatzidis, Environ. Sci. Technol., 2013, 47, 75407547.

105 B. J. Riley, J. O. Kroll, J. A. Peterson, J. Matyáš, M. J. Olszta, X. Li and J. D. Vienna, ACS Appl. Mater. Interfaces, 2017, 9, 32907-32919.

106 B. J. Riley, D. Pierce and A. J. Chun, Efforts to Consolidate Chalcogens with Adsorbed Iodine, 2013.

107 B. J. Riley, D. A. Pierce, J. Chun, J. Matyáš, W. C. Lepry, T. G. Garn, J. D. Law and M. G. Kanatzidis, Environ. Sci. Technol., 2014, 48, 5832-5839.

108 B. J. Riley, J. Chun, J. V Ryan, J. Matyas, X. S. Li, D. W. Matson, S. K. Sundaram, D. M. Strachan and J. D. Vienna, RSC Adv., 2011, 1, 1704-1715.

109 D. Banerjee, X. Chen, S. S. Lobanov, A. M. Plonka, X. Chan, J. A. Daly, T. Kim, P. K. Thallapally and J. B. Parise, ACS Appl. Mater. Interfaces, 2018, 10(13), 10622-10626.

110 A. S. Munn, F. Millange, M. Frigoli, N. Guillou, C. Falaise, V. Stevenson, C. Volkringer, T. Loiseau, G. Cibin and R. I. Walton, CrystEngComm, 2016, 18, 8108-8114.

111 Q.-Q. Dang, X.-M. Wang, Y.-F. Zhan and X.-M. Zhang, Polym. Chem., 2016, 7, 643-647.

112 Z. Yan, Y. Yuan, Y. Tian, D. Zhang and G. Zhu, Angew. Chem., Int. Ed., 2015, 54, 12733-12737.

113 C. Wang, Y. Wang, R. Ge, X. Song, X. Xing, Q. Jiang, H. Lu, C. Hao, X. Guo, Y. Gao and D. Jiang, Chem.-Eur. J., 2018, 24, 585-589.

114 C. Pei, T. Ben, S. Xu and S. Qiu, J. Mater. Chem. A, 2014, 2, 7179-7187.

115 M. Chebbi, B. Azambre, C. Volkringer and T. Loiseau, Microporous Mesoporous Mater., 2018, 259, 244-254.

116 C. Falaise, C. Volkringer, J. Facqueur, T. Bousquet, L. Gasnot and T. Loiseau, Chem. Commun., 2013, 49, 10320. 117 S.-Y. Ding and W. Wang, Chem. Soc. Rev., 2013, 42, 548-568. 118 X. Zhang, I. Da Silva, H. G. W. Godfrey, S. K. Callear, S. A. Sapchenko, Y. Cheng, I. Vitórica-Yrezábal, M. D. Frogley, G. Cinque, C. C. Tang, C. Giacobbe, C. Dejoie, S. Rudić, A. J. Ramirez-Cuesta, M. A. Denecke, 
S. Yang and M. Schröder, J. Am. Chem. Soc., 2017, 139, 16289-16296.

119 B. Assfour, T. Assaad and A. Odeh, Chem. Phys. Lett., 2014, 610-611, 45-49.

120 T. Assaad and B. Assfour, J. Nucl. Mater., 2017, 493, 6-11.

121 B. F. Abrahams, M. Moylan, S. D. Orchard and R. Robson, Angew. Chem., Int. Ed., 2003, 42, 1848-1851.

122 M. H. Zeng, Q. X. Wang, Y. X. Tan, S. Hu, H. X. Zhao, L. S. Long and M. Kurmoo, J. Am. Chem. Soc., 2010, 132, 2561-2563.

123 K. W. Chapman, D. F. Sava, G. J. Halder, P. J. Chupas and T. M. Nenoff, J. Am. Chem. Soc., 2011, 133, 18583-18585.

124 T. D. Bennett, P. J. Saines, D. A. Keen, J. C. Tan and A. K. Cheetham, Chem.-Eur. J., 2013, 19, 7049-7055.

125 Y. Yuan, X. Dong, Y. Chen and M. Zhang, Phys. Chem. Chem. Phys., 2016, 18, 23246-23256.

126 K. S. Park, Z. Ni, A. P. Côté, J. Y. Choi, R. Huang, F. J. UribeRomo, H. K. Chae, M. O'Keeffe and O. M. Yaghi, Proc. Natl. Acad. Sci. U. S. A., 2006, 103, 10186-10191.

127 D. F. Sava, T. J. Garino and T. M. Nenoff, Ind. Eng. Chem. Res., 2012, 51, 614-620.

128 Y. Lan, M. Tong, Q. Yang and C. Zhong, CrystEngComm, 2017, 19, 4920-4926.

129 J. T. Hughes, D. F. Sava, T. M. Nenoff and A. Navrotsky, J. Am. Chem. Soc., 2013, 135, 16256-16259.

130 D. F. Sava, K. W. Chapman, M. A. Rodriguez, J. A. Greathouse, P. S. Crozier, H. Zhao, P. J. Chupas and T. M. Nenoff, Chem. Mater., 2013, 25, 2591-2596.

131 B. Li, X. Dong, H. Wang, D. Ma, K. Tan, S. Jensen, B. J. Deibert, J. Butler, J. Cure, Z. Shi, T. Thonhauser, Y. J. Chabal, Y. Han and J. Li, Nat. Commun., 2017, 8, 485.

132 D. F. Sava Gallis, I. Ermanoski, J. A. Greathouse, K. W. Chapman and T. M. Nenoff, Ind. Eng. Chem. Res., 2017, 56, 2331-2338.

133 X. Qian, B. Wang, Z. Q. Zhu, H. X. Sun, F. Ren, P. Mu, C. Ma, W. D. Liang and A. Li, J. Hazard. Mater., 2017, 338, 224-232.

134 D. Chen, Y. Fu, W. Yu, G. Yu and C. Pan, Chem. Eng. J., 2018, 334, 900-906.

135 Y. Liao, J. Weber, B. M. Mills, Z. Ren and C. F. J. Faul, Macromolecules, 2016, 49, 6322-6333.

136 X. Qian, Z. Q. Zhu, H. X. Sun, F. Ren, P. Mu, W. Liang, L. Chen and A. Li, ACS Appl. Mater. Interfaces, 2016, 8, 21063-21069.

137 H. Ma, J. J. Chen, L. Tan, J. H. Bu, Y. Zhu, B. Tan and C. Zhang, ACS Macro Lett., 2016, 5, 1039-1043.

138 A. S. Sigen, Y. Zhang, Z. Li, H. Xia, M. Xue, X. Liu and Y. Mu, Chem. Commun., 2014, 50, 8495-8498.

139 Y. Chen, H. Sun, R. Yang, T. Wang, C. Pei, Z. Xiang, Z. Zhu, W. Liang, A. Li and W. Deng, J. Mater. Chem. A, 2015, 3, 8791.

140 Q. Q. Dang, X. M. Wang, Y. F. Zhan and X. M. Zhang, Polym. Chem., 2016, 7, 643-647.

141 F. Ren, Z. Zhu, X. Qian, W. Liang, P. Mu, H. Sun, J. Liu and A. Li, Chem. Commun., 2016, 52, 9797-9800.

142 Y. Zhu, Y. J. Ji, D. G. Wang, Y. Zhang, H. Tang, X. R. Jia, M. Song, G. Yu and G. C. Kuang, J. Mater. Chem. A, 2017, 5, 6622-6629.
143 H. Li, X. Ding and B. H. Han, Chem.-Eur. J., 2016, 22, 11863-11868.

144 R. T. Yang, Adsorbents: Fundamentals and Applications, 2003. 145 C. Y. Yin, M. K. Aroua and W. M. A. W. Daud, Sep. Purif. Technol., 2007, 52, 403-415.

146 J. Laine and S. Yunes, Carbon, 1992, 30, 601-604.

147 C. M. González-García, J. F. González and S. Román, Fuel Process. Technol., 2011, 92, 247-252.

148 N. I. Ampelogova, V. G. Kritskii, N. I. Krupennikova and A. I. Skvortsov, At. Energy, 2002, 92, 336-340.

149 C. C. Chien, Y. P. Huang, W. C. Wang, J. H. Chao and Y. Y. Wei, Clean: Soil, Air, Water, 2011, 39, 103-108.

150 H. Chun, J. Kang and B. Han, Phys. Chem. Chem. Phys., 2016, 18, 32050-32056.

151 C. Herdes, C. Prosenjak, S. Román and E. A. Müller, Langmuir, 2013, 29, 6849-6855.

152 M. Gourani, A. Sadighzadeh and F. Mizani, Radiat. Prot. Environ., 2014, 37, 179.

153 T. Kravchik, S. Levinson, S. Oved, S. Tsroya, O. Pelled, M. Haim and U. German, Appl. Radiat. Isot., 2008, 66, 972-975.

154 A. K. Srivastava, A. Saxena, B. Singh and S. K. Srivas, Carbon Lett., 2007, 8, 274-279.

155 J. Zhou, S. Hao, L. Gao and Y. Zhang, Ann. Nucl. Energy, 2014, 72, 237-241.

156 V. G. Kritskii, N. I. Ampelogova, V. I. Krupennikova, V. N. Kornienko, V. D. Ivanov and N. I. Rybkin, At. Energy, 2004, 97, 851-857.

157 C. M. González-García, S. Román, J. F. González, E. Sabio and B. Ledesma, Appl. Surf. Sci., 2013, 282, 714-717.

158 M. J. Chinn, P. R. N. P. A. Barnest, E. A. Dawsont and D. P. Down, Proceedings of the 24th Biennial Conference, Charleston, 1999, pp. 528-529.

159 R. J. Fessenden and J. S. Fessenden, Organic Chemistry, Wadsworth, Inc., Belmont, California, USA, 5th edn, 1994.

160 M. Takahashi, S. Nukatsuka, T. Hashimoto and Y. Tanaka, Workshop Proceedings, NEA/CSNI/R(99)7, Vantaa (Helsinki), Finland, 18-20 May, 1999, pp. 297-310.

161 A. Karhu, Report VTT Energy, NKS, Finland, 1999, pp. 11-13. 162 M. Nakamura, T. Ohba, P. Branton, H. Kanoh and K. Kaneko, Carbon, 2010, 48, 305-308.

163 A. Corma and A. Martinez, Adv. Mater., 1995, 7, 137-144.

164 Y. Traa, B. Burger and J. Weitkamp, Microporous Mesoporous Mater., 1999, 30, 3-41.

165 J. Weitkamp, Solid State Ionics, 2000, 131, 175-188.

166 E. Erdem, N. Karapinar and R. Donat, J. Colloid Interface Sci., 2004, 280, 309-314.

167 M. Stöcker, Microporous Mesoporous Mater., 2005, 82, 257292.

168 L. Zhang, Y. Peng, J. Zhang, L. Chen, X. Meng and F. S. Xiao, Chin. J. Catal., 2016, 37, 800-809.

169 S. G. Aspromonte, M. D. Mizrahi, F. A. Schneeberger, J. M. R. López and A. V. Boix, J. Phys. Chem. C, 2013, 117, 25433-25442.

170 S. H. Bruffey, R. T. Jubin and J. A. Jordan, Procedia Chem., 2016, 21, 293-299. 
171 K. W. Chapman, P. J. Chupas and T. M. Nenoff, J. Am. Chem. Soc., 2010, 132, 8897-8899.

172 T. Bučko, S. Chibani, J.-F. Paul, L. Cantrel and M. Badawi, Phys. Chem. Chem. Phys., 2017, 19, 27530-27543.

173 T. M. Nenoff, M. A. Rodriguez, N. R. Soelberg and K. W. Chapman, Microporous Mesoporous Mater., 2014, 200, 297-303.

174 Y. Nan, L. Tavlarides and D. W. DePaoli, AIChE J., 2017, 63, 1024-1035.

175 S. H. Bruffey, R. T. Jubin, K. K. Anderson and J. F. Walker, Fuel Cycle Research \& Development, Oak Ridge National Laboratory, 30 April, 2014, FCRD-SWF-2014-000465, ORNL/LTR-2014/153.

176 C. W. Abney, Y. Nan and L. L. Tavlarides, Ind. Eng. Chem. Res., 2017, 56, 4837-4846.

177 H. Zhao, T. M. Nenoff, G. Jennings, P. J. Chupas and K. W. Chapman, J. Phys. Chem. Lett., 2011, 2, 2742-2746.

178 S. H. Bruffey and R. T. Jubin, Fuel Cycle Research and Development, Oak Ridge national laboratory, 30 September, 2014, FCRD-SWF-2014-000280, ORNL/LRT2014/482.

179 D. F. Sava Gallis, I. Ermanoski, J. A. Greathouse, K. W. Chapman and T. M. Nenoff, Ind. Eng. Chem. Res., 2017, 56, 2331-2338.

180 L. Puppe and J. Wilhelm, US Pat., US4913850A, 1990.

181 J. G. P. Binner, G. Dimitrakis, D. M. Price, M. Reading and B. Vaidhyanathan, J. Therm. Anal. Calorim., 2006, 84, 409412.

182 D. R. Haefner and T. L. Watson, Summary of FY 2010 Iodine Capture Studies at the INL, Idaho National Laboratory, Idaho Falls, ID, 2010.

183 Y. Wei, D. Zhang, Z. Liu and B. L. Su, J. Catal., 2006, 238, 46-57.
184 P. Verger, a Aurengo, B. Geoffroy and B. Le Guen, Thyroid, 2001, 11, 353-360.

185 B. S. Choi, G. Il Park, J. W. Lee, H. Y. Yang and S. K. Ryu, J. Radioanal. Nucl. Chem., 2003, 256, 19-26.

186 L. Burger and R. Scheele, Pacific Norhtwest National Laboratory, PNNL-14860, Pacific Northwest National Laboratory, Richland, WA, 2004.

187 Y. Inagaki, T. Imamura, K. Idemitsu, T. Arima, O. Kato, T. Nishimura and H. Asano, J. Nucl. Sci. Technol., 2008, 45, 859-866.

188 Q. Cheng, W. Yang, Z. Li, Q. Zhu, T. Chu, D. He and C. Fang, J. Radioanal. Nucl. Chem., 2015, 303, 1883-1889.

189 R. T. Jubin, D. W. Ramey, B. B. Spencer, K. K. Anderson and S. M. Robinson, WM2012 Conference, 2012, pp. 1-15.

190 L. B. Pankratz, Thermodynamic Properties of Halides, US Dept. Interior, Bureau of Mines Bulletin, 1984, vol. 674, pp. 1-826.

191 R. C. Weast, CRC Handbook of Chemistry and Physics, CRC Press, Inc., Boca Raton, Florida, USA, 64th edn, 1983-1984.

192 IAEA Report, Treatment, Conditioning and Disposal of Iodine129, 1987, vol. 276.

193 J. H. Yang, J. M. Shin, J. J. Park, G. Il Park and M. S. Yim, J. Nucl. Mater., 2015, 457, 1-8.

194 M. Gliński and U. Ulkowska, Can. J. Chem., 2011, 89, 13701374.

195 S. U. Nandanwar, J. Dantas, K. Coldsnow, M. Green, V. Utgikar, P. Sabharwall and D. E. Aston, Adsorption, 2016, 22, 335-345.

196 S. F. Estefan, M. B. Morsi, G. A. El-Shobaky and I. F. Hewaidy, Powder Technol., 1987, 49, 143-147.

197 P. Li and M. T. Bernards, Nucl. Sci. Eng., 2015, 181, 310-317. 198 A. P. Côté, A. I. Benin, N. W. Ockwig, M. O'Keeffe, A. J. Matzeger and O. M. Yaghi, Science, 2005, 310, 11661170. 